

Frauke Reitemeier (ed.) "Deepe things out of darkenesse"

This work is licensed under the Creative Commons License 3.0 "by-nd", allowing you to download, distribute and print the document in a few copies for private or educational use, given that the document stays unchanged and the creator is mentioned. You are not allowed to sell copies of the free version.

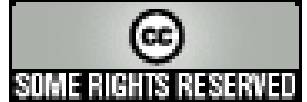


erschienen in der Reihe der Universitätsdrucke im Universitätsverlag Göttingen 2013 
Frauke Reitemeier (ed.)

"Deepe things out of darkenesse"

English and American

Representations of Conflicts

Göttinger Schriften zur

Englischen Philologie, Band 7

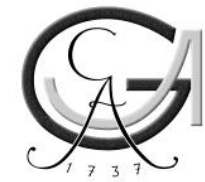

Universitätsverlag Göttingen 2013 


\section{Bibliographische Information der Deutschen Nationalbibliothek}

Die Deutsche Nationalbibliothek verzeichnet diese Publikation in der Deutschen Nationalbibliographie; detaillierte bibliographische Daten sind im Internet über $<$ http://dnb.ddb.de $>$ abrufbar.

Anschrift der Herausgeberin

Frauke Reitemeier

Seminar für Englische Philologie

Käte-Hamburger-Weg 3

37073 Göttingen

e-mail: Frauke.Reitemeier@phil.uni-goettingen.de

This work is protected by German Intellectual Property Right Law.

It is also available as an Open Access version through the publisher's homepage and the Online Catalogue of the State and University Library of Goettingen

(http://www.sub.uni-goettingen.de). Users of the free online version are invited to read, download and distribute it. Users may also print a small number for educational or private use.

Satz und Layout: Frauke Reitemeier

Umschlaggestaltung: Franziska Lorenz

(C) 2013 Universitätsverlag Göttingen

http:/ / univerlag.uni-goettingen.de

ISBN: 978-3-86395-129-0

ISSN: $1868-3878$ 


\section{Table of Contents}

Introduction: “Culture is Ordinary” (FRAUKE REITEMEIER) 9

Who Was "Shakespeare"? Ideas of Authorship, Conspiracy Theories, Personality Cult, and a Debate Under Scrutiny (TONIA KRÜGER) 15

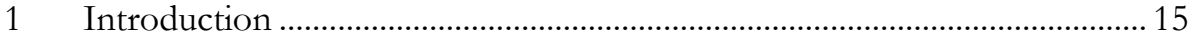

2 The Authorship Debate As a Question of Personal Ideals ......................... 18

3 The Authorship Debate As a Question of (Religious) Belief..................... 27

4 The Authorship Debate As a Question of Authorship............................... 36

5 Meeting “Shakespeare"-As-Himself.............................................................. 47

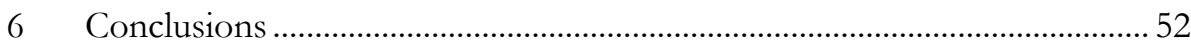

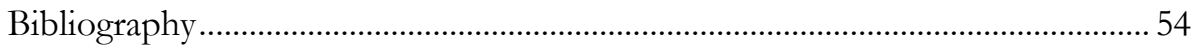

Vietnam Goes Intermedia - Reconsidering Media Boundaries in Michael Herr's Dispatches (MADITA OEMING) 59

1 Introduction: The Vietnam War In- and Outside Plato's Cave.................. 59

2 Theory in the Making - The Concept(s) of Intermediality ......................... 61

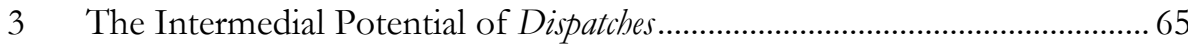

4 A Mass Media Sensitive Close-Reading of Dispatches................................... 68

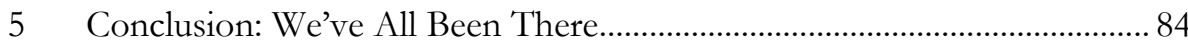

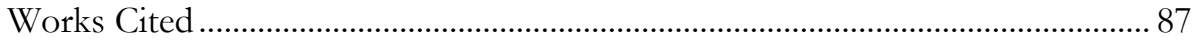

The 'War on Terror' in Contemporary Hollywood Cinema: Ridley Scott's Body of Lies and Jeffrey Nachmanoff's Traitor (DENNIS EDELMANN) 93

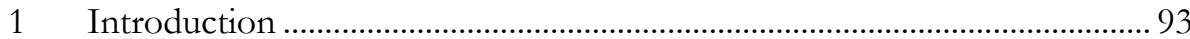

2 The American Self-Image After 9/11 _........................................................ 94

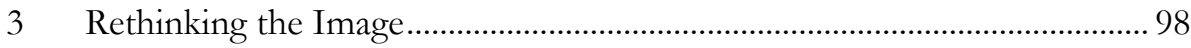

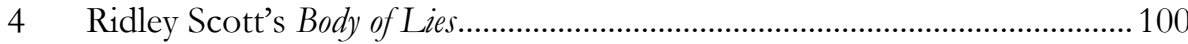

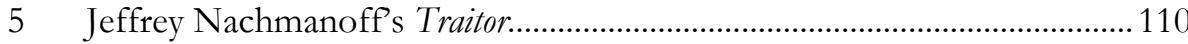

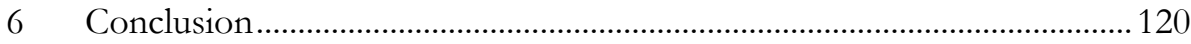

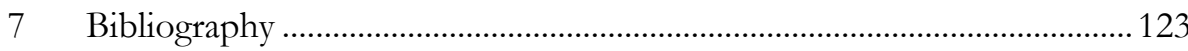


The Construction of Identity and Identification in Tim Minchin's Storm (LENNART BRIEGER)

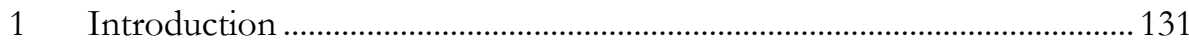

2 An Applicable Theory of Identity Construction ....................................... 133

3 How the Narrative and Narrative Techniques Elicit Identification......... 143

4 How Poetry Invites Identification through Pleasure................................. 160

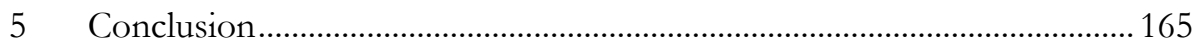

6 Transcript: Tim Minchin's Storm the Animated Movie ................................... 167

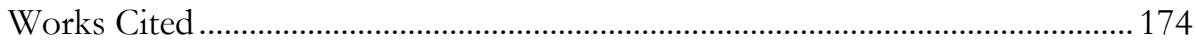

„Göttinger Schriften zur Englischen Philologie“: Zum Konzept

der Reihe (FRAUKE REITEMEIER) 


\title{
Introduction: "Culture is Ordinary"
}

\author{
Frauke Reitemeier
}

Students new to English Studies at Göttingen University are often surprised to notice that their course of study does not only refer to Literature (with a capital L) but also takes other kinds of cultural production and all sorts of cultural and literary theories into consideration.

"Culture is ordinary": In 1958, when Raymond Williams made his programmatic statement in an essay of the same title, the relations between culture, society, and class were being renegotiated and redefined, and Williams had some impact on the direction in which the discussion would move. Williams's thinking was influenced by Marxist theory. To him, the system of production in any given society was the key to understanding the culture - or cultures - that exist in that society. Thus, economic changes affect the social organisation that he perceived art to be an element of (93). Williams, however, did not believe that to bring about social changes a particular approach to the arts should be taken; culture, he insisted, "is common meanings, the product of a whole people, and offered individual meanings, the product of a man's whole committed personal and social experience" (96). His 1958 essay discusses Marxist theory and Williams's responses to it, but it also looks at the standpoint of F. R. Leavis, perhaps the most important English author on culture in the first half of the twentieth century. Leavis rejected the consequences the growing industrialisation had on what he considered culture, something that "has always been in minority keeping" $(1930,3)$, and that contains the "power of profiting by the finest human experiences from the past" (1930, 5). He made a distinction between high culture and low culture, and for him the advent of mass media marked a sharp decline in cultural products. To Williams, this made 
little sense. He believed that ordinary people should not, and indeed cannot, be equated with the mindless masses that Leavis envisioned. Nor did Williams believe in the stipulated downfall of culture as a whole; culture expands, he contended, and all elements of culture are also expanding, so it quite logically follows that more 'bad' culture would be noticed (100).

F. R. Leavis's ideas about the necessity of preserving the continuity of English (high) culture date from the early 1930s, a time when the relationship between culture and national heritage was discussed not only in England, but all over Europe. In one of his most important contributions on the subject, Culture and the Environment, he mourned the death of a particular kind of society:

What we have lost is the organic community with the living culture it embodied. Folk-songs, folk-dances, Cotswold cottages and handicraft products are signs and expressions of something more: an art of life, a way of living, ordered and patterned, involving social arts $(1964,1)$.

Like Williams, Leavis noticed changes in society - Culture and Environment alone contains two chapters on the loss of 'organic' communities - , but his reaction was different from what Williams's would be some thirty years later. For Leavis, literary education - "training taste and sensibility" (1964, 1) - was to replace what had been lost. Culture and the Environment was followed up by his study on The Great Tradition (1948) in which Leavis charted the development of what he considered as the tribute of English novelists to culture: The novelists he singled out were, or so he stated, "significant in terms of the human awareness they promote; awareness of the possibilities of life" (2). Closely bound up with this was the authors' take on morality: "Without her intense moral preoccupation Jane Austen] wouldn't [sic] have been a great novelist." (7) To Leavis, Literature (with a capital L) should serve mankind as a beacon, but the literature (with a small 1 ) that was produced in Leavis's own lifetime was obviously more of a will-o'-the-wisp instead.

Leavis was not the only one uneasy about the relationship between art, culture, and society in the context of the mass production of works of art in the first half of the twentieth century; in fact, it was a common concern of many critics, and it covered not only literature. Walter Benjamin, like Williams influenced by Marxist thinking, also believed that art and economic conditions reflect on each other's changes and developments. Benjamin noted that the 'truth' of a work of art - its 'aura', in Benjamin's terms - changes, and to a certain extent degenerates, when it is mechanically (re)produced. Thus, the reproduction of a work of art results in the shakeup of tradition ("Erschütterung des Tradierten", 477), and Benjamin recognised the then modern medium of film as its prime agent. Partly this was triggered by the Nazi's and Mussolini's use of propaganda films. Yet to Benjamin, films were only the final stage in a more general and sweeping development in the mechanisation of art production. Unlike the production of a theatre play, a film is less 'realistic', or so Benjamin claims; getting used to this representation of the world results 
in an audience that is mentally numbed and unused to critical thinking. For Benjamin, thinking along similar lines as Leavis, this meant the downfall of human civilisation.

Leavis's concern with high and low culture, and his belief that those who are more interested in low cultural products should be educated to understand how to mentally better themselves, influenced many critics of his time, though not everyone agreed with him on what should be done to remedy the situation. In the end a new kind, non-Leavis kind of literary and cultural criticism emerged. Authors like Richard Williams and Richard Hoggart - and others - critically reviewed these earlier ideas and found them wanting, creating a new kind of approach to literature and to culture in general: Cultural criticism is not interested in a high/low culture divide, but is concerned with all cultural products, in whatever form they come. Cultural critics do not study excellence in a particular author or genre but approach a stratum of cultural products in the way an anthropologist approaches an alien culture, as something to be evaluated and understood without prejudice and without hierarchies in mind. Even the production of films and books for a mass audience is considered in a different light, and while many critics are still trained in using Marxist thinking for assessing the impact of cultural artefacts on their recipients the commodification of the artefacts is not be universally condemned any more.

The papers in this volume reflect this change of topics. None is concerned with 'literature' in a traditional sense; even Tonia Kröger's paper on Shakespeare does not take his work into account, but rather studies how critics have tried to grasp Shakespeare as an author and how they defended their idea of who really filled Shakespeare's shoes. While this may seem very arcane, these 'Shakespeare wars' show how irrelevant the author's person really is when studying his work: The very range of authors and politicians who were and are still considered to have used 'Shakespeare' as a pseudonym effectively debunks the notion that Shakespeare's plays can be understood better (or even only) if the life of the author is taken into account.

War is also the background to two other papers, Madita Oeming's "Vietnam Goes Intermedia" and Dennis Edelmann's paper on two contemporary films on the American military intervention in Afghanistan ("The 'War on Terror"). Oeming is primarily interested in how a very particular text, Michael Herr's book about his experience as a journalist in the Vietnam War, tries to show the reality of life in a warzone both by using its own medium - the core of the book is formed by articles Herr published in various magazines - and by reflecting various other media such as films. At the same time, many readers of Dispatches would also see the book against the backdrop of other war books. Edelmann, on the other hand, moves away from literature in the sense of printed texts completely. He analyses the representation of the US 'war on terror' in two recent films, Ridley Scott's Body of Lies and Jeffrey Nachmaninoff's Traitor (both 2008). The phrase 'war on terror' 
seems unanimously positive; it indicates that it is legitimate to destroy the enemy not because he is an enemy, but because he is a terrorist. For German audiences, the distinction between the 'good' and the 'bad' side in a conflict is usually not clear-cut, for reasons of German twentieth-century history. For an American audience, this is different. Edelmann's study shows how the two films illustrate a change in the American way of thinking by analysing how 'the enemy' is depicted both visually and acoustically.

Finally, Lennart Brieger's paper also looks at the depiction of a conflict about world views, though it is on a relatively small scale. Tim Minchin's Storm was originally a beat poem which was turned into an animated movie in 2009 , available both online and on DVD. Storm's speaker recounts a discussion at a dinner party, and though this does not sound as if anything very controversial could have taken place, the movie illustrates very clearly how argumentative the speaker gradually becomes. Brieger is mainly interested in how the speaker tries to win the reader/viewer/listener over to his side, which strategies he uses to make the reader/viewer/listener identify with his views. To this end, Brieger also looks at various ideas of how identity is constructed both on the side of the speaker and of that of the recipient.

None of these papers confirms to a traditional notion of literary criticism, and questions of high and low culture are not directly touched upon. Instead, they all consider various cultural productions which also include texts, and which aim at a broad audience. Together they illustrate how various conflicts both shape the view of the contestants and shape the audience's views on the contestants, and in this they give an insight into how society tries to come to terms with the conflicts: The authors of these papers show their readers various "deepe things out of darkenesse" - "yea, who knoweth not such things as these?" (Job 12:22; 5) 


\section{Literature Cited}

Benjamin, Walter. Gesammelte Schriften. Eds. R. Tiedemann, H. Schweppenhäuser. Frankfurt/Main: Suhrkamp, 1991. 7 vols. Vol. 1.2: "Das Kunstwerk im Zeitalter seiner technischen Reproduzierbarkeit. Erste Fassung." (1991) 431469.

The English Bible. Translated out of the Original Tongues by the Commandment of King James the First, Anno 1611. 6 vols. London: Nutt, 1903. (= Tudor Translations 33.)

Highmore, Ben. The Everyday Life Reader. London/New York: Routledge, 2002.

Leavis, F. R. The Great Tradition. New York: Stewart, 1950.

Leavis, F. R., and Denys Thompson. Culture and Environment: The Training of Critical Awareness. London: Chatto and Windus, 1964 (11933).

Leavis, F. R. Mass Civilisation and Minority Culture. Cambridge: Minority Press, 1930.

Williams, Raymond. "Culture is Ordinary", in: B. Highmore, The Everyday Life Reader (London/New York: Routledge, 2002), pp. 92-100. 



\title{
Who Was "Shakespeare"? \\ Ideas of Authorship, Conspiracy Theories, Personality Cult, and a Debate Under Scrutiny
}

\author{
Tonia Krüger
}

\section{Introduction}

"Master Shakespeare. Next time you come to Greenwich come as yourself and we will speak some more." "These words by Judi Dench as Queen Elizabeth I in John Madden's 1998 film "Shakespeare in Love" are obviously fictional. As it will be shown, however, the boundaries between fact and fiction are often blurred when it comes to Shakespeare biography. Since the publication of the first Shakespeare biography by Nicholas Rowe in 1709, texts about Shakespeare's life have kept appearing in large numbers. The story of his life that is woven around the known documentary facts differs greatly at times from one biography to the next. Even within a single text, the image of Shakespeare often is multi-faceted. Shakespearethe-writer, Shakespeare-the-actor, Shakespeare-the-businessmen, the list of Shakespeare attributes is long. Graham Holderness in his latest work from 2011 postulates Nine Lives of William Shakespeare.

The problem apparently inherent in the whole mass of pages written about Shakespeare is that nobody ever seems to be able to really encounter Shakespeareas-himself. In that respect, the Queen's request in "Shakespeare in Love" may be more acute today than ever. In Nine Lives Holderness takes an interesting and cou-

1 Compare: "Shakespeare in Love” (1998) directed by John Madden, 1:45:44-49. 
rageous approach to biography in that he tries to put on display the process that leads to the partial fictionalization of the facts concerning Shakespeare's life. He explains that there are two sets of rules when it comes to biography: that of academic and scholarly discourse and that of creative and imaginative writing. It is his distinct aim to obscure the clear separation of the two sets of rules. Throughout his book he carefully indicates what is fact, what is fiction and what story might be developed from both. As a result, the reader is enabled to keep close track of the process that necessarily influences all Shakespeare biography.

I do not want to write yet another story of Shakespeare's life. With an awareness of the above-mentioned in mind I want to take a look at a certain field of Shakespeare biography - doubts. For more than 150 years a war has been raging: the Shakespeare Authorship Debate. I chose this rather dramatic formulation deliberately and for two main reasons: First, doubters, who believe in Shakespearethe-businessman and maybe Shakespeare-the-actor but certainly not Shakespearethe-writer, tend to fight passionately for their alternative candidate of choice (one they picked from over 70 suggestions). As I will show, it is rather themselves and their personal image of the author they fight for than the one they put in the foreground. Many of them are no professional Shakespeare scholars but they cannot be called laymen, either, because they often are intellectuals having invested whole lifetimes in the study of "Shakespeare". The work and achievements of these nonprofessional Shakespeare scholars - as I call them here - must not be regarded as wholesale valueless. It seems to be the case, however, that the scholarly discourse bypasses them to a certain degree. Thus, one reason why the debate often takes dramatic forms is the very personal involvement of many of those fighting for one candidate or other.

Secondly, I will argue that the Shakespeare Authorship Debate became a war of beliefs a long time ago. What is attempted throughout the debate is something similar to a proof of God. Nobody can tell what God really looks like. Apparently, nobody can do so in the case of "Shakespeare". The second reason for the fierceness the discussion often takes on lies, I will argue, in its quasi-religious dimension. Shakespeare-as-himself, the person who lived within the early modern world of English theatre - not above $\mathrm{it}^{2}$-, will remain to some degree a mystery to scholars, professional as well as non-professional. Having understood this, I want to take a step back and ask why it actually matters to know who Shakespeare was or why it began to matter.

In order to do so I structure this paper as follows: In chapter $1 \mathrm{I}$ will look at the authorship question as a question of personal and circumstantial ideals. Francis Bacon, Edward de Vere and Christopher Marlowe will be presented as exemplary not only for main candidates of a certain time or epoch but also for the kind of historic figure chosen - philosopher, aristocrat and poet. The aim is to find out what kind of arguments are brought forward to defend or advertise the different

2 This is also reflected upon by Grace Ioppolo (8-9). 
candidates but also to try and detect patterns the respective claimants might share in their argumentation. In chapter 2 the authorship question will be formulated as a question of (religious) belief. At one level the origin of the debate as of religious context will be outlined. At another level analogies between worship of Shakespeare and worship of God will be pointed out. The deification of Shakespeare played an important role in the widening of the gap between Shakespeare-ashimself and Shakespeare-as-imagined. The authorship question as a question of ideas of authorship will be examined in chapter 3. It is here that the gap dividing Shakespearian scholarly discourse and the argumentation of non-professionals becomes the most apparent. Therefore, it is here that this rift receives its actual meaning for the reception of Shakespeare outside the academic world of literary criticism - something professionals must find an answer to. Finally, chapter 4 will try and join the already interlinked threads from the previous chapters in a more targeted way in order to come up with answers to the central question of this paper: Who was "Shakespeare"?

The literature dealing with Shakespeare's life, alternative biographies and the authorship debate are vast. As John Michell puts it: "It would now be impossible to read it all. Not that anyone would want to, since much of it is repetitive, dull and cranky. It is the sheer weight of it that is so impressive." (9). On that account, for chapter 1 I tried to select texts that are conceived of as representative or even groundbreaking by defenders of the same candidate. In the course of my discussion of each candidate, I will briefly present which texts might be considered such works.

Leading the way for this paper was James Shapiro's Contested Will. Who wrote Shakespeare? Shapiro is one of the first Shakespeare academics to take the Authorship Debate seriously by asking how it actually came about. He arrives at an explanation of the reasons for his belief that it is indeed Shakespeare who wrote "Shakespeare" not by putting forth evidence against other candidates but by analysing why people started to doubt and why certain candidates were chosen over others as convincing alternatives. His method is to explain the development of the respective theories with personal experience and societal influence. I take a slightly different angle, though, asking who was instead of who wrote "Shakespeare", placing an emphasis on "Shakespeare" images rather than the contents of particular theories.

Furthermore, I consider Seán Burke as of major importance for a more general discussion of authorship. Authorship: from Plato to the postmodern. A reader gives an overview over discussions of authorship by presenting key readings from Plato to twentieth-century theorists such as Roland Barthes and Michel Foucault thereby putting these texts into their historic contexts. For a more detailed discussion of twentieth-century approaches to authorship, The death and return of the author: criticism and subjectivity in Barthes, Foucault and Derrida also by Seán Burke might be helpful.

A work such as this obviously cannot go without asking why there is a prevailing interest in questions of authorship in the first place. The answer is that scholars 
have been and still are in the middle of a debate attempting to come to the core of what an author actually is. The debate reached a first peak in the Romantic Age. The image of the author as genius in many cases is still dominant and very much alive in the Shakespeare Authorship Debate. A second peak was reached in the 1980s with the proclamation of 'the death of the author'. The question is why "Shakespeare" did not die at this point if he was an author. The question is why, on the contrary, there was a wave of new publications dwelling on Shakespeare's life in the 1990s. Today, there is a shift towards an acceptance of authorship as a collaborative effort - elaborated on, for example, in Contested Will (254-259). On top of that, more recent Shakespeare biographies - like Stephen Greenblatt's Will in the world: how Shakespeare became Shakespeare and Holderness's Nine Lives - show a growing awareness of the fictional and autobiographical aspects that influence all biography and especially that of Shakespeare.

An investigation of the Shakespeare Authorship Debate can contribute to this in that it distinctly shows how and to what extent personal, situational and societal aspects add to the perception of the past and the interpretation of facts. Sometimes both are hardly recognisable because filtered by time and circumstance. For this reason exactly, I ask who "Shakespeare" was. Along with this question, however, goes another one: Why does it matter?

\section{The Authorship Debate As a Question of Personal Ideals}

\subsection{Francis Bacon - the Scientific Philosopher}

"If you really want to know, once and for all, if there are authentic ciphers which prove, beyond a reasonable doubt, that Sir Francis Bacon, not William Shakespeare, wrote the plays and the sonnets, I tell you categorically that there are." (Peck ix) In 2001, Andrew Stevens Peck chose a mathematical approach to the authorship question as is claimed on the blurb of his book. Not only does he want to show that Bacon's authorship of the Shakespearian texts can be proved by the decoding of a hidden cipher but also that Bacon as legitimate heir of Queen Elizabeth I should have been king (x). It is writings like this which make it easy to ridicule proponents of Francis Bacon-as-"Shakespeare". Anyway, Peck seems to be quite late with the publication of his book to contribute to the Authorship Debate in any meaningful way. Bacon as a candidate for being the author of Shakespeare's plays was hotly tipped about 150 years before Peck. This is the reason why most texts proposing Bacon stem from the second half of the nineteenth century but there is no text that could be put forth as some kind of standard reference. After the idea had been born, many texts on the topic were published - quickly taking bold shapes. 
As will become clear later, Peck poses an interesting example of how the Shakespeare Authorship Debate is kept alive, though. The hunt for a hidden cipher as a desperate search for any kind of proof is symptomatic. The complete lack of documentary evidence by which Francis Bacon could be linked to the works of Shakespeare left proponents of Bacon with nothing but the plays in their hands. They had no choice but to look for proof within these texts. Accordingly, attempts of deciphering "Shakespeare" are part of the Bacon Theory from a very early stage onwards (Mitchell 134-153; Shapiro 118-128).

The question is, of course, how the Bacon Theory came about when there is no documentary evidence pointing towards Bacon. Charles LaPorte as well as Shapiro suggests a theological origin of the Shakespeare Authorship Debate. Both LaPorte and Shapiro argue that it was only a matter of time until in the climate of religious criticism in the pious society of the mid-Victorian era the Shakespeare Question would arise (LaPorte 613-619; Shapiro 69-79). In 1835, David Friedrich Strauss in The life of Jesus had critically studied the Holy Script and the evidence at hand to conclude that Jesus might have been a noteworthy historic figure but certainly not divine. In order to prevent the spreading of Strauss's ideas and with Shakespeare's deification well underway, Shapiro argues that Samuel Mosheim Schmucker published Historic Doubts Respecting Shakespeare only to hit out at Strauss's reasoning. "Parodying Strauss's line of attack, Schmucker takes the reader step by step through all the reasons that prove that Shakespeare's authorship is suspect." (77) Schmucker missed his point. Instead of dispersing doubts concerning Jesus, doubts concerning Shakespeare began to grow in line with those affecting the Son of God.

Delia Bacon belonged to the first to pose a case for Bacon. She recognised a political meaning in the plays attributed to Shakespeare and suspected them to have been written in collaboration by a group of republicans under the leadership of Francis Bacon. She was the first to take the step and think of an alternative candidate. Bacon being one of the greatest minds of the Renaissance came to mind quite naturally. Bacon-the-scientist and Bacon-the-philosopher had a great reputation already, so why not add Bacon-the-poet as well (Shapiro, 89-90)? William Henry Smith had managed to publish a pamphlet with the title "Was Lord Bacon the author of Shakespeare's plays?" one year before Delia Bacon in 1856. Smith claims in his text that Bacon's life was exactly like how one would expect Shakespeare's to have been (Shapiro, 105-106). The case for Bacon quickly gained momentum from then on.

In a more recent work from 1990 Penn Leary, himself a Baconian, summarizes the arguments usually brought forward in support of Bacon. Just to mention the most important:

The Baconians claim that the Stratford Shakespeare was not qualified to write the Works, and that Francis Bacon was. They claim that Bacon possessed the stupendous equipment - both natural and 
acquired - for the miracle; and that no other Englishman of his day possessed the like; or, indeed anything closely approaching it (Leary, 34).

Consequently, the main argument for Bacon is his education and the explanation for his using a pseudonym is politics. As a statesman he had to be careful with every word uttered, which would have hindered him in the wording of his literature. For scholars of Bacon it is inconceivable, though, that he could have written the plays - a lot too scientific and precise seems to be his language and his thinking (Michell, 119-121). But for Baconians "Francis Bacon was the only man of his time who was capable of producing such great works." (115) This is not surprising, however, when the growing importance of science and technology in the Victorian Age is taken into account. Bacon-as-scientist and philosopher was just the person to bridge the opposition of science and art when he could also be Bacon-the-poet. " [It] celebrated the marriage of science and sensibility." (Taylor 214)

The decipherers of Shakespeare's works fit well into that picture and the time when telegraph and Morse code became more and more prominent. By coming up with all kinds of ciphers and codes nobody could find but the ones promoting them, they combined a kind of spiritualism with technology (Michell 134-153). Yet, this was no concept made for the twentieth century.

\subsection{Edward de Vere - the Aristocratic Autobiographer}

"Once the compelling figure of Edward de Vere steps into the spotlight, however, wonder turns into doubt. De Vere's candidacy as an alternative Shakespeare is bolstered by an imposing cumulative weight of circumstantial evidence that demands serious evaluation.” (11) So claims William Farina in 2006. The case for Edward de Vere, 17th earl of Oxford is over half a century younger than that for Bacon. It came to life when the movement for Bacon began to fade. As Shapiro puts it, "[p]hilosophy and politics were out, Oedipal desires and mourning for dead fathers in." (149)

In 1920, John Thomas Looney proposed in 'Shakespeare' identified in Edward de Vere, the Seventeenth Earl of Oxford that de Vere instead of Shakespeare had authored the plays and poems. Up to today, de Vere is traded as the likeliest candidate for an alternative Shakespeare. Roland Emmerich made a case for de Vere in his recent blockbuster "Anonymous". ${ }^{3}$ What is told, feels much more real than what is written in the history books. For Emmerich, this is the reason why John Orloff's film script made so much sense to him. ${ }^{4}$ Among those who found their "Shakespeare" in de Vere were several great thinkers like Mark Twain, Sigmund Freud and Henry

\footnotetext{
"Anonymous" was released in the USA, Canada and the United Kingdom 28 October 2011.

4 Consult the following URL: http://www.youtube.com/watch?v=AUmwQsfX1wY for the full ntoi-interview with Emmerich. (Last seen 6 July 2012).
} 
James. Freud especially left his mark on the interpretation of de Vere-as"Shakespeare".

Again, Shapiro does a great job in tracing when and why de Vere was first introduced to the discourse as a candidate. Looney was a member of the "Church of Humanity" which was inspired by August Compte's positivism and his concept of a "religion of humanity" (164-167). Shakespeare Identified must be seen as a product of positivism. Sensory experience as the single source of knowledge and empiricism as the only valid method of accumulating knowledge are the basic foundation of this philosophy. Shapiro presents some of Looney's own commentary in his book (168-169), which reveals Looney's interpretation of the Shakespearian texts to have been clearly autobiographical (171). When it is experience that creates knowledge, experience must be the basis of Shakespeare's writings. Michell gives an account of the 18 points Looney came up with to outline the image of "Shakespeare" he derived from the plays and poems. Among this criteria is the notion of genius, the author must stand up to, as well as a kind of mysteriousness and a feeling of not being appreciated enough. The man must be of refined education, have an aristocratic background and be an admirer of Italy (Michell 164-165; Shapiro 172-173). Obviously, Shakespeare did not fit that nineteenth-century image of an author. De Vere, however, seemed to match the description well enough so that Looney could stop looking for his candidate. It is other aristocrats in the first place to pose as competitors for de Vere.

As Looney's approach required to interpret the Shakespearian plays and poems as drawn from experience and thus as being autobiographical, it was just what would take Freud's fancy. It brilliantly corresponded to his theory of the unconscious that is confined to the more remote regions of the human mind but pushes to the front in dreams or writings etc. (Hazelton 307-310). De Vere was easily identified, for example, as the author of Hamlet - the play in which he, according to Freud, tried to come to terms with the death of his father who had always been inadequate to him (Shapiro 185). The hunt for parallels between de Vere's life and passages from the plays and poems was declared open. "... Oxfordians since Looney's time have greatly expanded the case, adding so many new suggestive points of interest that it has grown cumbersome." (Michell 171) Nothing of that, however, cumulated to proof or even gave an answer to the big problems confronting the Oxford Theory. For one thing, de Vere's early death in 1604 requires a re-dating of most of the plays, which so far has not convincingly been done. For another thing, nobody has yet succeeded in explaining why de Vere would have needed a front man. If he wanted to remain unrecognised as the author of the plays, he could have published them anonymously, which was commonly done during his time. ${ }^{5}$

5 Robert Detobel in the harsh kickback he published as a response to Shapiro tries to give an explanation. He claims Shakespeare was a masquerade for de Vere not a stooge. De Vere needed someone to put in his place as a measure to distance himself from the theatrical world. His involvement with the theatre - which was his passion - had him banned from court, explains De- 
In short, the Oxfordian case relies heavily on an interpretation of the plays and poems as autobiographical. The parallels sometimes seem astonishing and therefore convincing. As an example Michell gives the story of Bertram in All's Well That Ends Well which seems to be almost identical to de Vere's early life - piquant details included. Yet, it has a 14th century source (170). As stated earlier, Freud and his theory proved quite influential to the Oxfordian reading of Shakespeare's texts. Although there were some who tried to locate hidden messages in the plays and poems in order to link them to their candidate, these endeavours did never reach the same dubious levels as for Bacon - at least not in this respect. ${ }^{6}$ In de Vere's case, it is rather the attempts from the direction of depth psychology that often seem overdone. Freud's psychoanalytical influence on the general direction the movement for de Vere took was already hinted at above. To give but one example, Hazelton, trying to psychologically explain what makes a genius in order to see who fits the description best, maintained that creative writers more often than not are later-born children. This indicator of genius as one among several features points to de Vere rather than Shakespeare. Shakespeare was the first surviving offspring of his parents whereas de Vere was a second-born at least to his father (315).

It is these heavily biased and far-fetched contributions to the Shakespeare Authorship Debate that make it difficult for professional scholars to take it seriously. On the other hand, examples for the dramatic scale which is partially taken on from those adding to the discourse can prove highly interesting for an analysis of the debate as attempted here.

\subsection{Christopher Marlowe - the Suffering Genius}

"This is the book which proves almost beyond a shadow of a doubt that Christopher Marlowe is the author of the plays and poems attributed to the actorbusinessman named William Shakespeare", promises Calvin Hoffmann on the blurb of "The murder of the man who was "Shakespeare" from 1955. Despite his ambitious aim Marlowe never gained a fellowship comparable to that of Bacon or de Vere. The reason might be that Marlowe according to documentary evidence died in 1593, a few months before Shakespeare's first publication - Venus and Adonis. The problem therefore is that while defenders of Bacon or de Vere sometimes like to add some incredible and scandalous conspiracy to their respective

tobel, to which de Vere wanted to return. (257-259). Detobel relies on very scarce evidence relating to general court procedures citing John Davies of Hereford and the French philosopher Philibert de Vienne while dismissing two facts: First, there is a great availability of evidence linking Shakespeare to his work. Second, there is a complete lack of evidence linking de Vere to it.

6 See, for example, Thorpe's "Nil Nero Verius"-worldplay - depicted by Michell (180-181) included in a paragraph on the Oxford Anagram (178-184). 
theories ${ }^{7}$, defenders of Marlowe do not get around it. They must think of a scenario in which Marlowe survived the night of 30 May 1593 in Deptford in spite of what is in the coroner's report and the examination of the corpse by several jurors. Readers must be convinced of the scenario before they can be convinced of Marlowe's authorship of the Shakespearian plays. D. Maure Wilbert argues: "It is highly likely the stab wound was not fatal to Marlowe but put him into a comatose state from which he would revive hours later, after the sixteen jurors had viewed a bloody and apparently lifeless body." (30)

I am not interested in judging the plausibility or probability of the various candidates. What I am interested in is to look for ways in which candidates are presented to later conclude what kind of image of the Author they correspond to. For this reason I decided to seize on Marlowe here. Indeed, the case for Marlowe is especially interesting because "[i]f he really did survive his own murder there is no limit to what he can be supposed to have done later." (Michell 240) Defenders of Marlowe are given almost complete liberty as they can use their imagination even more freely than the others to create their personal image of the Author.

Marlovians present Marlowe as an ultimate genius. To them Marlowe made influential friends like Sir Francis Walsingham when he worked as an agent for the government. These friends helped him feign his murder when Marlowe had to fear for his life because he was accused of atheism and fell out of favour with the government (Hoffmann 57-68; Blumenfeld 37-39, 212-229). Wilbert even goes so far as to interpret Marlowe's "death" as the moment the genius was shaped: "There is an almost messianic or Christ-like quality about Marlowe, if we allow his anointing by the muses, and the idolatry that belongs to him, not Shakespeare, along with the putative experience of resurrection at Deptford!" (147-148) This perception corresponds to romantic concepts of authorship, as they will be analysed in chapter 2 .

Adding to that, Marlovians seem overly ready to reject the inclusion of historical facts to their theory and make abundant use of the liberty they can take with Marlowe's alleged life in exile. For Wilbert, it is obvious that - because the First Folio contained additions, revisions and improvements - Marlowe must have lived until 1623 at least. "... for the master poet-dramatist who first penned them would hardly allow others to retouch his own creations." (101) Such claims reveal a serious lack of knowledge about the early modern world of English theatre, which will be looked at in some detail in chapter 3 .

It is particularly amazing that Marlowe-as-"Shakespeare" is presented and imagined in these romantic terms. The murder of the man who was 'Shakespeare' - the main work promoting Marlowe - was first published in 1955. One should assume that romantic ideals had faded to dominate images of authorship by then. This, however, seems not to be the case. On the contrary, romantic images of author-

According to one such theory, Bacon is the rightful heir to the Crown (e.g. Peck, 1-19). Similarly, the Prince Tudor Conspiracy sees de Vere as the secret lover of Queen Elizabeth I - described, for example, by Shapiro (196-197). 
ship appear overly dominant, even in the latest film "Anonymous". 8 This is why I will argue in chapter 3 that the scholarly discourse concerning questions of authorship has to a large extent bypassed contributors to the Shakespeare Authorship Debate.

Of course, Marlovians as well as Baconians and Oxfordians before them tried to find convincing evidence for their theory within the plays and poems. Image cluster analysis is supposed to reveal the trauma of Deptford, which reappears not only in Shakespearian plays but others as well which consequently must also have been penned by Marlowe (Wilbert, 34-35, 47-49). Marlovians like to cite Thomas Corwin Mendenhall who published one of the first attempts at stylometry in 1901 - a statistical method to analyse author's styles by a frequency distribution of different word lengths. Mendenhall's results did not support Bacon-as-"Shakespeare" but amazingly Marlowe (Michell 228-231). Marlovians of course fell on the results (Hoffmann 137-140; Blumenfeld 338). Yet, Michell points out the problem with stylometry that "every stylometrist has a different approach and rejects everyone else's method." (230)9 In other words, it is in not very reliable.

Furthermore, the poems are considered as clearly autobiographical by Marlovians - a consistent conviction, asserts Blumenfeld (254) - and they obviously do not fit Shakespeare's biography at all. He never experienced pain and desperation as Marlowe did which is taken to have spawned the sonnets and plays (e.g. 307). Holderness correctly criticises the habit of reading especially the sonnets as autobiographical. “... this is still literature, not life. The drama is real enough but drama is not biography." (143)

\subsection{Alternative "Shakespeare" Biographies - What They Have in Common}

It is easy enough to cast doubt on the others, but no theorist has both answered the objections to, and made a positive case for, any particular author of Shakespeare. ... Unless some new, dramatically conclusive evidence turns up, the whole subject looks to be approaching a dead end (Michell 10).

It does, indeed, seem as if everything has been said about the Shakespeare Authorship Debate and every single one of the different candidates. Then, however, new books keep being published. Scott McCrea, a non-professional scholar arguing for Shakespeare-as-"Shakespeare", promised in the title of his 2005 publication The case

8 The screenwriter John Orloff has the young Edward de Vere say in "Anonymous": "My poems are my soul." (0:24:25-26), which directly refers to the romantic concept of the source of inspiration within the poet. The logical consequence is the veneration of the poet by the audience. The viewers of de Vere's plays are in raptures through the sheer beauty of his verses and demand for the playwright. It is the illiterate Shakespeare who cannot resist and presents himself as the author (0:34:54-36:08). Everyone wants to touch him as if he was a saint (0:53:06-50).

9 Craig comments on Shakespeare's style as compared to Marlowe's in Craig/Kinney: „Shakespeare, Computers and the Mystery of Authorship" (6-7). 
for Shakespeare: the end of the authorship question to finally put an end to the debate. His conclusion then, however, is that there can be no end (217). One must wonder why there can be no end when nobody has to add anything new and when speculations take more and more untenable forms. Contested Will would have had the potential to end the debate by reviewing its origins but it only provoked a fierce response by Robert Detobel who immediately summoned all the notable de Veredefenders to bring them into position against Shapiro. ${ }^{10}$ By looking for similarities between the different groups in their argumentation and presentation, I want to take one step closer to answering the question of why there is no prospect of an end. I ask how so many people can look at the same facts and come up with so varying interpretations - always with complete certainty.

Sandra G. L. Schruijer tries to explain the irreconcilable opposition of the different groups from a psychological perspective and explains mechanisms of group behaviour at work, such as stereotyping, selective listening and the tendency to identify with one group placing it above other relevant groups to achieve personal prestige (127-128). However trivial this might sound, she certainly is right in her conclusion: "Getting acceptance from one's opponent in this case would be the Stratfordians saying to the Oxfordians or Marlovians for that matter: 'you are right, we were wrong all along.' Simply put, this is not going to happen.” (130)

The problem of the incompatibility of the different groups lies within the method used by all "Shakespeare" biographers since the nineteenth century. A candidate is chosen and only later is the evidence at hand arranged around him speculation and imagination used as adhesive. This method is commented on by Holderness in Nine Lives. A tautology is immanent in this kind of thinking: evidence is extracted from the plays and poems and used to identify the Author whose life is then taken to explain their contents - a process which is selfreinforcing. At the beginning of this process stands a person - a professional or non-professional scholar - who has the feeling to know "Shakespeare". Caroline Spurgeon's pioneer study Shakespeare's imagery and what it tells us was first published in 1935 but regularly reprinted since then until 2001. She analysed metaphors, similes and analogies she isolated from Shakespeare's plays to discover the author's range of experience. The approach rests on the assumption that images reflect what is familiar to an author. Spurgeon contrasts her findings to other poets of Shakespeare's time. Although one must expect overlaps because of societal and cultural factors, she was able to uncover differences. Yet, she carries her theory a decisive step further by arguing that the imagery reveals the author's character.

10 His endeavours were published in 2010 - under the title: Will - Wunsch und Wirklichkeit: James Shapiros Contested Will. Detobel shows himself grateful that a professional Shakespeare scholar at least admits to the Shakespeare Authorship Debate and is willing to look into the history of Oxfordianism (302). Yet, he considers Shapiro's method of researching motives and aims as completely amiss because it is not asked if people had right and reason for their deliberations (303), an accusation made by several contributors of Will - Wunsch und Wirklichkeit. 
As I have collected and examined these many thousands of images, and have pondered over them the last nine or ten years, there has gradually emerged before my eyes a very definite figure of the man who was the author of them. (200)

This appears to be the crucial point: scholars who have spent their lives with "Shakespeare" develop a very personal image of the man but see it as a universal truth. Like Spurgeon they consider themselves experts of his character, philosophy and worldview. Spurgeon, for example, describes him as gentle and kind, honest, brave and true and attests him a deep understanding of all living things. "He is indeed himself in many ways in character what one can only describe as Christlike" (207) After having become an expert of "Shakespeare's" soul and nature, it is nearly impossible to understand the subjectivity of that "knowledge", which is why many contributors to the Shakespeare Authorship Debate feel so astonished when defenders of other candidates are completely unreceptive towards their argumentation.

The film "Shakespeare in Love" freely creates a "Shakespeare" popular with a today's audience. This is legitimate because the film simply wants to tell a good story. There are no known details about "Shakespeare's" personality and private life. Creating their "Shakespeare" is not only what the film does but to a certain degree also what scholars do when they make assumption about him - however reasonable and logical these assumptions might be. In the end "[w] hat we will find ... is an image of ourselves.” (Garber, 2003, 176) The gap between professional and non-professional Shakespeare scholars is widened by the fact that professionals like Shapiro or Holderness are much more aware of this process than nonprofessionals who hardly ever reflect on it.

In a nutshell, one must admit that the Shakespeare Authorship Debate has indeed reached a dead end. The authors of books arguing for one of the several candidates often are convinced to prove "beyond a reasonable doubt"11, only to find that those who already were convinced share their opinion and those who were not convinced before do not change their minds. Many announce their amazement when people they call "otherwise intelligent" do not accept the candidate they argue for. ${ }^{12}$ Everyone accuses everyone else of speculation while speculating themselves. ${ }^{13}$ They all detect all sorts of parallels and clues in the Shakespearian texts

11 E.g. Hoffmann, blurb; Blumenfeld, 1; Malim, 1; Peck, ix-xi.

12 For example, Felicia Hardison Londré writes in the Introduction to Farina: "I have wondered why the minds of otherwise intelligent people often snap shut when it comes to the Shakespeare authorship question." (Farina 2).

13 This can be found in almost all contributions to the Shakespeare Authorship Debate. Jolly, for example, writes in the Introduction to Great Oxford: “... when 'orthodox' scholars speculate, de Vere's supporters seek to rest their arguments upon documentary evidence." (8). William D. Rubinstein writing from a historian's perspective sees himself as above this accusation (53-57). For a typical example, compare Detobel's critique of Greenblatt and Shapiro (285-287). 
that seem to point to their candidate exactly but have to reject parallels and clues found by others indicating other candidates. ${ }^{14}$

All this supports one conclusion: the debate has reached a dead end because it has dissolved into something entirely different a long time ago. At the very moment when it was first speculated about "Shakespeare's" personality, when the first assumptions were being made linking the contents of "Shakespeare's" plays and poems to the author's personal experience, this was something one could believe in or not. It was nothing anybody could know for sure. There is no proof. Certainty is derived from belief.

\section{The Authorship Debate As a Question of (Religious) Belief}

\subsection{Theological Origins of the Shakespeare Authorship Debate}

Above, I have already declared the Shakespeare Authorship Debate a war of beliefs, and I have underpinned this idea by pointing out that contributions almost never are about facts and almost always about ideas taken for facts by those bringing forward a particular argument. The question is how it could come to that, what factors favoured this development. My analysis includes two levels: On an external level I want to look at the religious origins of the Shakespeare Authorship Debate and at structural aspects of Shakespeare Criticism. On an internal level I want to attend to a contentual layer - namely "Shakespeare's" deification during the Romantic Age.

In chapter 1 I mentioned the theological origins of the Shakespeare Authorship Debate as suggested by Shapiro or LaPorte because an explanation of the debate's beginnings cannot go without at least hinting at the matter. Here, I will elaborate on Shapiro's and LaPorte's line of thought by which they transfer the concept of Higher Criticism to the questioning of Shakespeare. It was Friedrich August Wolf who introduced a new method to the authorship question concerning Homer. In 1795 he published Prolegomena ad Homerum. In his work he asked how texts were transmitted over time - a method derived from biblical studies (Shapiro 69-73). His conclusion was that Homer was not the single writer who had authored the works attributed to him but only an imagined entity. LaPorte calls Wolf's approach reflexive in effect because the Bible as well as Homer offers no clue of who the author might be. Accordingly, Wolf's hypothesis did not go down well by Christians (LaPorte 616-617). Forty years after Prolegomena, David Friedrich Strauss published The life of Jesus. Strauss's bottom line becomes clear when he says that "[i]t is an incontrovertible position of modern criticism that the titles of the Biblical books represent nothing more than the design of their author, or the opinion of Jewish and Christian antiquity respecting their origin." (part 1 56-57 cit.

14 E.g. Hoffmann, 203-232; Detobel, 81-100; Londré (see foreword to Farina), 1-5. 
from LaPorte 617) This idea was of explosive nature especially when applied to the New Testament, which Strauss did not hesitate to do. According to LaPorte's thesis the emergence of the Shakespeare question was from now on unavoidable in the "mid-Victorian religious atmosphere" (LaPorte 617). Similarly, Shapiro claims: "In such a climate, it was only a matter of time before someone would try to do to Shakespeare what Strauss had done to Jesus." (76) What followed was the publication of Schmucker's Historic doubts concerning Shakespeare.

Obviously, this can only be fully understood in the light of the meaning Shakespeare had at that time. It can only be understood in the light of Shakespeare's divinity. That is why I will now leave the external level before coming back to it at the end of the chapter. For now, I deem it necessary to take a look at the reception of Shakespeare in the decades after his death. "Less than an author in the 1660s", writes Michael Dobson, "Shakespeare was by the 1760s something more than an author" (185). Rather than having been born a genius, Shakespeare was made a genius. I will try and outline when and how his apotheosis occurred.

\subsection{Shakespeare's Apotheosis}

\subsubsection{From Man to Entity - Editing Shakespeare}

Above, I quite freely referred to "Shakespeare"-as-genius or -as-divinity. One could criticise that a clearer distinction should be drawn between the two concepts. I will not do that here at length. Both seeing "Shakespeare"-as-god or -as-genius must be viewed as symptomatic of one and the same tendency: "Shakespeare" is not seen as part of the world he lived in but as standing above it. Thus, the two concepts are interrelated. To avoid confusions, I suggest that genius is used more generally in terms of the literary high esteem "Shakespeare" is praised with, and the theological diction more specifically to refer to the personality cult around "Shakespeare" in the nascent Romantic Period.

"[It] seems we want to make Shakespeare less like a man, and more like a kind of god", concludes Marjorie Garber her brief reflections on the Shakespeare Authorship Debate $(2004,21)$. I want to ask why that is. Gary Taylor explains that "Shakespeare" was actually forgotten after his death several years before he was "reinvented". "Almost no publication, almost no performance, almost no biography, almost no criticism: we might take 1659 as the nadir of Shakespeare's posthumous history." (12) It was only with the Restoration that "Shakespeare" reappeared on the scene. With the return of Charles II a political amnesia spread. The Interregnum with all statutes passed during those years was feigned to never have taken place. Shakespeare and Jonson happened to be the preferred readings of Charles I and "returned from exile with Charles II" (Taylor 13). They both underwent their own literary restoration (10-13). 
Taylor's thesis of that close a connection between a political and literary restoration is not fact. Yet, Shakespeare certainly did reappear from oblivion although he did not necessarily match Restoration tastes, his language being too loaded (36). Still, he remained in the repertoire. Restoration audiences tended to interpret plays in terms of politics and societal circumstances. Many Shakespearian plays had a potential in this field. The obvious solution was adaptations. It was only these revised versions of Shakespearian plays that were now and again performed on the Restoration stages (Dobson 4). ${ }^{15}$ Meanwhile and independently from that, "Shakespeare's" reputation was gradually improved upon and established. The process that contributed to this development was the fading interest of the royalty in the theatre from Charles II to George I. Actors had to find new audiences in the middle classes, which gained them the disdain of the upper classes. The accusation of cultural decline accompanied the theatre's return to the public (Taylor 61-62). Admiration of "Shakespeare" was possible only because he was subject to a gradual shift from 'stage to page'. ${ }^{16}$

Alexander Pope, in his 1725 edition of Shakespeare, commented on the Shakespearian texts by highlighting paragraphs he considered especially pure and beautiful. This shows that the plays and poems were now actually meant to be read instead of be viewed in performance. What Pope did, however, was more than to simply put emphasis on the passages he valued highest. He also identified moral or textual failures within the texts and declared them undesirable side effects owed to "Shakespeare's" close connections to the public stage (Dobson 129-130; Taylor 82-83). It was "the stage that was to blame for obscuring Shakespeare's genius." (Taylor 83) Pope's opinion is related to the method he used for his Shakespeare edition, which he must be credited for. Habitually, former editors of Shakespeare had simply relied on the most recent editions, which had been altered severely from the First up to the Forth Folio. Pope, however, collected all the early Quarto editions he could lay his hands on, compared text passages and restored words, phrases and passages he assumed to be truly "Shakespeare" (iibd.). "Pope's edition reveals more clearly than any other Augustan publication the connection between the desire to rescue Shakespeare from the theatre in the interests of print culture and the urge to delete his plays' lapses into vulgarity." (Dobson 129)

Pope thereby contributed to a process that can be called an abstraction of "Shakespeare" from his texts that were in circulation but felt to have been corrupted by their usage in the theatre. ${ }^{17}$ After the Restoration, "Shakespeare" was

15 For a more detailed description of the repertoire of the Restoration stage see, for example, Taylor (20-30).

16 The shift 'from stage to page' and in what way it affected Shakespeare criticism and the reception of Shakespeare is, for example, dealt with by Tiffany Stern in "Making Shakespeare: from Stage to Page".

17 Compare Taylor (74-87) for a detailed analysis of Nicholas Rowe's 1709 edition of Shakespeare prefaced by the first attempt of a Shakespeare biography - which kept to theatrical conventions concerning the treatment of texts. Rowe, thus, derived authenticity from theatrical tradition while Pope relied on principles associated with the development of books during the Augustan Age. 
considered part of the past that was seen as present again and that was enacted as such. "Shakespeare" gained a conservative importance and meaning. At the end of the eighteenth century, this obtained new relevance when the French Revolution let fears of revolution increase in England. Famous Shakespeare editors like Edmond Malone - the first to include the poems as well as the plays in his Shakespeare edition - continued the pursuit for documentary authenticity because Shakespeare seemed to belong to exactly the past they wanted to conserve and protect (Taylor 131-133).18

De Grazia suggests that Malone's method of comparing text passages with what Shakespeare had written elsewhere in order to recover their true meaning and wording implies that Malone looked for answers and for truth within "Shakespeare" instead of language (204-205). In accordance with the abstraction of "Shakespeare" from his texts, this must be hold as an important step to create "Shakespeare"-as-abstract entity, detached from the playwright of around 1600. Even if Shakespeare was dead, this entity could still be consulted and would yield answers. The process of splitting Shakespeare in two is completed here. On the one hand, there is the playwright who lived and worked around 1600 in a world strange to following generations and up to a certain degree always inaccessible for scholars of later centuries. On the other hand, there is the entity "Shakespeare", the person one knows, the person one has such a clear image of in one's head. In a way, of course, this separation always has existed. Yet, with the abstraction of Shakespeare's plays from the theatre and then the abstraction of "Shakespeare" from his texts in circulation, the distinction was reinforced. Marjorie Garber in this context speaks of "Shakespeare"-as-two playwrights: the playwright of then and the playwright of now $(2004,28)$. The differentiation does not seem far-reaching enough, though. The process that led from Shakespeare to "Shakespeare" is more complex than is reflected by a distinction like that. The process took a playwright and yielded an author. ${ }^{19}$ It took a historic person and yielded a universal entity. It took a man and yielded a god. For that reason, I prefer the distinction between Shakespeare-as-historic figure, and "Shakespeare"-as-framework filled with the respective projections of those trying to establish a clear picture of him.

At this point, however, I have to take a step back. Even if Malone unknowingly contributed to establishing "Shakespeare"-as-entity, he did not make him a god. Although, Malone's inclusion of the sonnets in his Shakespeare edition furthered the shift from a dominant image of "Shakespeare"-as-public dramatist to "Shakespeare"-as-private poet, which might be considered essential for the Romanticists veneration of "Shakespeare" (Taylor 156), it was not quite enough. As necessary as the distancing of "Shakespeare" from the theatre had been to allow

\footnotetext{
18 For a more detailed analysis of this process and the development of the concept of authenticity see: Margreta de Grazia, 49-93.

19 This will be of concern in chapter 3 .
} 
for his admiration, so necessary was the marketing of "Shakespeare" within the theatre for his apotheosis.

\subsubsection{From Entity to God-Garrick's Product}

As mentioned above, plays by Shakespeare did not belong to those that were staged often during the eighteenth century (Cunningham 20-22). While masquerades and farces featured prominently in the theatre repertoires, tragedies were only rarely put on stage. Cunningham points out, however, that under the tragedies that were performed Shakespeare's outnumbered those of other playwrights (21). In the second half of the eighteenth century, theatres began to prosper again. The country achieved new wealth and military power. The population was constantly growing (Taylor 115). "Shakespeare" benefitted from the fact that hardly any new tragedies came forth at the time and even most comedies had a very short lifespan so that Drury Lane and Covent Garden in London had to rely on successes of the past (Taylor 115-116; Cunningham 20-21). Apart from that, Shakespeare's tragedies had something else to offer: "A role is the meeting place for an actor and a play; if the actor triumphs so does the play." (Taylor 22) Several of the Shakespearian plays provide strong roles for actors. Suddenly, the fate of "Shakespeare" was closely linked to that of a young actor with the name of David Garrick.

Garrick first became known or even famous for his embodiment of Shakespeare's main character Richard III (Cunningham 4). His style of acting thereby differed greatly from what were the usual practices at the time. In an elocutionary conception of acting, the art of conveying the idea of an emotion was generally valued highest. Garrick, however, dismissed the requirement of dignity on stage instead using his whole body to convey deep inner passions (Woo 22-23).

He departed from the entire mode of using the voice as primary instrument of stage communication, caring little for maintaining the customary graces of form and dignity, and instead allowing his conception of the character to more fully inhabit his body (25).

It seems Garrick had found a kind of gap in the market and made full use of promoting his product "Shakespeare".

As explained above, no "authorised" version of Shakespeare's plays existed in the eighteenth century. Theatre-goers only knew "Shakespeare"-as-great-author that could still be improved (Garber, 2004, 12) or they were not even aware that the plays put on stage were adapted versions. Garrick now claimed to retrieve the "authentic Shakespeare", to have his plays performed as they had been written by him (Cunningham 7-9). His efforts are judged ambiguously, though. "Whereas 
Stone $^{20}$ had championed a Garrick intent upon driving his theatre ever closer to textual fidelity to Shakespeare, Vickers ${ }^{21}$ accuses Garrick of lacking the courage and the inclination to revive Shakespeare as written." (Cunningham, 10). Indeed, Garrick did continue "to shorten, adjust and re-present, in both small and large ways, his idol's plays." (42) 22 . Yet, Garrick restored some text passages and more importantly several characters who had been deleted in other adaptations (Vickers,1989, 212-231; Cunningham 43-75).

Woo, in her analysis of Garrick's contribution to the making of "Shakespeare", testifies he had an "acute sense of what his society would and would not tolerate." (31). Cunningham somewhat more ironically concludes:

Rather than literal adherence to any printed text or indeed to any absolute principles of alteration, the best service that Shakespeare's self-selected high priest believed he could offer to his idol was to bring forward his plays in forms acceptable to contemporary audiences (75).

When Cunningham almost mockingly dubs Garrick "Shakespeare's self-selected high priest", she seizes on the designation of Garrick as "Shakespeare's priest" in his own lifetime. This "status" he did not just achieve by performing his new Shakespeare adaptations. His clever marketing catapulted "Shakespeare" into the foreground. While promoting Shakespeare, Garrick also promoted himself-as"Shakespeare". Garrick drew audiences to the theatre by introducing new stage machinations and thus more "action" to the stage, which made "Shakespeare" more accessible for middle class audiences. He also distributed paintings and pamphlets, in which he presented himself as "Shakespeare"-promoter in self-mocking ways (Woo, 28-30). In 1755 Garrick had a temple erected in his own garden on the banks of the River Thames at Hampton which was devoted to Shakespeare. He himself posed for the statue (Woo, 41; Cunningham, 5). Briefly speaking, his approach was multimedia.

Furthermore, Garrick was the first who had the name of "Shakespeare"-asauthor put on the playbills (35). However minor this might seem, it played its part in tracing the plays put on stage to "Shakespeare" and in tracing "Shakespeare" to his roots. Garrick's enactment of "Shakespeare" reached a climax in 1769 when he was approached by leaders of the town of Stratford-upon-Avon with the request to fund a Shakespeare statue to stand in the Town Hall. Garrick had the idea to cele-

20 George Winchester Stone made Garrick the champion of his doctoral thesis “Garrick's treatment of Shakespeare's plays and his influence upon the changed attitude of Shakespearean criticism during the eighteenth century".

21 Brian Vickers is one of those making a case against Garrick: "Shakespearean adaptations: the tyranny of the audience", in Returning to Shakespeare: 212-233.

22 For an example of the kind of alterations Garrick had Shakespeare's plays subjected to see, for example, Cunningham (63-75). 
brate "Shakespeare's" birthday with a Jubilee in the very town his idol had been born in (Woo, 32-35). In the course of the festivities a procession of Shakespeare characters went through Stratford, plays were performed - notably none of Shakespeare's - and Garrick himself presented a poem he had written in praise of "Shakespeare" (Cunningham 106-112). For Garber, this re-creation of Stratfordupon-Avon as "Shakespeare's" birthplace was a cultural event that celebrated the author rather than his plays and thus is indicative of the personality cult that was created $(2004,16)$. Possibly due to bad weather conditions the Shakespeare Jubilee was not as great a success as organizers must have hoped for. In the aftermath, however, a new Shakespeare industry developed with Garrick as driving force. He wrote a play about the Jubilee that was performed at Drury Lane and was quite popular with the audiences (Woo 34).

This clearly shows that "Shakespeare" by then had achieved a status independent from his creations. Garrick's play The Jubilee looks like a comment on the cult he himself had sparked. He can be called the first bardolator of Shakespeare ${ }^{23}$, but he took others with him. In Shakespear's Garland of 1770 a song appeared in praise of the Mulberry Tree, supposedly planted by Shakespeare in Stratford. The personality cult gained momentum. All kinds of items were sold that were allegedly carved from the wood of the Mulberry Tree (Woo 32-38). The fan was established as a consumer who wanted to obtain a piece of "Shakespeare", even if his plays were still only tolerated as adaptations.

"Those who believe in the high and serious calling of literary criticism will be disappointed that so many intelligent men and women who cared about Shakespeare and the drama failed to stop the 'new-modelling' of his plays", assumes Vickers (1989, 229). This, however, seems somewhat beside the point. Today's focus on authenticity, the focus on the very words "Shakespeare" had committed to paper only developed after his deification. At the end of the eighteenth century the Shakespearian plays became more acceptable although they were still put on stage in adaptations. "Shakespeare" was given national importance. ${ }^{24}$ For England, the uprising trading nation, "Shakespeare" became a cultural export (Taylor 123).

The Shakespeare of the mid-eighteenth century is imagined and rewritten as an author at once domestic, national, and moral, and in all of these aspects, which spectacularly converge on the Jubilee, he is rapidly escaping from the stage altogether (Dobson 186).

23 "Bardolatry" refers to the worshipping of Shakespeare and was as a term introduced by George Bernhard Shaw. Shaw invents the term "bardolatry" to sneer at the alleged Shakespeare Worship of Garrick, Cibbers and the like, whose representations of the plays he calls "spurious and silly". "So much for Bardolatry!" (718).

24 See Dobson for an analysis of ,"The Making of the National Poet” and Celestine Woo for a more specific approach dealing with John Philip Kemble and his enactment of "Shakespeare"-asnational poet in the aftermaths of Garrick (49-85). 
Garrick, who felt he had been called to mediate between "Shakespeare's" actual words and the people, drew upon the mystery surrounding Shakespeare and the abstraction of Shakespeare from his plays and poems. He made "Shakespeare" his product of worship. The story of "Shakespeare"-as-product was so great a success because the abstractness of "Shakespeare" enriched by a sense of mystery made it easy for people to believe in the product (Woo 38). It was a god-like status that had been produced for "Shakespeare" and "Shakespeare" had obtained an independent existence when Garrick died in 1779.

The two processes described here can be seen as separate developments but they interact in certain aspects. On the one hand, there is the interpretation of the Shakespearian texts as poetic rather than dramatic - for example by Pope - and the abstraction of "Shakespeare" especially by Malone in Pope's tradition. Within the theatre this developing abstractness was used by Garrick for promoting "Shakespeare" and for making him an idol of worship. Later, it served to give the entity Malone established a godlike, omniscient meaning.

This image of "Shakespeare" prospered within the Romanticist Movement. Taylor's criticism is doubtlessly justified: "most literary critics do not ask themselves why Shakespeare stayed on top during the Romantic period, because they assume that he belongs on top, and they assume too that continuity is normal." (147) All those who question Shakespeare's authorship because they assume his life does not fit their image of genius are not aware of one fact: Shakespeare was not born a genius. He was made one long after his death. In "Shakespeare in Love" Joseph Fiennes presents the viewer an image of the poet - alone in his study, equipped with quill and parchment, his fingers stained with ink - that corresponds to notions of authorship formed during the Romantic era - solitude, pensiveness, reflectiveness. These still seem prominent with contributors to the Shakespeare Authorship Debate - independent of the name and identity they assign to the figure at the desk.

\subsection{Believing in "Shakespeare" - A Structural Analysis of the Debate}

After Shakespeare had been made divine, he also became more vulnerable. Divinity is closely related to faith, and faith to doubt. "Shakespeare's" apotheosis was followed by his idealization in the Romantic Age. In 1848, Schmucker's attack Historic Doubts was published. The deification of Shakespeare must be considered vital for the Shakespeare Authorship Debate and leads me back to the external level of my analysis.

The theological origins of the Debate as suggested by Shapiro and LaPorte were pointed out above. They are reflected in the respective labelling of Stratfordians as Orthodox and of anti-Stratfordians as Heretics, which is done by many contributors to the Debate. Shakespeare of Stratford and Jesus of Nazareth both are historic figures about whose lives only little is known. Although Shakespeare's life is much better documented than that of most of his contemporary writers, the 
obtainable information concerns his birth and marriage and otherwise his business life. There are few guidelines for establishing an image of his character and personal life. Both Shakespeare and Jesus underwent an abstraction from their lives and from their works that is essential for the cult that developed around their personalities. The notion of divinity or sacredness even extends to things they are said to have touched which automatically turn into relics. In the same way that pieces of Jesus' cross were sold and revered as sacred, pieces of "Shakespeare's" Mulberry Tree were sold and revered as sacred (Woo 34-35).

Péter Dávidházi interprets The Shakespeare Jubilee as a religious event. Even today do the recurring birthday celebrations of the Bard evoke ideas of religious celebrations. The official Shakespeare's Birthday website advertises:

Every year a unique event takes place in Stratford-upon-Avon to mark the birth of the world's greatest playwright. ... The birthday weekend brings together performers, artists, the local community and ambassadors from around the world in a vibrant celebration of the life and works of William Shakespeare. During the two day event, the town's streets overflow with music, pageantry and drama... ${ }^{25}$

Today, the event is highly commercialized but, as Woo assumes, David Garrick was already well aware of the "marketing possibilities of Shakespearian religiosity" (35): He was the first to erect "Shakespeare" a temple. He was "Shakespeare's" priest. He initiated the Shakespeare worship and Bardolatry imitated Christianity. LaPorte even goes so far as to see Bardolatry and Christianity as strongly connected by an interlacing of religious and literary discourses that goes beyond analogy and of which the Shakespeare Authorship Debate is the most prominent consequence (609). To break it down, it can be hold that doubts concerning the historic Shakespeare are related to doubts concerning the historic Jesus.

There is, however, one major difference between the two: never ever has an alternative Jesus been proposed. The reason might be that Strauss stripped Jesus of his divinity and left a person who still had interesting things to say. Schmucker however unwillingly and however unjustified - stripped Shakespeare of his authorship and left a person with nothing but austere business transactions. Doubts only started to rise when "Shakespeare" was split in two - the historic person and the divine poet. The nineteent century first created doubts concerning Shakespeare and then started looking for a more suitable author. "The key point to grasp about all these contenders is that their names - every one of them - only entered the frame after the apotheosis of Shakespeare from accomplished dramatist to god of our idolatry." (Bate 106, highlighting in original). None of the idealised "Shakespeares" that were built from the nineteenth century readings of the plays and

25 http://www.shakespearesbirthday.org.uk/ (last seen: 6 July 2012). 
poems could be proven to have written them. Nobody could claim to know. They were embodiments of a "Shakespeare" one could believe in.

Orthodoxy and Heresy are terms that have no place within a serious debate. They are symptomatic, though, for the moment when the Debate ceases to be a debate and becomes a war of beliefs instead. This is the reason why the debate will not be solved one way or another. Belief or faith is seldom open to reasoning.

\section{The Authorship Debate As a Question of Authorship}

\subsection{Changing Conceptions of Authorship}

\subsubsection{The Birth of the Genius}

To most contributors to the Shakespeare Authorship Debate the Shakespearian plays and poems were written by a genius. Their interpretation of "Shakespeare"as-genius has far-reaching consequences. Indeed, the Shakespeare Authorship Debate would not exist without it. This is because of what scholars - as analysed in chapter 1 - interested in "Shakespeare" do: they look at what is left of him and find it curious because within their understanding of authorship, writing processes and the concept of literary genius, the documentary evidence and the poetry do not fit together. Obviously, what should be done by them is understand that William Shakespeare of Stratford lived in a world different from their own. It must not be assumed that it is obvious what he thought, what influenced his behaviour and what made sense to him.

In the preceding chapter it was demonstrated that "Shakespeare" always is and always was imagined. Nobody knows the real Shakespeare, "Shakespeare"-ashimself. "Every age creates its own Shakespeare." (Garber, 2004, 3). Every biographer imagines and thus invents their own Shakespeare. It seems therefore impossible to find out who the "real Shakespeare" was. The question that must be answered at this point is why it matters who he was anyway. The Shakespeare Authorship Debate is the best of indicators that it does matter. It is the identity of the Author that is questioned. The Author seems to be an entity existing on its own waiting to be assigned a name, a life and a personality.

In order to find an answer to why it matters who "Shakespeare" was, I will analyse conceptions of authorship with regard to the influence they have on the image of "Shakespeare". Yet, I will also take into account conceptions of authorship that interestingly do not seem to sway that image. Any survey of the developing ideas about authorship is at risk of interpreting the past as a series of events that inevitably lead to the present. Scholars who write a history of ideas are always confronted with this problem, which is why it is a necessity to reflect on it within any work concerned with abstract notions subject to transformation. When I 
sketch a development here that seems more linear in nature, I justify that with my focus on "Shakespeare". Still, the Author is no natural concept, even though most contributors to the Shakespeare Authorship Debate use the term as taken for granted.

The conception of authorship is closely related to that of originality and truth. Truth, thereby, gives authority. Christian culture found truth in God. This truth was approachable chiefly through the word. Christian culture, therefore, brought together notions of inspiration and autonomous truth in that authority for inspiration was given by God (Burke, 2006, 7). ${ }^{26}$ For the further development of the literary author, Burke emphasises the importance of a shift within Bible interpretation. Instead of an allegorical (divinely-authored) conception of authorship a literary (humanly-authored) one became prevalent (ibd.). This is one example for the interlacing of religious and literary discourses that LaPorte maintains.

Edward Young was the first who attempted in "Conjectures on original composition“", which was published in 1759, to dissociate the source of inspiration from God and place it within the subjective self instead. This entailed a notion of originality as innate that had not existed before. Because of his rejection of imitating classicism and his promotion of the superiority of genius, Edward Young might be discerned as a pioneer of Romanticism (Burke, 2006, 8). "In Romantic literature, we see the clear emergence of a central emphasis upon the imaginative genius' of the poet." (Moore/Strachan 2). Creative imagination is the impulse that enables a poet to create art without imitating the outside world (ibd.). The Romantic Age must be seen as one of the peak moments in the discourse of authorship when conceptions of authorship were renegotiated. Therefore, it is difficult to bring the different ideas down to a common denominator. The first generation of Romantics had to emancipate themselves from their neo-classical predecessors (123). Wordsworth heavily criticised the 'poetic diction' in its stead demanding a language that was natural, more spontaneous, and supposed to come straight from the heart (125). Shakespeare was nothing of that. Still, he was seen as the greatest of poets to express human passions and nature. John Keats found in "Shakespeare" an embodiment of his conception of negative capability. "Keats's brand of poet, who identifies empathetically with other people's natures and beings, is a poetic chameleon with 'no identity' and 'no self of its own." (155) "Shakespeare" excelled in negative capability because Keats found that no personal attitudes were reflected in the plays. Instead, it seems to be something outside of him that is represented in his texts, something that surpasses his individuality. Keats's concept of negative capability stands in opposition to Wordsworth's more self-centred notion of

26 Seán Burke in his portrayal of Authorship : from Plato to the postmodern distinguishes between two main sources of authority within conceptions of authorship: Literature can either be derived from an inspirational or from an imitative discourse. Inspiration includes the notion of "otherness" by which the author is set apart from the common everyone, while at the same time denying him any originating power. Imitation sees a subjective individual at work reproducing an objective reality, which means the author is a kind of expert answering to or commenting on the established system (5-7). 
poetic production, which Keats critically refers to as Wordsworth's 'egotistical sublime'. ${ }^{27}$ Poets of the first and second generation, however, are one on the idea of the 'transcendent genius' as author. Moore and Strachan stress selfhood as the central preoccupation of Romanticism (3). "Shakespeare" was now interpreted as the "archetypal genius" (Bennett 20) Even if the Romantic Era was none that produced great drama itself, interest in drama persevered (Moore/Strachan 169-172). For Romanticist notions of literature, Shakespeare's plays, however, rather seemed fit to be enjoyed before the inner eye. Performance on the stage would reduce "Shakespeare's" verbal power and beauty (Moore/Strachan 170-171). In this conception of the Shakespearian texts "Shakespeare constitutes the model of the Romantic author as transcendent genius." (Bennett 20)

The source of imagination continued to be debated, though. As Burke goes on to explain, Stéphane Mallarmé was the first to state that the poetic origins are to be found in the outside world. Thus, he denied all ideas that saw the poetic origins in the imagination or the unconscious, the inner world of the poet so to say (Burke, $2006,9)$. His approach was pointing the way ahead to the twentieth century.

\subsubsection{The Death of the Author}

That it is not the conscious subject that rules but the linguistic unconscious was an insight of the twentieth century. It was in the first place Claude Lévi-Strauss and Jacques Lacan - based on Saussure's structuralism - who made language the crucial point of intellectual thought. What they did was apply linguistic structures to phenomena which had formerly been considered "natural" and had never really been called into question (Burke, 2008, 12-13). One concept that quite famously came under scrutiny was that of the author.

According to Burke, it was at the juncture of phenomenology and structuralism that a "far-ranging form of anti-subjectivism" was produced (13). The first means, in Edmund Husserl's conception, to systematically study structures of consciousness thus opening up new layers of reflectiveness. The second, being a theoretical paradigm which was borrowed for application in a diverse range of scholarly fields, places truth in language which can only be understood in relational terms. Consequently, one could conclude that it is the structural system of relationships that is the source of inspiration but not the poet. Lacan and Lévi-Strauss stressed the importance of the 'unconscious infrastructure' as determining every thought and action. In their theories the "conscious subject" is replaced by the "linguistic unconscious". Burke cites Lévi-Strauss: "the goal of the human sciences is not to constitute man, but to dissolve him." (cit. from Burke 13) This paved the way for Deconstruction.

27 For a more detailed description of Keats's negative capability and how Shakespeare fits into it, see Moore/Strachan (153-157). 
After Burke, these developments were the fertile ground for the theories of the mid-twentieth century. Yet, in relation to the interpretation of authorship, he argues that these new theories were more than extensions of the arisen opposition towards the Author for the benefit of a focusing on literature itself. New Criticism interpreted literature as a "self-contained aesthetic object", whereby Burke sees this anti-authorialism simply as a reaction to the preceding biographical positivism, where the Author was treated as key to understanding a text. (15) "[T] he history of literary criticism had for the most part been the history of the glorification of the author." (24) Jacque Derrida mitigated this relationship by explaining that what is meant by a text, what is the Author's intention is only a subset of what is written. Burke, however, points out the difficulty of determining where intentions end, where the exact moment of deconstruction can be located (Burke, 2006, 68-69). It is Roland Barthes who finally "reaches the zero-degree of the impersonalising tradition through negatively maintaining the analogy of Author and Divinity to argue that the death of the latter implies the removal of the former." (69)

This is where it all comes together: the interlacing of religious and literary discourses, the analogies of Bardolatry and Christianity, and "Shakespeare". "Shakespeare" was made an Author and a god. William Shakespeare of Stratford died in 1616. "Shakespeare" was recreated in the eighteenth century as God and since lived as the Author. When Barthes declared the death of the author after God had already been declared dead by Friedrich Nietzsche, it would have been a logical consequence if "Shakespeare" had finally ceased to be a matter of interest. Yet, he is as proves the wave of Shakespeare biographies and the success of films like "Shakespeare in Love" and "Anonymous" very much alive until this very day.

In order to comprehend this phenomenon, it is necessary to make tangible what exactly it was that made Barthes declare the 'death of the author'. For Barthes, the author exists - if at all - in the very instance of writing but is then nothing more than the figure produced by using $I$. He is, thus, not real in his existence. " linguistically, the author is nothing but the one who writes, just as $I$ is nothing but the one who says I." (Barthes 122-123). What Barthes targets is not the author - as the person by whom a given text is written. It is the Author as an institution of critical inquiry that he wants abolished. The reason for this is the practice of critically approaching a text with the idea that each text can be assigned exactly one possible interpretation. In lieu of God, it is now the Author who gives authority to the one reading of his text. Truth is found in him. Truth is found in "Shakespeare". Barthes's criticism is that this prevents other or new interpretations thereby limiting the possibilities of a text. Instead, it is the reader who produces the text. The Reader is no individual subject, though, but an abstract ideal type of reader. Everyone will see and understand certain aspects of a text, never all of them and probably not the same as anybody else. "[T] he unity of a text is not in its origin but in its destination, but this destination can no longer be personal: (...) [the reader] is only that someone who holds collected into one and the same field all of the traces from which writing is constituted." (124, highlighting in original) The 
abolition of the author means to free language from its representational status (Burke, 2008, 41-42). For "Mallarmé, as for us, it is language which speaks, not the author" (Barthes 122).

In a sense, this implies that reading is like peering through a keyhole but there is no author who could unlock the door. The Author loses his key role. Instead, the readers create sense from what they see by themselves. As Burke points out, the death of the Author resembles the death of God because both include a dismissal of belief in authority (Burke, 2008, 21).

In the wake of Barthes, Michel Foucault asked What is an author?. In his essay he sees the author as a constructed social position. The author is firmly placed within the system of discourse that created him. "The author-function is ... characteristic of the mode of existence, circulation, and functioning of certain discourses within a society." (Foucault 148) The possibility or even danger of a text transgressing the system's boundaries becomes more and more inherent to literature. The author is in this sense a category invented to protect the system. The embedding of the author into the system thereby works through the fixation of authors' rights. "Foucault's bracing conjunction of modern literary authorship with copyright law has done much to energize the historiography of authorship." (Knapp 10) Foucault unmasks the term "author" as a historical mechanism of suppression. His conclusion therefore is that it should not matter at all who is speaking within a given text (Burke, 2008, 89). Still, it is the name of the author that holds a body of texts together and gives them a meaning. The name of the author is different to any other name in that it is related to the author function.

If I discover that Shakespeare was not born in the house that we visit today, this is a modification which, obviously, will not alter the functioning of the author's name. But if we proved that Shakespeare did not write those sonnets which pass for his, that would constitute a significant change and affect the manner in which the author's name functions (Foucault 146).

For Foucault the author has long been disappeared. They only exist as servant to their text - not their creator.

What consequences does this have for the treatment of Shakespeare? Brooks reflects on "Shakespeare" as having achieved an iconic status as the Author, as having become a symbol of modern ideas of Authorship (2). He does mention Barthes and Foucault (3-4) like several of the recent works on "Shakespeare" do. In none of them is "Shakespeare"-as-the Author dethroned, though. Knapp brings up Barthes's theory in "Shakespeare only" (9) to conclude later that anti-Bardolatry blinds scholars to the fact that Shakespeare indeed was special (19).

When the Author is dead, however, "Shakespeare" as embodiment of the Author finally should be dead. Yet, it has been pointed out that none of the theories or developments of the twentieth century seems to have had a lasting impact on the 
image of "Shakespeare"-as-the Author. Burke states that the problem with the death of the author is that the author-as-god had to be created first before he could be destroyed (25). Even after his proclaimed death, "the author lives on within and without theory." (165) Burke proceeds to explain that the absence of the author only has an "intra-critical" meaning. "The decision as to whether we read a text with or without an author remains an act of critical choice governed by the protocols of a certain way of reading rather than any "truth of writing." (169) The absence of the author feels unnatural because an absence is created where an idea already exists (165).

Deconstruction is carried on a meta-level when it comes to the weird situation that not only the author is an imagined category but also is his absence an imagined one. Burke's analysis is applicable to "Shakespeare"-as-the Author. Even if "Shakespeare" was given his status long after his death, it is now nearly impossible to imagine him without it. The canonization of his texts and the readings of his texts have to a great extent been influenced by his new status (Dobson 184-185). Theories concerning authorship may have progressed but the romantic picture of the genius-author creating from free imagination has prevailed as a powerful force within heads. "In spite of postmodernist scepticism, we conceive, in our still romantic way, of all art of any worth as being the privileged expression of the unlimited creative imagination of the individual artist." (Kernan 169) This is the point where the separation of professional scholars and non-professional scholars within the Shakespeare Authorship Debate takes effect.

\subsubsection{Specialist versus Amateur - Rivalling Images of the Author}

The deconstruction of the Shakespeare myth (Holderness, 2010, 105-106) has consequences for professional Shakespeare studies. Even if it is difficult to "suppress the instinct to think of Shakespeare as unique and supreme[, we] need to return to the age before Bardolatry and recover the perceptions of Shakespeare's own time." (Bate 106-107) The awareness that it is the reading of a text that to a large degree constructs its meaning seems to distance scholars from "Shakespeare". This awareness, on the other hand, enables them to write a history of the reception of "Shakespeare". Tracking down the circumstances of life in Shakespeare's own time, how he might have been perceived in his own time, might be what takes scholars closest to "Shakespeare" as they can get.

This awareness seems to be missing in most of the works by non-professional Shakespeare scholars, though. Answers given to the question why it actually matters who wrote the plays often sound similar. Farina writes: "To know more about a writer's life is to have a better understanding and appreciation for the writer's work - plain common sense, one would think." (13) For Calvin Hoffman as well it is not a question of difference when it comes to knowing the author's identity but a question of better understanding (x). "The personality of the author of the plays and poems is inescapably linked to the creations themselves. ... it is nonsense to 
believe one can, at the same time, admire merely what has been written and ignore the author." (ix-x) Freud as an Oxfordian also tried to explain why one bothers about the author's identity. It is that "we desire to bring ourselves nearer to such a man in a human way as well." (cit. from Hazelton 307)

There is a divide obvious in the conception of authorship and the approach to texts between professional and non-professional Shakespeare scholars. It is especially problematic that most non-professionals base their contemplations on an already-mentioned tautology. In trying to decode what the author meant with his text, they want to find hints to his identity, which they then use for a better understanding of the text. Because the distribution of academics and non-professionals is very uneven within the camps of Orthodoxy and Heresy (Schruijer 135; Rubinstein 41-42), power relations are asymmetric. Taylor drastically subsumes: "The Baconians were all amateurs writing for amateurs against specialists." (220) Even if this condensation was exaggerated, the high proportion of non-professional scholars defending alternative candidates reinforces their perception of having to deal with a conspiracy. They run against the wall of academics who they perceive make up the established system which tries to choke off all dissident thinking out of selfprotection (Rubinstein 44-45) "Non-Stratfordians can be seen as heretics as they challenge the establishment and the establishment feels threatened", concludes Schruijer (138). Tom Hunter - one of the contributors to Detobel's Will - Wunsch und Wirklichkeit - compares doubts about "Shakespeare" with Galilei's doubts about the sun circling the earth. In the same way as Galilei encountered the massive and impenetrable resistance of the Church that made him repeal his claims, Anti-Stratfordians encounter the massive and impenetrable resistance of the established circle of Shakespeare academics occupying the respective professorships (303). Accordingly, like-minded Oxfordians are often encouraged to not repeal their claims. ${ }^{28}$

In this climate, defenders of alternative candidates start to conceive of themselves as a small group fighting against an overly powerful opponent, standing up for the common good - which in this case consists in the truth about the Author and who they see as his respective embodiment. Their aim is to help the Author and his readers to justice because "the readers of those plays would not only want to know of the man who wrote [the plays and poems] but would also want to honour him as the greatest literary genius in history." (Blumenfeld 1)

It is these asymmetric power relations that contribute to the hardening of the situation. Apart from being a war of beliefs the Shakespeare Authorship Debate also is subject to power relations - superiority and denial of defeat. The group processes and mechanisms accompanying firm belief and feelings of minority blind contributors and turn the debate into a psychologically charged "minefield"

28 For an example see the Preface and Foreword of Great Oxford as well as the Conclusion (355). Hunter argues in Will - Wunsch und Wirklichkeit that the throng of sceptics is growing each day. "Es wird der Tag kommen, dass orthodoxe Befürworter des traditionellen Barden wie Professor Shapiro gewisse Fragen werden beantworten müssen, ..." (309) 
(Schruijer 125) outside of serious scholarship. The mutual insults that have entered the debate are symptoms of the emotional layers through which evidence and arguments are judged. While Hunter compares himself and his colleagues to Galilei, Scott, for example, compares "Shakespeare-deniers" to "Holocaust-deniers" (McCrea 222). ${ }^{29}$ This supports Schruijer's thesis that the debate is characterized by relational rather than rational conflicts (129). Clearly, professional scholars want to keep out of this. After having spent a few sentences on the Shakespeare Authorship Debate, David Bevington almost disgustedly interrupts himself: "Enough. I am an academic" (12).

So far, aspects distancing scholars from "Shakespeare"-as-himself have been in the focus. Yet, I also demanded with Ioppolo that Shakespeare be seen within the theatrical world he lived in instead of above it (8-9). In the second part of this chapter I want to have a brief look at this world to outline how researchers can actually get closer to "Shakespeare". Obviously, such an attempt is linked to most recent images of authorship.

\subsection{Who Was "Shakespeare"?}

"[Shakespeare] was a working man of the theatre and worked as his colleagues and collaborators worked." (Ioppolo 184) Being a playwright in the early modern world of English theatre meant to be one among many other playwrights. There was a huge demand for new plays to satisfy the regularly returning audiences. The institutionalized theatres had to compete with bear fights and public hangings. The lifespan of a play was short. ${ }^{30}$ That it was rather the names of theatre companies than the names of "authors" that drew audiences into the playhouses, is demonstrated by the fact that "[r] oughly half of the dramatic texts produced in the last two decades of the $16^{\text {th }}$ century were anonymous" (Brooks 176).

As has been made clear above, it is essential to not just transfer modern ideas of authorship to a different period of time when "authors" were referred to as playwrights - hence the inverted commas. The term playwright thereby gives interesting insights into contemporary images of "authorship". A wright is a maker of some kind. The old English word denotes a craftsman. A cartwright, to choose a random example, is someone who makes - i.e. builds - carts. A playwright correspondingly is someone who makes - i.e. crafts - plays. He uses words and gives them a dramatic form (2). Apparently, the production of plays for a theatre performance as entertainment first and foremost was seen as a technical process. In order to be a playwright one had to be good with one's hands rather than with one's head or heart. Clearly, these producers of plays do not appear especially fit for glorification as gods or saints.

29 Steven Greenblatt draws this comparison in a letter to the editor published 4 September 2005 in the New York. Times (Leahy, 121-122).

30 See, for example: Baker/Hinds (ed). The Routledge Anthology of Renaissance Drama, 1-13 and for suggestions of further readings: 14-20. 
For Brooks, authorship is only gained by "the translation from stage to page", by the printing and publishing of written texts (167). The printed text is longer-lasting than the word spoken before an audience. A reader has different expectations towards a text than has a theatre-goer. Given the quantitative and qualitative limitations to book production at the time, printed texts appreciated in value. The shift from "stage to page" brought with it a shift from a quickly-outdated produce for the masses to a work of art not anybody could afford (cf. Finkelstein/McCleery esp. 441-449). The person behind the produce was a craftsman. The person behind the art, however, had some higher qualities - some authorial qualities - even if there was still no clear indication of who wrote what (Brooks 167).

The shift described here has already been mentioned in chapter 2 . It is interesting to note that Shakespeare and his colleagues lived at a time when there was first created a market for printed drama (36). Shakespeare's earliest publications were his poems Venus and Adonis (1593) and The Rape of Lucrece (1594). Their publication fell right within the years of 1592 to 1594 when all the theatres were closed because of a severe outbreak of bubonic plague. One can conclude that Shakespeare was only secondarily interested in publication and wrote for theatre performance in the first place (cf. Brooks 55-56). Venus and Adonis as well as Lucrece were never intended for the stage, though. It is rather the publication of some of Shakespeare's plays in Quarto editions that is noteworthy. The merger of professional theatre and print publication had consequences on the authorial status of the plays. While in the first decades of professional theatre less than 20 percent of published plays gave an "author's" name on their title pages, there was a sharp increase of author attribution over the next two decades until roughly 60 percent of the plays published were attributed to an "author" - or even several "authors" (Brooks 138139).

The 1647 Beaumont and Fletcher folio is one of the examples Brooks gathers in his analysis of title pages. It is one of the examples in which one text or one collection of texts is assigned to more than one "author" (140-188; Vickers, 2002, 3-43, esp. 8-18). This is where a problem arises, which is formulated by Brooks as the question: "How can two become one? How can two authors write one text?" (167). Two authors' names cannot unequivocally be linked to one text. Singular authorship - the idea of the author or its denial - has been the dominant theme in authorship theories. Therefore, it appears not quite so natural to conceive of authorship as collaborative.

The idea of collaborative authorship is further complicated by the entanglement of the concept of the author and the concept of copyright which was already proposed by Foucault. Mark Rose explains that "the author is conceived of as the originator and therefore the owner of a special kind of commodity, the work." (1) The other way round, "[c]opyright is founded on the concept of the unique individual who creates something original and is entitled to reap a profit from those labours." (2) In this straightforward relationship it is not easy to define what shared proprietorship means and what consequences it implies. Does each sharer's own- 
ership comprise specific pages, paragraphs or even words? It is from here on that things start to get complicated. Rose declares copyright to be a specifically modern invention dependent on the invention of the printing press and the development of an advanced marketplace society (3). The first copyright statute was introduced to Britain in 1710 - almost 100 years after Shakespeare's death (4). Before, "the concept of an author owning a work did not quite fit the circumstances of literary production in the traditional patronage system." (17) This does not mean, however, that playwrights did not have literary interests. Even if they did not own their texts, they did own their manuscripts for which booksellers as well as theatre companies were a market (17-18). Still, different playwrights seemed to have had different images of themselves as playwright or "author". Rose names Shakespeare and Benjamin Jonson as two examples: Whereas Shakespeare could be characterised as a "reteller of tales" and seemed to conceive of himself as "a modest storyteller", Jonson actively promoted the publication of his plays and presented himself as the "author" of his 1616 folio The Workes of Benjamin Jonson (25-26).

Rose identifies "Shakespeare" as participant in an essentially collaborative process. Seeing in "Shakespeare" "the master poet-dramatist" who would never have anyone "retouch his own creations" (Wilbert 101), more than anything indicates the serious lack of knowledge some scholars have of the world Shakespeare was part of. Rose's assertion that "[t] he author's claim [to his manuscript] (...) ceased with the transfer to a bookseller or theatre company" (18) is partly suspended by Grace Ioppolo, though. She makes clear that the transmission of texts "in the age of Shakespeare, Jonson, Middleton and Heywood" was a circular and by no means linear process. Collaboration is identified as the main mechanism in all stages of production (1). This does not only concern the working together of more than one playwright on a single text but also the working together of playwrights with acting companies and brokers (42). As stated above, the demand for new plays was enormous, and it was trial and error that taught playwrights what worked out on the stage and what pleased the audiences (70-74). Ioppolo demonstrates that playwrights accompanied their texts throughout their production on stage maintaining close contact with the actors (41-44, 134-140). Even after the completion of a manuscript did a continuous revising of the texts remain part of a play's production. The revisions partly were done by the playwright but changes could be introduced by actors, editors or censors as well (121-125). Editors also kept close relations to scribers and other theatre personnel to come by the manuscripts they needed (145-147). Still, concludes Ioppolo, the dominant circulation of plays in Shakespeare's time was in performance rather than print (184).

Ioppolo, by making use of extant archival evidence such as contracts, theatre records and accounts, receipts etc., offers new insights into the early modern world of English theatre. She follows the transmission of texts from playwright to censor to playhouse to audience finding that the way of transmission was not as clear as it might appear on first glance. "Authors" kept returning to their texts after their composition. Even circular - the term she assigns to the process of text transmis- 
sion - seems almost too straightforward for this interrelation of the theatrical business (esp. 138). A business world it was, indeed - with all participants in the process thinking of strategies to keep the audiences returning to the respective playhouses. Ioppolo explains that theatre people - including the playwrights were businessmen not too blue-eyed to not think of marketing strategies that would bind audiences. The production of sequels and circles like, for example, Shakespeare's Henry plays holds as an example (73).

Altogether, it seems that it was the theatrical world that connected playwrights with their work while printing rather distanced them from their texts. Highly collaborative as this world was, a collaborative image of authorship is what follows.

Shapiro presents "Shakespeare"-as-collaborator in the last chapter of Contested Will where he tries to draw a picture of the man within his world. Shakespeare must be seen as an integral part of his acting company, which he remained with longer than most other playwrights (228-240). "Shakespeare's" authorship must be understood as collaborative in nature. Most recent, post-revisionist conceptions of authorship emphasise this social embeddedness of authors and their texts.

The method, as for example used by Shapiro, might bring the researcher closer to "Shakespeare"-as-himself than any guesswork concerning bits and pieces taken from his plays and sonnets to construct a relation to his life could. Even if Shapiro had got it all wrong, which Detobel accuses him of, he achieved more through this approach than any of the speculators about "Shakespeare's" thoughts, feelings and experiences. The problem, however, remains that "Shakespeare"-as-collaborator appears much more unnatural and contrived than "Shakespeare"-as-genius. In Brooks words "Shakespeare" seems to be the

anti-type of collaboration. (...) Translated into nearly one hundred languages and sold in nearly every country on earth, Shakespeare's plays have come to represent the standard by which 'great literature' is measured, and the name of Shakespeare has become a synonym for authorship itself (2). ${ }^{31}$ (My own highlighting.)

The name of Shakespeare - is there nothing more than a name in the end?

31 As Blumenfeld states, collaboration as the fashion of creation of the plays must be excluded when Marlowe writing from exile is assumed as author of the plays. "And that is why the plays in the First Folio stand out as the miraculous work of an extraordinary genius working alone.", concludes Blumenfeld (343). Marlovians tend to take the easy way out. 


\section{Meeting "Shakespeare"-As-Himself}

\subsection{Who Is "Shakespeare"?}

The inherent problem of most Shakespeare biographies and alternative Shakespeare biographies is that they never ask who "Shakespeare" was. Unconsciously or not they instead ask who "Shakespeare" is. Asking who "Shakespeare" was means to try and trace the social and communicative codes of his time, the perceptions and mentality people shared. Asking who "Shakespeare" was means to see the known facts about him in light of the past. The answer then is that "Shakespeare" was an actor-playwright-businessman of the London theatre around 1600. When he is seen in relation to others of his profession, one can by pointing out similarities and differences draw a picture of the man that actually might be a valuable contribution to understanding how theatres, performances and audiences worked at the time and what part plays held in that context, what meaning they had.

Edmond Malone was the first who in a way tore "Shakespeare" and his plays apart. As was mentioned, "[u]ntil the late eighteenth century, the text selected for editing was the one closest to the editor rather than that closest to the author: the text that had undergone the most rather than the least mediation." (De Grazia 52) Malone's obsession with authenticity changed a lot. Authenticity placed the Shakespearian texts in the past (70-71). Ideas of their author, however, moved farther and farther away from contemporary notions of authorship. This is why I propose that most (alternative) Shakespeare biographies ask who "Shakespeare" is. In their argumentation they take their own imagination of authorship, their own perspectives and their own worldview as guidelines. The obvious outcome is that "[e]very age creates its own Shakespeare." (Garber, 2004, 3)

While the temporal distance between the author and his plays is widening, discrepancies between the known facts about Shakespeare and the image of "Shakespeare" are becoming more and more conspicuous. Finally, the critical point is reached when there are others who seem to make by far a better Author. As was demonstrated in chapter 1 by means of Bacon, de Vere and Marlowe the propositions of the alternative candidates were very much children of their time. These candidates replaced Shakespeare of Stratford as god of idolatry and gained their own communities of faith, of followers who believed in them and set out to missionize not recognising how heavily biased their beliefs were.

It seems almost surprised when Rose ascertains "Shakespeare" to have been a participant in a cultural production that was essentially collaborative, but to see him of all people - not Jonson for that matter - installed as the "epitome of original genius". Because so little is known of him, is Rose's assumption, "Shakespeare" had to be invented (122). Then, of course, relative to his fellow playwrights it is not so little that is known about Shakespeare. What is known about him simply is not what people are after, what would satisfy their respective image of the Author (Holderness, 2012, 3). 
In the last chapter I will try to bring together the abstract notion of "Shakespeare"as-imagined, as caught between questions of religion and authorship with the actual images of him as they have survived the deconstruction of the Author. Even, or maybe especially, professional Shakespeare scholars cannot avoid the question of who "Shakespeare" was. They must find answers when they are asked who the true author is. Truth is closely connected to a name.

\section{2 "What's in a name?"}

Roland Emmerich's "Anonymous" is the most recent film on "Shakespeare's" life that reached a mass audience. Many may have watched the film as an Elizabethan thriller. Yet, it develops its influence beyond entertainment in a more subtle way. Clearly, "Anonymous" is fiction and has its justification as entertainment. Emmerich's doubts concerning "Shakespeare's" authorship, however, are real and he expresses them in interviews about the film. What consciously or not remains in people's heads is a question mark. Sometime or other this question mark might turn into the articulation of a question. In the Prologue of Contested Will Shapiro describes a situation when a nine-year-old asks him: "My brother told me that Shakespeare really didn't write Romeo and Juliet. Is that true?" (5) It seems to be a simple question that requires a simple answer - yes or no. The nine-year-old looks for confirmation by an expert he trusts has more authority than his brother. Such a question wants a name as an answer. But is it that simple?

Even if scholars agree on a collaborative interpretation of "Shakespeare's" authorship and even if "Shakespeare's" glorification happened pretty much independently of the plays and poems, his name is by now irrevocably linked to his texts. In Foucault's sense, it is the name of "Shakespeare" that denotes a body of works including a number of plays and poems while excluding others. "Shakespeare's" name holds together this body of works. The plays and poems are referred to as "Shakespeare's" by scholars who know them as a product of collaboration and even by defenders of alternative candidates who talk about the "Shakespearian texts" or the "plays and poems attributed to Shakespeare".

What's in a name? That which we call a rose

By any other name would smell as sweet.

$$
\text { Romeo and Juliet (II, ii, 1-2) }
$$

Maybe there is a lot more in "Shakespeare's" name. The works and the name seem to be mutually dependent. Today, "Shakespeare" would be nothing without the plays and poems. The plays and poems, however, are only what they are because they are read as the works of the Author, the romantic genius, the god of bardolatry. They will never be de Vere's plays and poems or that of any other candidate.

John Heminges and Henry Condell put the name of "Shakespeare" before a body of works collected in the First Folio in 1623. Brooks points out that within 
the decade the First Folio appeared the habit of attribution had changed so that there was an author attribution of about 70 per cent while company attribution had dropped to roughly 45 per cent. Brooks imagines that Heminges and Condell took their chance and found a new market for their old dramatist (138). Had they not done so, neither the name nor the plays could possibly have developed their power. As it is with "Shakespeare" and his plays and poems, the name and the texts seem to be two parts of one thing. In the end, "Shakespeare" seems to be a name and the rest is imagination. "No biography: that's 'Shakespeare", states Sean Gaston.

Shakespeare is like God: unparalleled creation, and no biography. Or, perhaps more accurately he is like Jesus Christ, whose scraps and traces of an unprovable and unproved life sustain the belief in a more than human life, in an exception without example (91).

The lack of knowledge about "Shakespeare's" personal life comprises the possibility for scholars to imagine "Shakespeare"-as-their ideal author. This is why some biographers conceive of him as being "Christ-like" because what "Christ-like" denotes is the consolidation of all the characteristics they consider worthwhile and valuable in one person - or rather the image of one person.

All this, however, only adds up to who "Shakespeare" is - "Shakespeare"-as-a name, "Shakespeare"-as-an image, "Shakespeare"-as-who people want him to be. " $[\mathrm{H}]$ e changes so as his texts respond to our questionings." (Bevington 238) It does not say anything about who "Shakespeare"-as-himself was. Yet, it suffices as a simple answer to a simple question. In the end, it indeed is that simple. The answer to the little boy's question could be that it is "Shakespeare" who wrote Romeo and Juliet. Or the answer could be that the extant evidence and the circumstances of life in the theatrical world of early modern England support no conclusion but that it was William Shakespeare of Stratford, the actor-playwright-businessman, who wrote Romeo and Juliet in a collaborative effort. The answer in both cases is a name and the names in both cases sound alike.

When there is no decisive difference, however, where is the point in going on discussing "Shakespeare's" authorship, where is the point even in discussing the debate itself?

\subsection{In the end there is no end}

Defenders of alternative candidates for "Shakespeare" often seem to feel treated condescendingly by professional Shakespeare scholars. For that reason do most contributors to Detobels Will - Wunsch und Wirklichkeit mention somewhat appreciatively that an expert in his field like Shapiro at least went so far as to admit to the Shakespeare Authorship Debate before they start hacking away at Contested 
Will.32 Shapiro deals with the debate by convincingly showing why it does exist by which he simultaneously shows why it should not. From what has been set out in this paper, however, it must be concluded that in the end there indeed is no Shakespeare Authorship Debate. What does exist is a "Shakespeare" War of Beliefs and this in turn is exactly the reason why there will be no end.

On the one hand the lack of knowledge about "Shakespeare's" personal life is what made possible the apotheosis of "Shakespeare". Shakespeare is "Shakespeare" because of what is not known about him. On the other hand, the lack of knowledge is what led to the building up of belief. To repeat what was stated in the beginning: belief is not knowledge. Leahy explains that it is belief which determines truth and not the other way round (119). "Belief (...) consists much more in the idea of believing in something because other people do than in any individual adherence to a dogma or truth." (120) Indeed, it seems as if facts did not play such an important role in the debate - they are interpreted conveniently, misunderstood, ignored or arranged in favour of the one or the other theory. It is the respective narration itself that is of importance.

"[B]elief resides in the telling - citing and reciting - rather than in any original object" (120). Belief means to again and again reiterate what is believed in. The process is decisive, not the actual object of belief. In other words, it is not God who holds together the religious community but the Church as an institution, the organization of religious life through the Holy Script, sermons and rituals. Similarly, it is not the respective candidate who holds together the respective believers. Each of the "Shakespeare" candidates is worshipped as "Shakespeare"-as-god of bardolatry. This worship is founded on firm belief and for to keep this belief alive it must be articulated over and over again. The consequence now is obvious: the Shakespeare Authorship Debate must live or none of the alternative candidates is going to survive. The debate must live on for each of the "Shakespeares" to live even and especially after the death of the author. For this reason will Shakespeare biographies, alternative Shakespeare biographies and polemics continue to be written, published and criticised. For this reason, there will be no end.

Belief and scholarship that is based on fact, knowledge, and logical interpretation do not seem to go together. It might be argued that if the Shakespeare Authorship Debate cannot be taken seriously, it should not be part of the scholarly discourse. This is the wrong conclusion, though. For one thing, if scholars do not want to exist as a caste all by themselves and above everything else, they must be able to provide answers to questions like that of Shapiro's nine-year-old and also be prepared to answer to films like "Anonymous" that leave their marks on the people having seen it. For another thing, some scholars have already recognised the value inherent to the Shakespeare Authorship Debate: LaPorte sees it as symptomatic for the shaping of ideas of literature by religious discourses and raves: "Many examples of this exist, but none are more salient than popular debates

32 Compare, for example: Hunter, 302; Whalen, 310. 
about the historical identity of Shakespeare that emerged 150 years ago in connection to related doubts about the historical identity of Jesus." (609) In that respect the debate is "an epiphenomenon, a secondary symptom, a consequence for the extraordinary elevation of the dramatist's status that occurred in the $18^{\text {th }}$ century." (Bate 106) and, thus, a rewarding object of authorship studies. It is a cultural phenomenon that carries a Darwinian and a Freudian heritage (Gaston 98). It is here that the scientific nature of academics is itself put in the focus when in the heap of publications there must be made a difference between what is "research" and what is "search" (99). "Research" then also means to reflect on today's influences on all research conducted.

Holderness thinks along similar lines when he emphasises in "Nine lives" that Shakespeare biographies are revealing more of the biographers than their subject of biography (12). He cites Samuel Schoenbaum: "Trying to work out Shakespeare's personality is like looking at a very dark glazed picture in the National Portrait Gallery: at first you see nothing, then you begin to recognise features, then you realize that they are your own." (Schoenbaum ix)

In this sense the Shakespeare Authorship Debate should be taken seriously as an object of study. It is a multi-faceted interrelated complex. There are literary, cultural, religious, psychological, technical and historical aspects to it. Scholars from many different fields have the feeling they had something to add to it. William D. Rubinstein contributes a "Historian's perspective" seeing himself in a superior position because, for him, the Shakespeare Question is a historical one "to which normal concepts of historical evidence surely apply." (41) ${ }^{33}$ Somewhat more modest Schruijer adds a psychologist's analysis and so does Sally Hazelton arguing for Edward de Vere.

At the moment, most of these interdisciplinary voices seem to come to nothing. As long as the debate is intruded only to append just another point of view to one theory or other, the value of these new perspectives is very limited. Only on a meta-level can they really contribute to a fuller understanding not only of the debate itself but also of the processes and developments which the Shakespeare Authorship Debate is symptomatic of. The prerequisite for this is a reflected and differentiated agreement of how writing and authorship should be understood. Holderness proposes:

we can think about writing, not via the romantic image of the writer as an isolated individual genius, but rather, in a more modern sense, as a collective cultural activity taking place in the busy professional

33 In a most recent work from 2012, Rubinstein presents a detailed historical anlysis of several „Shakespeare“ candidates. Although he rather made a case against Shakespeare in his contribution to Shakespeare and His Authors, he concludes in Who Wrote Shakespeare's Plays? that a relatively strong case for Shakespeare can be made. The historical evidence most prominently suggests Sir Henry Neville-as-"Shakespeare" while it is considered surprisingly weak for de Vere (152). 
environment in which a collaborative work like Sir Thomas More was messily and roughly concocted (27, highlighting in original).

If anything, this is who "Shakespeare" was.

\section{Conclusions}

In order to answer the central question of this paper - who was "Shakespeare" - I first summarized the cases for three exemplary Shakespeare candidates in chapter 1. Based on Shapiro's Contested Will my aim was to constitute the respective theories as historically evolved. The analysis of structural and argumentative similarities between the different groups establishes methodological weaknesses most works of defenders of alternative candidates share and also is a first step towards an understanding of the debate as a question of belief rather than knowledge.

That there are still publications in favour of Bacon - like the one by Andrew Peck - although the number of his defenders has been shrinking for about 150 years is indicative of how the objects of belief are kept alive. As long as there are publications, there will be a Shakespeare Authorship Debate and so long doubt and belief will live. All in all, the methods used by defenders of alternative candidates have no reliability and no validity. They are too much creations of their own time.

There are two basic fields from which I looked at the Shakespeare Authorship Debate - one being religion and the other one authorship theories. Both have a major bearing on imaginations and inventions concerning "Shakespeare". Analogies between bardolatry - the "Shakespeare"-cult - and religion can be found on an external as well as an internal level. On the external layer, I referred to the theological origins of the debate and the structural and literary discourses as suggested, for example, by Shapiro and LaPorte. On the internal layer, I argued that new ways of editing Shakespeare abstracted him from his works. Back in the theatre this abstractness was used to create a god-like image of the author to worship. In the Romantic Age this turned into the veneration of "Shakesepeare" - as poetic genius, which is the still dominant image of the Author, especially outside the field of scholarly literary criticism. As the most recent candidate presented in chapter 1 Marlowe is the best example for how Romantic images of authorship prevailed.

Closely related to images of "Shakespeare" are ideas of authorship in a more general sense. I asked why "Shakespeare" - the embodiment of the Author - did not die after the deconstruction of the Shakespeare myth by poststructuralists like Roland Barthes and Michel Foucault. With Burke I argued that the idea of noauthor feels unnatural because the idea of author already existed. Therefore, it can only be a decision of criticism to read a text with or without the author. My suggestion was that the divide between professional and non-professional Shakespeare scholars becomes most evident here. The reason is that non-professionals rather 
ask who "Shakespeare" is instead of who he was. The image created in this case is very often dominated by Romantic ideals of authorship. Yet, it is in trying to answer the question who "Shakespeare" was that has the potential to take scholars closer to the truth. Even if that means to accept an interpretation of "Shakespeare" opposed to personal imaginations and ideals. A brief outline was then given of what the professional world of the Elizabethan and Jacobean theatre was like for Shakespeare-as-one among several playwrights. This served to illustrate today's approach towards authorship as collaborative and as a culturally embedded process.

The question of who "Shakespeare" was can only be answered by taking the documentary evidence and interpreting it carefully in terms of what is known about the situation of playwrights in the early modern world of English theatre. The way to go is from documentary evidence to "author" instead of the other way round from the 'as Author identified figure' to an explanation for the documentary evidence. What the documentary evidence renders in the case of William Shakespeare of Stratford-upon-Avon is an actor-playwright-businessman and as such he is approachable. As was stated in the Introduction, the question who "Shakespeare" was does not go without the question of why it does matter. The answer is the inherent consequence of the debate being about faith rather than fact. When belief means to articulate what is believed in, the Shakespeare Authorship Debate is a necessity because it is symptomatic of the efforts to keep the respective objects of belief upright, to keep the different Shakespeare candidates alive. Belief is a selfreinforcing process.

In the end, it must be kept in mind that today's theories also are creations of their time. Everyone and everything is part of history. Nobody stands above it. With this in mind, however, scholars are given a methodological choice in approaching Shakespeare making him open to interpretation. As soon as this is understood the Shakespeare Authorship Debate may serve as a fascinating object of study for a history of ideas. Outside the professional field of literary criticism, readers can take their liberty to find "Shakespeare", to quite freely imagine the Author and his text. It might be interesting and revealing to see what is made of him today. Next time maybe - when reading "Shakespeare" - one should just come as oneself. 


\section{Bibliography}

\section{Books and Articles}

Baker, Simon and Hinds, Hilary (eds.). The Routledge Anthology of Renaissance Drama. London: Routledge, 2003.

Barthes, Roland. "The Death of the Author." The Routledge Critical and Cultural Theory Reader. Ed Neil Badmington and Julia Thomas. London and New York: Routledge, 2008. 121-125.

Bate, Jonathan. "Scenes from the Birth of a Myth and the Death of a Dramatist." Shakespeare's Face. Ed Stephanie Nolen. London: Piatkus, 2003. 103-125.

Bennett, Andrew. "On not Knowing Shakespeare (and on Shakespeare not Knowing): Romanticism, the Authorship Question and English Literature." Shakespeare and His Authors: Critical Perspectives on the Authorship Question. Ed William Leahy. London/New York: Continuum International Publishing Group, 2010. 11-22.

Bevington, David M. Shakespeare - the Seven Ages of Human Experience. Malden (Mass.): Blackwell Publishing, 2005.

Blumenfeld, Samuel L. The Marlowe-Shakespeare Connection: a New Study of the Authorship Question. Jefferson (NC.) [a.o.]: McFarland, 2008.

Brooks, Douglas A. From Playhouse to Printing House: Drama and Authorship in Early Modern England. Cambridge [a.o.]: Cambridge University Press, 2000.

Burke, Seán. Authorship. From Plato to the Post-modern: a Reader. Edinburgh: Edinburgh University Press, 2006.

The Death and Return of the Author: Criticism and Subjectivity in Barthes, Foucault and Derrida. Edinburgh: Edinburgh University Press, 2008.

Chenney, Patrick. Shakespeare's Literary Authorship. Cambridge: Cambridge University Press, 2008.

Craig, Hugh and Kinney, Arthur F. Shakespeare, Computers, and the Mystery of Authorship. Cambridge [a.o.]: Cambridge University Press, 2009.

Cunningham, Vanessa. Shakespeare and Garrick. Cambridge [a.o.]: Cambridge University Press, 2008.

Dávidházi, Péter. The Romantic Cult of Shakespeare: literary reception in anthropological perspective. Basingstoke (a.o.): Macmillan, 1998. 
De Grazia, Margreta. Shakespeare Verbatim: the Reproduction of Authenticity and the 1790 Apparatus. Oxford [a.o.]: Clarendon Press, 1991.

Detobel, Robert. Will - Wunsch und Wirklichkeit. James Shapiros Contested Will (= Neues Shakespeare Journal, Sonderbd. 2). Buchholz: Laugwitz, 2010.

Dobson, Michael. The Making of the National Poet: Shakespeare, Adaptation, and Authorship, 1660-1789. Oxford: Clarendon Press, 1992.

Farina, William. De Vere as Shakespeare: an Oxfordian Reading of the Canon. Jefferson (NC.) [a.o.]: McFarland \& Co., 2006.

Finkelstein, David and McCleery, Alistair (eds.). The Book History Reader. London: Routledge, 2006.

Foucault, Michel. "What Is an Author?" Textual Strategies. Perspectives in PostStructuralist Criticism. Ed Josué V. Harari. London: Methuen \& Co. Ltd, 1980. 141-160.

Garber, Marjorie B. "Looking the Part." Shakespeare's Face. Ed Stephanie Nolen. London: Piatkus, 2003. 156-177.

Shakespeare After All. New York: Pantheon Books, 2004.

Gaston, Sean. "No Biography: Shakespeare, Author." Shakespeare and His Authors: Critical Perspectives on the Authorship Question. Ed William Leahy. London/New York: Continuum International Publishing Group, 2010. 91-103.

Greenblatt, Stephen. Will in the World: how Shakespeare Became Shakespeare. New York [a.o.]: 2004.

Hazelton, Sally. "Freud and Oxford." Great Oxford: Essays on the Life and Work of Edward de Vere, 17th Earl of Oxford 1550-1604. Ed Richard Malim. Tunbridge Wells: Parapress, 2004. 307-311.

"Phantasies of Shakespeare." Great Oxford: Essays on the Life and Work of Edward de Vere, 17th Earl of Oxford 1550-1604. Ed Richard Malim. Tunbridge Wells: Parapress, 2004. 312-316.

Hoffman, Calvin. The Murder of the Man who Was Shakespeare. New York: Grosset \& Dunlap, 1960.

Holderness, Graham. Nine Lives of William Shakespeare. London [a.o.]: Continuum, 2011.

"Shakespearean Selves." Shakespeare and His Authors: Critical Perspectives on the Authorship Question. Ed William Leahy. London/New York: Continuum International Publishing Group, 2010. 104-113. 
Hunter, Tom. "Die Suche nach verborgenen Motiven." Will - Wunsch und Wirklichkeit. James Shapiros Contested Will (= Neues Shakespeare Journal, Sonderbd. 2). Buchholz: Laugwitz, 2010. 302-309.

Ioppolo, Grace. Dramatists and Their Manuscripts in the Age of Shakespeare, Jonson, Middleton and Heywood: Authorship, Authority and the Playhouse. London [a.o.]: Routledge, 2006.

Jolly, Eddi. "An Introduction to the Oxfordian Case." Great Oxford: Essays on the Life and Work of Edward de Vere, 17th Earl of Oxford 1550-1604. Ed Richard Malim. Tunbridge Wells: Parapress, 2004. 7-9.

Kahan, Jeffrey. Reforging Shakespeare: the Story of a Theatrical Scandal. Bethlehem: Lehigh University Press, 1998.

Kernan, Alvin B. Shakespeare, the King's Playwright: Theater in the Stuart Court, 16031613. New Haven [a.o.]: Yale University Press, 1995.

Knapp, Jeffrey. Shakespeare Only. Chicago (Ill.) [a.o.]: The University of Chicago Press, 2009.

LaPorte, Charles. "The Bard, the Bible, and the Victorian Shakespeare Question." English Literary History 74 (3) (2007): 609-628.

Leahy, William. "Shakinomics; or, the Shakespeare Authorship Question and the Undermining of Traditional Authority." Shakespeare and His Authors: Critical Perspectives on the Authorship Question. Ed William Leahy. London/New York: Continuum International Publishing Group, 2010. 114-124.

Leary, Penn. The Second Cryptographic Shakespeare: a Monograph wherein the Poems and Plays Attributed to William Shakespeare Are Proven to Contain the Enciphered Name of the Concealed Author, Francis Bacon. Omaha (Neb.): Westcherster House [a.o.], 1990.

Malim, Richard (Ed). Great Oxford: Essays on the Life and Work of Edward de Vere, 17th Earl of Oxford 1550-1604. Tunbridge Wells: Parapress, 2004.

McCrea, Scott. The Case for Shakespeare: the End of the Authorship Question. Westport (Conn.) [a.o.]: Praeger, 2005.

Michell, John. Who Wrote Shakespeare? London: Thamse and Hudson, 1996.

Moore, Jane and STRACHAN, John. Key Concepts of Romantic Literature. Basingstoke/Hampshire [a.o.]: Palgrave Macmillan, 2010.

Peck, Andrew Stevens. Francis Bacon Tudor Equals William Shakespeare. Hauppauge (NY.): Kroshka Books, 2001.

Rose, Mark. Authors and Owners. The Invention of Copyright. Cambridge (Mass.)/London: Harvard University Press, 1993. 
Rubinstein, William D. "The Authorship Question: An Historian's Perspective." Shakespeare and His Authors: Critical Perspectives on the Authorship Question. Ed William Leahy. London/New York: Continuum International Publishing Group, 2010. 41-57. Who Wrote Shakespeare's Plays? Stroud: Amberley, 2012.

Schoenbaum, Samuel. Shakespeare's Lives. Oxford: Clarendon Press, 1970.

Schruijer, Sandra G. L. "Fighting over Shakespeare's Authorship: Identity, Power, and Academic Debate." Shakespeare and His Authors: Critical Perspectives on the Authorship Question. Ed William Leahy. London/New York: Continuum International Publishing Group, 2010. 125-141.

Shaw, Bernard. Prefaces. London: Constable, 1934.

Shapiro, James S. Contested Will: who wrote Shakespeare? New York [a.o.]: Simon \& Schuster, 2010.

Spurgeon, Caroline F. E. Shakespeare's Imagery and What It Tells Us. Cambridge: Cambridge University Press, 1966.

Stern, Tiffany. Making Shakespeare: from Stage to Page. London [a.o.]: Routledge, 2004.

Stone, George Winchester. Garrick's treatment of Shakespeare's plays and his influence upon the changed attitude of Shakespearean criticism during the eighteenth century, PH.D. thesis, 2 vols. Cambridge (Mass.): Harvard University Press, 1940.

Taylor, Gary. Reinventing Shakespeare: A Cultural History, from the Restoration to the Present. New York: Weidenfeld and Nicolson, 1989.

Vickers, Brian. Returning to Shakespeare. London [a.o.]: Routledge, 1989. Shakespeare - Co-author: A Historical Study of Five Collaborative Plays. Oxford [a.o.]: Oxford University Press, 2002.

Whalen, Richard. "Shapiros Methode." Will - Wunsch und Wirklichkeit. James Shapiros Contested Will (= Neues Shakespeare Journal, Sonderbd. 2). Buchholz: Laugwitz, 2010. 310-324.

Wilbert, D. Maure. Silent Shakespeare and Marlowe Revivified. Sheboygen (Wis.): Daurus Press, 1998.

Woo, Celestine. Romantic Actors and Bardolatry: Performing Shakespeare from Garrick to Kean. New York [a.o.]: Lang, 2008. 


\section{Websites}

Anon. "Official Shakespeare's Birthday Celebrations Website." Shakespeare Birthplace Trust, 21 Apr 2013. Web. 25 May 2013.

<http://www.shakespearesbirthday.org.uk/>. Date of Access 6 July 2012.

Anon. "ANONYMUS. Roland Emmerich Interview Full-HD Kino 2011

Deutsch." 2011. Video. http://www.youtube.comWeb. 25 May 2013. <http://www.youtube.com/watch?v=AUmwQsfX1wY>. Date of Access 6 July 2012. 


\title{
Vietnam Goes Intermedia - Reconsidering Media Boundaries in Michael Herr's Dispatches
}

\author{
Madita Oeming
}

\section{Introduction: The Vietnam War In- and Outside Plato's Cave}

What does Plato have to do with the Vietnam War? To turn to a piece of philosophical writing from antiquity to approach a twentieth-century political event seems absurd. However, re-reading Plato's The Republic with this aspect in mind opens up an illuminating perspective. His famous cave allegory in Book VII suddenly reads like a trenchant commentary on the splitting of the American people during the Vietnam era: soldiers experiencing the war first hand versus civilians following it via the media. To be more precise, those going to Vietnam left the cave to face reality; while those staying in the US lingered in the cave's darkness with nothing but representations of reality. It almost goes without saying that this dichotomy implies the primacy of the former over the latter, for whom "the truth would be literally nothing but the shadows of images" (Plato 42). Aligning the experience of war with the "beatific vision" portrayed in Plato (45) - which is to equate the soldier with the philosopher - would certainly be over the top. Yet, the inherent hierarchy of contrasting the "uninformed of the truth" (ibid. 47) with those who have been to "the world of knowledge" (ibid. 44) can be discovered in much Vietnam writing - "there exists within the cultural production of Vietnam a privileging ... of personal experience, of 'Having Been There, Man'” (Bonn 208). 
Though being in fact applicable to virtually any other war, this binarism of firsthand war experience versus mediated knowledge thereof is particularly characteristic of the Vietnam War. Dubbed "living-room war" (Arlen 6), it was typified by an unleveled omnipresence of mass media, taking events from 'in-country' to the 'home front.' American living rooms were flooded with images of war; just as if a thousand objects were passing by the fire behind the prisoners in the cave. Most aptly, the term used in Plato to describe the wall on which these shadows are cast translates as "screen" (41), which in the modern reader inevitably evokes the idea of a TV screen. Albeit written millennia before this invention, it reads like an ancient prophecy of a (post)modern phenomenon: The 1960s see an outpouring of visual representations of war, "introduc[ing] the home front to a new tele-intimacy with death and destruction" (Sontag 21). According to McLuhan, this type of mass mediated war means "the end of the dichotomy between civilian and military" that is between in- and outside Plato's cave - since "the main actions of the war are now being fought in the American home itself" (Global 134).

Precisely this standpoint - in its contradiction to the above indicated insistence "that the [civilian] reader is powerless to understand Vietnam" (Melling 6) - raises the questions that loom large in the background of this thesis: How do mass media and reality interact when it comes to Vietnam? Do modern media representations substitute firsthand experience? Or will the 'real war,' to echo Whitman, never get on screen? Finally, how do preconceived media images change the perception of those who actually come to face war? With these larger issues in mind, the present paper examines the significance of mass media in one of the key texts of American Vietnam literature: Michael Herr's Dispatches (1977). As the subtitle suggests, the essence of this study lies in reconsidering media boundaries, both between media and literature and between media and reality. In so doing, the concept of intermediality will serve as the theoretical framework through which the primary text is to be read and analyzed. Against this backdrop, the overall objective is to demonstrate how the intermedial dimension of Dispatches functions as a deconstructive means within the text. Not only transgressing existing media boundaries but also blurring the underlying reality-representation-binarism, it emphasizes the work's ever recurring leitmotif of in-between and calls into question any rigid categories.

To get to these results, a brief introduction to the field of intermediality - delineating its history (2.1), its heterogeneity (2.2), and its relevance for literary studies (2.3) - will be provided as a point of departure. Building up on that, the overall intermedial potential of Dispatches will be outlined (3), before a close-reading of selected passages brings into focus one particular type of intermediality, consisting of the thematization (4.1) and the imitation (4.2) of various mass media. Subsequently, a conclusion will serve as a review section which places the previous findings within a broader context and links them back to the opening thought: Does intermediality in Dispatches eventually work towards unifying or distancing the soldier on the front and the civilian at home? Or, allegorically speaking, does it subvert or substantiate the dichotomy of in- versus outside Plato's cave? (5). 


\section{Theory in the Making - The Concept(s) of Intermediality}

Despite evolving as "a buzzword in academic discourse in the 1990s" (Stein 181), intermediality - as a term and discipline - still has to be considered as work in (rapid) progress. In 1992, Ulrich Weisstein notes that "we are still far from possessing a scholarly instrumentarium suited for handling interdisciplinary problems with methodological rigor, much less with a sure grasp of their theoretical implications" (1, original emphasis); fifteen years later, Maddalena Punzi finds that intermediality, though "gaining ground in the crowded panorama of contemporary critical jargon," is still a term "whose semantic field has not been thoroughly defined" (10); and it is only very recently that Jürgen E. Müller observes that "in spite of all attempts to draft a self-contained body of theory, intermediality research at present does not possess a coherent system which would allow a grasp of all intermedia phenomena" ("Digital" 16). In short: If the diverse voices in the field of intermediality can agree on one thing, it is the fact that the concept still lacks demarcation. Due to this reason, but also to the limited scope of this paper, the following chapter does not endeavor to present an all-encompassing panorama of intermediality ${ }^{1}$ but rather to offer a glimpse into this complex and still maturing concept.

\subsection{Horace's Long Shadow: A Concise History of Intermediality}

If intermediality is largely understood to be a relatively young discipline, then why can one hardly open a book on this field without coming across texts that date back to the nineteenth, eighteenth, seventeenth century and further? While intermediality as such is a phenomenon that has only rather recently begun to be discussed in academic discourse, the issues that lie at its heart seem to have concerned mankind since anti-quity: From Horace's 'ut pictura poesis,' via Leonardo's paragone to Wagner's Gesamtkunstwerk and Lessing's Laokoon, questions of various art forms, their respective strengths and weaknesses, and their interplay with one another have been a matter of discussion (cf. Heusser 11f; Wolf, Musicalization 2ff). In this long-standing tradition of inter-artistic comparison, the notion of competitiveness, rather than of collaboration, between different media has always played a central role. Inextricably linked to this issue was the idea of high versus low art; the question of "Kunstwürdigkeit" (Moninger 8).

Only with the ushering of post-modernism did this line begin to blur. Scholars and writers increasingly acknowledged that "what had been seen as a threat [could]

\footnotetext{
Comprehensive works that map out the broad territory of intermediality include Intermedialität. Theorie und Praxis eines interdis₹iplinären Forschungsgebiets (1998) by Jörg Helbig, Forschungsüberblick "Intermedialität" (2000) by Mathias Mertensand, and most recently, Jürgen E. Müller's Media Encounters and Media Theories (2008) as well as Joachim Paech's and Jens Schröter's Intermedialität Analog/Digital (2008). The two that have been met with the most universal approval in literary studies, and which will serve as central points of reference throughout this paper, are the oftquoted texts by Werner Wolf (most notably The Musicalization of Fiction (1999)) and by Irina O. Rajewsky (especially Intermedialität (2002)).
} 
also be understood as an interesting source of new artistic possibilities aiming at enriching all cultural forms rather than leveling them" (Allué 145). In the 1960s, American Fluxus artist Dick Higgins claims that "[m]uch of the best work being produced today seems to fall between media" (49). "[W]e are approaching the dawn of a classless society," he explains, "to which separation into rigid categories is absolutely irrelevant" (ibid.). Contradicting "Medienpuristen" (Moninger 9) and conventionally drawn media boundaries, Higgins coins ${ }^{2}$ the term intermedia in his same-named 1965 essay (cf. Preuss 17ff). While during the 70s, academic attention is drawn to another 'big word' - intertextuality - the idea of intermedia is only brought (back) to discussion in 1983 by Aage A. Hansen-Löve. His article ${ }^{3}$ takes it beyond the confines of art criticism and is usually considered the birth hour (cf. Winkelmann 18; Eicher 11) of the "ubiquitous catchword which came onto the scene in the 1990s" (Rajewsky, "Literary" 43): intermediality.

The twenty-first century, then, as Werner Wolf finds, shows "a marked tendency towards intermediality ... which is so apparent that one is inclined to add yet another 'turn"" (Musicalization 2). In the same vein, Maddalena Punzi speaks of "the transition from the "Gutenberg Age' to the "Age of Intermediality" which "is marked by the move from a monocentric to a polycentric type of logic; ... the logic of the network" (11). Indeed, it hardly comes as a surprise that the current explosion of New Media fuels and complicates the debate on intermediality to an unforeseen degree; "every new media technology rewrites the history of its predecessor, but the computer is on the verge of rewriting the entire history of media technology - and hence of media theory" (Winthrop-Young 189). In a time when books can be downloaded from the internet and read on an e-paper display, media boundaries have automatically become obscured: "The computer monitor is the place where the arts become indistinguishable" (Paech, "Artwork" n. pag.). Yet, or rather because of this fact, the questions that have already occupied early thinkers remain pressing to this day: What exactly constitutes the difference between media, can these boundaries be crossed and, if so, how, why, and with what effect? These are the conundrums that drive the present paper and that unite a plurality of different approaches now being practiced under the broad heading of intermediality.

\subsection{Inter-media(-)lity, a termine ombrellone}

In trying to determine the meaning of a complex term, it is often helpful to take a look at its distinct components. In the case of intermediality, however, this means to open a can of worms. While the Latin prefix inter-is quite readily translated into between, things get much more difficult with the second part, -media-. In general, the understanding of the word medium ranges from a very narrow notion (medium as a

2 In fact, the term goes back to Coleridge and the year 1812 (cf. Schröter 129, Oosterling 35) as Higgins later acknowledged (cf. "Origin of Happening." American Speech 51.3 (1976): 268-271).

3 "Intermedialität und Intertextualität. Probleme der Korrelation von Wort- und Bildkunst" (Dialog der Texte: Hamburger Kolloqium zur Intertextualität. Sonderband 11, Wien 1983: 291-361). 
physical transmitter of data or information, such as a CD), to a very broad notion (medium as "any extension of ourselves" (McLuhan, Understanding 7), including books as much as wheels or clothes). The OED requires almost 8000 words $^{4}$ to explain the etymology, development and countless different usages of medium, demonstrating how eclectic this term alone already is. ${ }^{5}$ In intermediality, the suffix -lity further complicates matters. Mediality brings in the aspect of materiality which has increasingly been included in recent scholarly debates on media. Though voices diverge on this issue, the consensus is that "even when they seek to make themselves invisible, media are not hollow conduits for the transmission of messages but material supports ... whose materiality, precisely, 'matters' for the type of meanings that can be encoded" (Ryan 2). Broadly put, intermediality - as a whole is a term supposed to describe something in between media; "ein Hyperonym für die Gesamtheit all jener Phänomene ... [die] in irgendeiner Weise zwischen Medien anzusiedeln sind" (Rajewsky, "Light" 31).

Within this very general frame, a plethora of different definitions has been put forward, which - as those of medium - oscillate between a wide and a rather narrow conception. Given the complexity of the term and the heterogeneity of approaches it brings forth, Irina Rajewsky rightly calls intermediality a "termine ombrellone," a term which comprises even more aspects than an umbrella term (Intermedialität 6$)^{6}$. Some approaches focus on the aspect of translation from one medium to another, regarding intermediality as the "movement of the message through a system of interrelated but different media" (Oosterling qtd. in Punzi 10); making a novel into a film, for instance. Most aptly, Roger Fidler terms this process "mediamorphosis" (xv). Other studies investigate the interplay of different media when being combined in one work, such as image and text in a comic book. Here, intermediality is understood as "Vermischung zwischen unterschiedlichen Medien [bis hin zu deren] Verschmelzung zu einer neuen Form” (Spielmann 79). ${ }^{7}$ A similarly text-centered approach is to view intermediality as "a kind of intertextuality which entails the crossing of artistic border lines" (Weisstein 3). In this case, references in a work of one medium to a work of another medium are of interest, as, for example, a song referring to a film or vice versa.

All of these perspectives belong, to use Rajewsky's distinction, to the second of the "two poles structuring the intermediality debate": They approach intermediality "as a critical category for the concrete analysis of specific individual media products" ("Literary" 47). By contrast, intermediality can also be seen as a more

\section{As per August 10 2011.}

5 Joachim Paech offers a brief but well-informed answer to "The Question of the Medium," as the chapter heading runs, in his essay "Artwork - Text - Medium. Steps en route to Intermediality."

6 In a footnote, Rajewsky explains that in Italian, the suffix -one indicates a larger unit; in this case, a (larger) sun shade, ombrellone, instead of a (smaller) umbrella, ombrello (cf. ibid.)

7 Sometimes this phenomenon is also referred to as multimodality or bybridization; to get into these (and other) alternative terms and their intersections with - or differences from - intermediality would, however, lead too far here. For basic thoughts on that matter, see Müller, "Konzept" 31f; Moninger 9; or Rajewsky, "Light" 29f. 
general and more complex cultural phenomenon, based on an understanding which "concentrates on intermediality as a fundamental condition or category" (ibid.). This kind of "Ur-Intermedialität" (146), as Jens Schröter calls it, is not an idiosyncrasy of individual works but is a transmedial "characteristic of all practices of cultural production and reception" (Sielke 157, emphasis added). As such, it also refers to "the constant exchange between old and new media" (Punzi 12). Seen from this perspective, intermediality is a process, rather than a state, which is closely linked to technological progress and cultural change - "Intermedialität ist ein Seismograph kultureller Umbrüche" (Hörner, Neumeyer \& Stiegler 12).

At first sight, the two outlined poles appear to be contradictory; at second sight, however, they are in fact two sides of the same coin that merely operate on different levels. Whether we consider the artifact itself as intermedial or our culture as a whole, does not matter after all, since the former can be seen as the manifestation of the latter, or the latter as the outcome of the former; a classic chicken-andegg dilemma. Thus, the crux of the matter lies in the perspective one chooses and the epistemological goals one pursues in dealing with intermediality. Without a doubt, intermediality has to be understood as a dynamic, not a static, concept that keeps changing with the advancement of technology but also with the respective discipline in which it is being used.

\subsection{Intermediality + Literary Studies $=$ Mutual Illumination?}

"Intermedialität ist in!" declares Joachim Paech in 1998 ("Intermedialität" 14). However, intermediality was at first received with reserve rather than enthusiasm by the academic audience. ${ }^{8}$ One major reason for this might be its interdisciplinary nature. As W.J.T. Mitchell explains in 1995, "[t]he field of literary studies encounters visual culture [in general] with a similar kind of ambivalence: It is not quite sure why textual scholars should suddenly be looking at visual arts and media" ("Interdisciplinarity" 542). Interestingly, it is the (age-old) idea of media rivalry that we find between the lines of early reactions to intermediality - "does the technological revolution spell the death of the book?" (Punzi 12) and, analogously, does intermediality supplant literary studies? Concerns like this may have caused hesitation towards intermediality studies but are, as Werner Wolf argues, entirely ungrounded: Quite the opposite, intermediality is a way of "(re)-affirm[ing] the flexibility, openness and adaptability of a verbal medium which some fear to be a loser in the present competition with the non-print media" (Musicalization 2).

8 It is to note here that there is a marked difference between Continental European and British/US-American discourse. Since the interest in media and materiality is, as Hans Ulrich Gumbrecht phrases it, "a specifically German phenomenon" (173), it is here that scholars have rather quickly absorbed and refined the notion of intermediality for literary studies, with Rajewsky and Wolf leading the way. Meanwhile, the English-speaking world (with the exception of Canada) would largely disregard the new-born term until quite recently and has still not 'caught up' with the current state of research in Germany or Europe. 
Even while disciplinary boundaries have become increasingly porous, Mitchell's observation remains largely valid; "transdisciplinarity, as we know, is [still] no easy matter" (Sielke 157). Since "[i]ntermediality research by definition integrates [at least] two scholarly fields, whereas scholars in the majority of cases ... are experts in one field only" (Wolf, Musicalization 6), the somewhat pragmatic problem of incompetence with the non-literary remains. In the long run, this can only change, if the skepticism for the unknown is turned into curiosity. What literary scholars need to accept, once and for all, is that intermediality is not a foreign discipline but that it is actually part of literary studies per se - "it ha[s] simply become unacceptable to see 'media' as isolated monads" (Müller, "Digital" 18). As a specific ingredient of culture, intermediality is precisely not non-literary. By contrast, it is maybe the only way to come to a full understanding of contemporary literature in its multi-layered resonance of the growing media saturation of our post-modern age. Obviously, "where there has been a change from print culture to electronic culture, the role and form of literature is due to evolve" (Allue 147); and accordingly, that of literary studies. Today more than ever, "intermediality studies ... neither add 'alien' matter to the study of literature nor deflect attention away from literature, but shed a most illuminating light on it" (Wolf, "Relevance" 20).

\section{The Intermedial Potential of Dispatches}

"It was the same familiar violence, only moved over to another medium" (Herr, Dispatches 209) - these are the simple but expressive words which motivated the present paper. Not only including the all-important signal word - medium - but also bringing it into relation with first-hand experience of Vietnam, this sentence inevitably turns the spotlight on the intricate interplay of war, media, and reality. Once attention is drawn to this matter, the preceding 200 (and remaining 50) pages of Dispatches appear in a new light. The more one (re-)reads, the more one realizes that this one sentence in fact contains the whole book en miniature; and the less one understands how it - the passage and the topic - could receive such disproportionately little attention within the literature on Dispatches. Reading it as a book about Vietnam, studies largely revolve around war-related topics such as trauma, gender, violence, mythmaking, etc. ${ }^{9}$ Reading it as a book about writing about Vietnam, others are concerned with more general topics, such as postmodernism, selfreflexivity, or autobiography. ${ }^{10}$ What both approaches seem to share, however, is their lack of thorough critical attentiveness to the significance of media.

9 As a small selection, see for example E. Carton's "Vietnam and the Limits of Masculinity" (American Literary History 3:2. 294-318), J. Hellmann's American Myth and the Legacy of Vietnam, esp. chapter V (New York: Columbia UP, 1986), T. Hawkins' "Violent Death as Essential Truth in Dispatches" (War, Literature \& the Arts 21 (2009): 129-143) and D. Ringnalda's Fighting and Writing the Vietnam War (Jackson: UP Mississippi, 1994).

10 Among others, "The Unspeakable Language of Life and Death in Michael Herr's Dispatches" (M. Van Deusen, Critique 24.2. 82-87), "Subverting Autobiobraphy: War, Narrative, and Ethics in Mi- 
If media become a topic, it is commonly confined to a strictly literary or maybe socio-historical scope, focused on the level of content not of form; and, on top of that, mostly limited to print media. Although references to other media, such as rock ' $n$ ' roll music or movies, keep reappearing, they are usually only addressed on the side, within the framework of one of the above mentioned overarching issues, rather than being the actual matter of interest. Self-consciously media-focused studies on Dispatches are scarce; intermediality-focused approaches are, to my knowledge, non-existent thus far. While there are certainly examples within the literature that hint at intermedial facets of Herr's work, they do not label and not even understand them as such. To bring all these findings together, reassess them in the light of intermediality and use them as a basis for a more detailed analysis of the book's intermedial dimension is one of the major goals of the present paper. In so doing, it is an attempt maybe not to fill but at least to point towards this gap in the existing body of research.

Undeniably - compared to other literary examples, such as William Blake's visual poems or Jonathan Safran Foer's experimental novels - Dispatches' potential for an intermedial reading is not as evident at first sight and is therefore easily overlooked; yet, it exists. In fact, the intermedial nature of Herr's work already begins with its genesis. While what we are now holding in our hands as Dispatches is clearly a book, parts of it have originally been published as articles in the American magazines Rolling Stone (1977: "LZ Loon," which coincides with the book's ending), Esquire (1969: "Hell Sucks") and New American Review (1971: "Illumination Rounds"). Though many secondary sources mention this origin, none of them makes an effort to go into more detail: How does the format interact with the narrative? Does the presence of a photograph supplement to or distract from the text? In how far does our perception of a four-page article in a magazine - positioned, for example, between a record commercial and the home story of a rock band, as in the November 1977 issue of Rolling Stone - generally differ from that of a coherent 260-page hardcover book? These are distinctly intermedial questions, which could put a new complexion to an understanding of Dispatches, but have remained without reply.

Depending on the definition of medium one uses, this peculiar publication history could already be seen as a form of 'mediamorphosis,' from one kind of print medium to another. Similarly, the book later served as an important source for the screenplay of Francis Ford Coppola's 1979 movie Apocalyse Now; another intermedial aspect of Dispatches which has repeatedly been brought up but never thoroughly thought through. Having already proceeded through the media circuit from journalism to literature to film - for more than thirty years, Herr's work has only recently been published as an audio book. ${ }^{11}$ Listening to the story again turns

chael Herr's Dispatches" (M. Lau, Life Writing 6.2. (2009): 193-210), and “It Don't Mean Nothin': Vietnam War Fiction and Postmodernism" (L. Carpenter, College Literature 30.2 (2003): 30-50) can be named as interesting examples.

11 Dispatches (1977). Unabridged. Read by Ray Porter. 7 CDs, 8.5hrs. Blackstone Audio, 2009. 
Dispatches into a completely new experience: The discs' data capacity structures the text; the reading (listening) speed is prescribed by the narrator; the pitch and volume of the voice, the tone, the stress, the American accent, and the mimicry of other voices now become new stylistic means - alterations which can decisively influence the effect of the original (written) story.

Though all of these facets are not exactly part of Dispatches (the book), they still can open up a new and enlightening perspective on it. By entering into dialogue with one another, the various versions stress the relevance of the (differing) medium for the (same?) message. Drawing on the three-partite subdivision of intermediality, which Irina Rajewsky suggests (cf. Intermedialität 20f; or "Remediation" 51f) and which is met with widespread approval, all of the outlined aspects fall into the category of medial transposition (Medienwechsel). This type, as has just been shown, describes the interplay of various 'texts' - namely, one work in diverse media rather than the characteristic of just one. By contrast, the second form that Rajewsky distinguishes, that of media combination (Medienkombination), designates the phenomenon of one artifact comprising (at least) two different media. As most conceptions of intermediality, this one is especially dependent on which definition of medium one chooses.

Sticking to a definition that is strongly bound to materiality, Dispatches - materially clearly consisting of just one medium - could hardly be identified as intermedial in this second sense. Drawing the media line between text and image, for example, the (material) combination of media in Dispatches does not extend the realm of what Gerard Genette would simply label "paratext” (23ff): book jacket design, cover illustration, author photograph, period. Treating different genres of writing as different media, however, makes the intermedial dimension of Dispatches indisputable: One of the most prominent features of Herr's work is that its "genre ... recalcitrantly refuses determination" (Spanos 185f); it blends fact and fiction, literature and journalism, to a degree in which they almost become indistinguishable. Yet, this generic border crossing has not been acknowledged as a crossing of media boundaries. While a considerable amount of importance has been attached to the matter of New Journalism, for example, it is mostly looked at as a new - literary - genre, and discussed with regard to questions of mimesis or subjectivity rather than of merging different media. Likewise, the ways in which Dispatches dismisses conventional journalism and literary realism, on the one hand; and struggles to establish itself against canonical war literature, on the other, have hardly ever been understood in terms of media rivalry. In fact, however, the motif of competing (print) media - most notably in the countless self-referential passages - runs as a constant subtext through Dispatches. The literary status of Herr's work, which critics tend to take for granted, is itself already the outcome of "a paragone, a struggle, a contest" (Cheeke 21) between different media.

To put it in a nutshell: The intermedial potential of Dispatches is almost inexhaustible. Whatever the reason why "those who have written the big word of 'intermediality' on their banners" (Gumbrecht 177) have not discovered Dispatches as 
a valuable source, yet, it is certainly not that the text does not allow for it. Though well aware of its existence, the paper at hand can, for reasons of space, not exploit this potential to the fullest. Therefore, the above indicated aspects of media combination and media transformation will not be examined in any more depth but have to be understood as pointers towards a research niche which certainly merits closer scrutiny. Instead, the focus of the following text analysis shall be placed on a third type of intermediality: intermedial references (Intermediale Bezüge). In Werner Wolf's terms - who labels the same phenomenon "covert" intermediality - this type is to be understood as:

[the] involvement of (at least) two conventionally distinct media in the signification of an artefact in which, however, only one (dominant) medium appears directly with its typical or conventional signifiers, the other one (the non-dominant medium) being only indirectly present. ("Revisited" 44)

Applying this definition to Dispatches, the sole 'dominant' medium would be literature (even if this designation is, as has been indicated, to some extent simplified in that it does not entirely do justice to its roots in journalism). Which media exactly constitute the 'non-dominant' part of Dispatches and in which ways they contribute to its signification shall be enlarged upon in the following close-reading.

\section{A Mass Media Sensitive Close-Reading of Dispatches}

As has been briefly outlined in the introduction to this paper, the Vietnam War as well as its remembrances and representations - is inextricably linked to the advancement of mass media that has accompanied the $1960 \mathrm{~s}^{12}$ Accordingly, mass media, instead of more traditional media, form the center of attention in the present text analysis. To be more precise, the focus will be on audio, visual and audiovisual media, which have been given comparatively little weight in the research done on Dispatches: (rock) music, photography, and film. Identifying these three as mass media may appear inadequate in that this label undermines their status as serious art forms. However, it is not to be forgotten that at the time of the book's genesis (in the 1960s) and publication (in the 1970s), these media were not yet as highly acknowledged as today. On top of that, it is precisely their role as widely received mass media products, their being part of 'the (American) media,' which is of significance for the purpose of this paper.

Obviously, all three of the selected media are not materially, but only indirectly' present in Herr's work. Yet, they are an integral part thereof which has a

12 For further reading, see for example chapter four of Gerhard Paul's Bilder des Krieges, Krieg der Bilder: die Visualisierung des modernen Krieges (2004), which also includes an interesting passage on German TV coverage of the Vietnam War (cf. 321f). 
not-to-be underestimated impact on how Dispatches affects us and on the message(s) it conveys. Correspondingly, the following close reading shall demonstrate, to borrow Werner Wolf's concise definition of intermediality, that "more than one medium of expression [participates] in the sense-making of" Dispatches (Musicalization 2). To do so, it shall be differentiated, in the first place, between what the work is about - its content- as distinct from how it mediates this content - its form. Put otherwise, the first part of the analysis will be concerned with intermediality IN Dispatches, having a closer look at crucial passages in which different mass media are being thematized (4.1); whereas the second part deals with intermediality OF Dispatches, discussing the various ways in which the work imitates the three given mass media (4.2).

\subsection{Thematization of Mass Media: Intermediality within Dispatches}

For the first half of the textual analysis, attention will be given exclusively to what Wolf calls "quasi-intertextual intermediality" (Musicalization 47) or "intermedial thematization" ("Relevance" 30). ${ }^{13}$ More precisely, intermediality is to be understood, for the moment, as a sort of "popkulturelles Verweissystem" (Wagner 243) - a framework of mass cultural references within Dispatches. Reference here means the explicit mentioning of another medium; either in the form of an "individual reference" (Einzelreferenz) - mentioning a specific work - or in the form of a "system reference" (Systemreferenz) - referring to the medium as a whole (cf. Rajewsky, "Remediation" 53). This "mere thematization" of other media (ibid. 54) is often overlooked or even explicitly denied as being an intermedial phenomenon. Mirroring its marginalization in the academic debate, Yvonne Spielmann dismisses this subcategory of intermedial references as nothing but a 'light-version' of intermediality (cf. Rajewsky, "Light" 43). Without disputing that there may be more intense or experimental forms of intermediality, the following pages shall demonstrate that also this one - "die bloße Thematisierung des Altermedialen" (ibid. 30) - deserves critical attention. In so doing, the specific media under scrutiny are, as already mentioned, (rock) music, photography, and film. To what extent do these three media become a topic in Dispatches and with what effect?

\section{Thematizing (Rock) Music}

One does not read far into Dispatches before coming across the first reference to rock music: "Page took the kid's picture, I got the words down and Flynn laughed and told him we were the Rolling Stones" ( $\left.D^{14} 7\right)$. A seemingly insignificant joke, this early passage already reveals, at a closer look, a few interesting aspects with regard to intermediality. First of all, this simple sentence brings together at least

13 For a detailed chart showing Wolf's complete systematization of all forms of intermediality, see for example Diagramm 2: System intermedialier Formen (178) in his essay "Intermedialität: Ein weites Feld und eine Herausforderung für die Literaturwissenschaft."

14 Dispatches will be abbreviated to the letter $D$ in all following parenthetical references. 
two - visual ("picture") and verbal ("words") - if not three - including aural ("Rolling Stones") - different media. These are, moreover, linked to specific persons, which is an idea that keeps recurring with regard to other characters in later chapters. Unsurprisingly, Herr is 'responsible' for writing and photographer Tim Page for visually documenting the situation. The interplay of different people is indirectly aligned with the interplay of different media; as if each means of representation captures one fragment of the whole action. On top of that, the 'action' itself is of interest with regard to media here: a commander mistakes the three colleagues for members of the USO (the 'entertainment unit') "“cause [their] hair's so long" (ibid.) what then triggers Flynn's joke. This implies, first of all, the setting apart of the (long-haired) correspondents from the (shaved headed) soldiers; and second, the representation of rock music as the anathema to military conformity and to the Vietnam War itself. In short, even the most inconspicuous reference to music (of which there are countless in Dispatches) can have far-reaching implications, which are easily overlooked. In general, the best way to group these various passages is by their function for the overall text.

Referring to the latter-mentioned role of rock music as mouthpiece of the antiwar subculture, it can be said that among the manifold functions of thematizing music in Dispatches, one is evidently of political nature. Through including references to songs and artists known for their outspokenly critical view on war, Herr ${ }^{15}$ lends them tacit approval; indirectly agreeing by not disagreeing. Likewise, the seemingly neutral remark - that he "never once heard [this kind of music] played over the Armed Forces Radio Network" (D 182) - turns into an implicit reproach of censorship; and Tim Page's plan - to "rig loudspeakers around the Lower House ... and play the freakiest music he could find as loud as the equipment would permit" (D 238) - into political protest. The depiction of rock music as "the in-country counterculture of the war" (Fish 390), becomes unmistakably clear when Herr recalls "the grunts who sat in a circle one night with a guitar, singing 'Where Have All The Flowers Gone?” (D 148). In other words, Herr finds a subtle way to create an ongoing political commentary without losing his work's 'apolitical' surface to a morally didactic tone; he lets music(ians) speak for him.

On top of providing a subversive counterpart to the government's view on the war, the continuous references to rock music also serve as a break with the readers' (genre) expectations. Incorporating allegedly 'low art' in a book, a medium considered 'high art,' challenges this very dichotomy. When the words of Frank Zappa are being mentioned in the same breath as those of renowned literati as Hemingway or Blake, it lends weight to the former as much as it debunks the latter. The same holds true, for example, for choosing lyrics by Bob Dylan as the opening quote of a chapter (cf. D 209). Standing representative for the coming of "younger generations [who] do not even perceive, let alone acknowledge, a priority of the written

15 I am, of course, oversimplifying matters here by using 'Herr' to refer to the narrator, the character and the author alike. I do so for pragmatic reasons of brevity and clarity but with full awareness of the intricate narratological interplay of these three instances. 
word over other semiotic systems" (Punzi 11), Vietnam is depicted as a place where the categorization into high and low art has been dissolved or even reversed - “a war where a lot of people talked about Aretha's 'Satisfaction' the way other people speak of Brahms' Fourth” (D 181).

In the same passage, another function of references to rock music becomes apparent: giving a voice to the soldiers. "This music [Jimi Hendrix] meant a lot to them," Herr writes (ibid.), showing an awareness of, as well as a genuine interest in, the soldiers' inner life and thus depicting them in an unusually humane and individualized way. For them, "sounds were as precious as water" ( $D$ 234), it is later repeated, presenting music as a fundamental human drive. An essential need of theirs, the consumption of rock music is repeatedly aligned with the soldiers' other few pleasures, such as drug use (cf. $D$ 8, 239, 245), food (cf. $D$ 109) and sex (cf. $D$ 38, 248). "These songs served as a strategy for survival," Lydia M. Fish finds with regard to the Vietnam War in general; "as a means of unit bonding and definition, as entertainment, and as a way of expressing emotion" (391). Accordingly, David E. James is right in stating that "Herr's breaking of the convention of overlooking rock's preoccupation of the soldiers' imagination is intrinsic to his project of telling the soldiers' own stories rather than continuing the misrepresentation of the war by the military and the administration" (84).

Early in the book, a sergeant is described who "chain-ate candy bars and played country-and-western tapes" (D 13). Implying that this was the music genre that is being enjoyed by those of a higher grade, country music serves as the counterpart to rock ' $n$ ' roll. With equal suggestiveness, Tim Page later asks: “[W]ould Ellsworth Bunker' like the Mothers of Invention"17?" and would "William C. Westmoreland ${ }^{18}$ dig the Mothers?" (D 238). Left unanswered these questions seem even more rhetorical, the answer most self-evidently being: 'No!' Of course, references to rock music in Dispatches can be seen as an element of verisimilitude, since such music was part of the Vietnam experience. However, it was only (or mostly) so for the US soldier; not so much for the generals and officers. Rock music belongs to the war as the 'grunts' - and with them Herr - experienced it; it was "part of life in the combat zone" (Fish 390). Hence, its ubiquitousness in Dispatches not only mirrors its actual role in Vietnam but also puts the reader in the shoes of those for whom it was of immense importance - the soldiers.

This effect is further intensified by the choice of songs. All of them released in the mid- to late 1960 s and many of them listed in the US-Top-100-BillboardCharts, any contemporary American reader will most likely have listened to the exact same tunes during the Vietnam years. ${ }^{19}$ A constant update of the latest US

16 Appointed U.S. ambassador to South Vietnam from 1967-1973 by Lyndon B. Johnson.

17 US rock band around guitarist and composer Frank Zappa.

18 United States Army General during the Tet Offensive (1964-68).

19 Such as Animals' "We Gotta Get Out Of This Place" (D 257) and Jr. Walker\& The All Stars' "Shotgun" (D 258) in 1965, Sam The Sham\& The Pharaohs' "Lil' Red Riding Hood" (D 22) and Paul Revere and The Raiders' "Hungry" (D 257) in 1966, Scott McKenzie's "San Francisco (Be 
hits was guaranteed in Vietnam, as Herr explains: "Whenever one of us came back from an $\mathrm{R} \& \mathrm{R}^{20}$ we'd bring records" ( $D$ 234). Apart from that, the radio made many popular songs available ${ }^{21}$ as the introduction to the lines of Buffalo Springfield's "For What It's Worth" emphasizes: "It was a song that had been on the radio a lot this winter" (D 138). Without a doubt, an American civilian back in the US would confirm this statement, Springfield's single being listed \#7 of the Billboard Charts in 1967 (cf. billboard n. pag.). In short, references to these works serve as shared cultural knowledge which further enhances the (American) reader's identification with the soldiers.

At the same time, however, by allowing an insight into the soldiers' perspective, Herr also uses references to rock music to show the different kind of sensemaking that is at work in war; or, as Cletus Keating nicely phrases it, "as a heuristic device to help his readers grasp the difference between the mind of the civilian and the mind of the soldier" (112). In various passages, it becomes evident how strongly dependent the meaning of a song is on the situation in which it is listened to. When a soldier in Vietnam hears the Rolling Stones singing "Please come see me at the Citadel," for example, he is inevitably reminded of the Citadel of Hue (see for example $D 74,80,242$ ) - "that word putting a chill in the room" just as much as the band name "the Grateful Dead" (D 234). In the same way, the lyrics of The Beatles' "Magical Mystery Tour" take on a new complexion when played in Vietnam: "The Magical Mystery Tour is waiting to take you away ... dy-ing [sic] to take you away"; words which Herr suddenly perceives as "incredibly sinister" ( $D$ 108). Without hesitation, the soldiers and Herr conclude: "That was a song about Khe Sanh!" (ibid.). The effect this description of the "inverted meaning of the Beatles song" has on a civilian reader familiar with the title (which almost every reader would be at the time) is aptly elaborated on by Keating:

These readers would be struck by the substantial change in meaning the war setting forces on the lyrics. Outside the war zone, the song could be taken as a nonsensical fantasy journey ... At Khe Sanh, however, ... the word 'tour' refers to the place where one is stationed, 'take you away' is an informal expression for being killed, and 'dy-ing' is not understood figuratively. (111)

The same effect, only in a reverse manner, is achieved in a passage citing lines from “Trouble Comin' Every Day" by the Mothers of Invention. Though (in contrast to "The Magical Mystery Tour") meant as a song about war and understood

Sure And Wear Some Flowers In Your Hair)" (D 123) in 1967 and Archie Bell\& the Drells" "The Tighten Up" (D 8) in 1968 (cf. billboard.com n. pag.).

20 Acronym for Rest and Recuperation.

21 In her essay on "Folksongs in the Vietnam War," Lydia M. Fish provides some interesting details on how US songs became available in Vietnam via radio, local bands, musically inclined soldiers, records etc. (esp. 392ff). 
as such in the US, Herr, speaking for himself and his fellow correspondents, distances their situation from the one described in the song: "That wasn't really about us, no" (D 218, original emphasis).

Last but not least, rock music is thematized in Dispatches to establish a direct parallel to Vietnam as such; almost a synonym for the war. Rock offers a "polysemy, by virtue of which it was used as an ironic metaphor ... for the war as a whole" (James 80). Correspondingly, Herr describes looking at the faces of the soldiers as "looking into the faces at a rock concert" (D 16) and aligns the painted face of a Lurp with "that of the Haight-Ashbury acid-heads" (Campbell 199) - two "extreme[s] of the same theater" (D 6). As Philip Beidler finds, in Dispatches "Vietnam is a song title ('Stop the War, These Cats Is Killing Themselves' $\left[\begin{array}{ll}D & 10\end{array}\right]$ ), a piece of radio traffic ('Willy Peter/ Make you a buh liever' [ibid.])" (271). Two pages towards the end, as if it took him all these years back in the US 22 to fully understand the connection, Herr brings this parallelism to the point:

Out on the street, I couldn't tell the Vietnam veterans from the rock and roll veterans. The Sixties had made so many casualties, its war and its music had run power off the same circuit for so long, they didn't even have to fuse. The war primed you for lame years while rock and roll turned more lurid and dangerous than bullfighting, rock stars started falling like second lieutenants ... What I thought of as two obsessions were really only one. (D 258)

\section{Thematizing Photography}

While rock music, as has just been shown, is mostly (and exhaustively) thematized by references to specific works, there are only few of such concrete individual references to photography to be found throughout Dispatches. One of them is "a Paris-Match photograph show[ing] Flynn and a French photographer carrying him on a door, his face half covered with bandages" (D 237), another "[a]n epiphany of Hue [which] appeared in John Olson's great photograph for Life, the wounded from Delta Company hurriedly piled on a tank" (D 81), and a third the February 1968 issue of TIME with "General Giap on the cover" (D 212). The latter two being published in two of the best-selling US magazines of the 1960s, they were certainly familiar to most readers; especially when the chapter which contains the Life-reference, "Hell. Sucks," was first published in Esquire magazine in 1969, the same year as the picture. Thus, mentioning it serves as a link between what is (just) being read to what has (previously) been looked at; a connection of the events and characters described in Dispatches to the images readers know from the media.

Notably, this correlation works reciprocally: on the one hand, it lends authenticity to the story by stressing its non-fictionality; on the other hand, it humanizes

22 The first and the last chapter (tellingly titled "Breathing In" and "Breathing Out") were only written seven years after Herr's return from Vietnam (cf. Herr, "We" 41). 
Madita Oeming

the referred to pictures by reminding their beholders that there are actual persons in front of and behind the camera. This appears particularly important in the light of the abundance of images of war. "Bilder [vom Krieg] lagen in den Wohnzimmern der Amerikaner 'wie ein Blutfleck auf dem Teppich' ... wenn [der Amerikaner] beim Frühstück mit Cornflakes und Toast die Morgenzeitung aufschlug, sah ihn der Krieg an" (Adam \& Fabian 31). Though or precisely because of the integration of such pictures into the daily life of American citizens, their content was easily overshadowed by their iconology: " $[\mathrm{H}]$ arrowing photographs ... may endure in memory, but the circumstances of those images and the story they once told become detached through their repetition and familiarity" (Hoskins 11); Dispatches puts them back into context.

More than only serving as a bilateral "Wirklichkeitsreferenz" (Wolf, "Intermedialität" 183), a reference to such pictures also functions as another connecting link to political protest. Photography was discovered "as a powerful tool that swayed public opinion in the United States" (Schwenkel 55). Shocking images - in part precisely due to their iconic quality - "fueled the antiwar movement, and arguably reversed public sentiment on the war" (ibid.); "photography as shock therapy," as Susan Sontag succinctly phrases it (14). Though only three of such photographs are explicitly referred to in Dispatches, they are implicitly called up whenever a picture magazine in general - such as Life or TIME - or a well-known photographer such as AP photographer Rick Merron, UPI photographer Tim Page, CBS/AP photographer Dana Stone, or freelance TIME photojournalist Sean Flynn - is being mentioned. All of these participated in what Nixon called (of course fiercely criticizing and misusing it for his own ends) "[the] relentless and literal reporting of the war, the result [of which] was a serious demoralization of the home front" (qtd. in Hallin 3). While this view on the part of the media in the Vietnam War can be (and has been) contested, it can still be said that "a new generation of war correspondents" was born in Vietnam, which "proved to be more skeptical and cynical than its predecessors" (Donovan \& Scherer 84).

Accordingly, the persons behind the cameras are presented as being deeply intertwined with the particular historical moment of Vietnam. Among "Those Crazy Guys Who Cover the War," as Herr (including himself) keeps calling the press corps (D 188), photographer Tim Page most clearly illustrates this point. Several pages of Dispatches are entirely dedicated to giving the reader a grasp of his personality. Depicted as "the Sixties Kid" par excellence (D 236), he takes the 60s drugs (cf. $D$ 238), listens to the 60s music (cf. D 239), and his "speech is [as] littered with the 60s Americanism "man"' (Hamilton 50) as his field gear is "augmented with freak paraphernalia, scarves and beads" $\left(\begin{array}{l}D \\ 7\end{array}\right) .{ }^{23}$ Although he is the "most extravagant" example of the "young, apolitically radical, wigged out crazies," he can be understood as a representative for this whole "authentic subculture" that has evolved in

23 Probably due to these characteristics, it was Tim Page who inspired the character of the photojournalist in Apocalypse Now, who looks like a hippie more than a prototype war correspondent. 
Vietnam ( $D$ 235f). References to Page thus serve to identify photography as "a medium whose practitioners are "hip"”; hipness here signifying "a young, apolitical recklessness," which allows to see "the Vietnam War as a sixties youth 'trip" (Hamilton 51).

Connoting tourism as much as drug use, the idea of a 'trip' positions the photographer not as "the producer of images with a political currency" but rather as "an objective tourist ... recording not only the horror, but also the beauty, as if on a Third World package tour" (ibid. 54). In this way, the photojournalists are turned into a tool of demonstrating how the war was constructed as a giant spectacle one could "turn on and trip out on" ( $D$ 235). One of the main motifs of Dispatches" penultimate chapter, "Colleagues," is to outline this view as a common feature not only of the photographers but also of the soldiers. Just like "those professional, specialized tourists known as journalists" (Sontag 18), the 'grunts,' too, inhabit Vietnam as "adventurers" (D 51, 223); seeking "Asia, war, drugs, the whole adventure" (D 236). The likening of the photographers - as observers - with the soldiers - as killers - works towards blurring the distinction between watching and doing:

A journalist's decision to photograph a moment of death or to capture terror and anguish on film raises complex ethical issues, as there is a paradoxical participation - taking the picture - through a lack of participation - not offering help but recording the act. (Schwenkel 56)

Exactly such a situation is described in Dispatches, when "a dying," not a dead, Southern Vietnamese soldier is brought to the camp: "We all gathered around to look at him, ... [a]ll of the photographers leaned in for pictures" - but not for help ( $D$ 235, see also D 202). It is hence ultimately through the thematization of photography that Herr expresses what the war taught him: "that you were as responsible for everything you saw as for everything you did” (D 20).

What demarcates the photographer from the soldier, however, is the allimportant fact that the latter was drafted, forced to be in Vietnam; while the former came on his own free will. 'You mean you don' have to be here? An' you're here?" (D 119, original emphasis), as one grunt expresses his disbelief (see also $D$ $115,187,206)$. This role of the photojournalist as the "true volunteer" ( $D$ 20), constitutes their probably most central function for Dispatches: to express the deep fascination with war that accompanies its gruesomeness. In the longest and most expressive passage on photography, this "infatuation with violence" $(D 63)$ is explained by an insatiable voyeurism:

You know how it is, you want to look and you don't want to look. I can remember the strange feelings I had when I was a kid looking at war photographs in Life, the ones that showed dead people or a lot of dead people lying close together in a field or a street, often touch- 
ing, seeming to hold each other. ... I didn't have a language for it then, but I remember now the shame I felt, like looking at first porn, all the porn in the world. ( $D$ 18)

Apart from again using photographs, and also their appearance in the magazine Life, to connect Vietnam to previous atrocities, these lines suggest a sexual dimension to the war (see also $D$ 63, 132, 136, 160), especially to war photography. "All images that display the violation of an attractive body are, to a certain degree, pornographic," Susan Sontag agrees; "[i]mages of the repulsive allure" (95). Calling this reaction "“morbid' suggests a rare aberration," she goes on, which it is not: "Everyone knows what slows down highway traffic going past a horrendous car crash" (ibid.). The above cited direct address - You know how it is - stresses this universality. In an interview for the documentary First Kill, Herr makes it even more explicit: "It would not be useful to pretend to anyone that [war] doesn't really turn people on ... it always has done and always will" (n. pag.). Accordingly, Herr calls the ambiguity towards war a "rough reconciliation that many of us had to look at" - not only the photographer - "trying to piece together the very real hatred of the war with the great love for it" (D 221).

In the end of the above begun text passage, to come to the last aspect, Herr uses his experience of looking at war photographs to comment on the relation of these to the reality of war:

Even when the picture was sharp and cleanly defined, something wasn't clear at all, something repressed that monitored the images and withheld their essential information ... I could have looked until my lamps went out and still I wouldn't have accepted the connection between a detached leg and the rest of a body. (D 18)

Here, pictures are described as being insufficient to convey all the information to its onlooker. This reference thus points to the impossibility of mediating the essence of war, even by means of a medium which allegedly captures reality. He goes on to explain how seeing the depicted objects in real life - instead of looking at them on photographs - is expected to change your understanding of war: "Supposedly, you weren't going to have that kind of obscuration when you finally started seeing them on real ground in front of you" (D 19). Now having faced such reality, he learnt that it does not make things any clearer at all: "You tended to manufacture it anyway because of how often and how badly you needed protection from what you were seeing, had actually come 30,000 miles to see" (ibid.). Obviously, Herr's experience of Vietnam has proved that the 'repressed information' of the photographs, does not make it through in reality either. Facing the 'real' war has not made it any more comprehensible to him: "Only see[ing] what you can bear to see" (Herr, First Kill n. pag.), the obscuration remains. 


\section{Thematizing Film}

With regard to the thematization of film in Dispatches, the reflection of the relation between reality and representations thereof can be identified as the most prominent function, which operates on at least three different levels. One dimension of this interplay are the expectations that movies have raised about going to war. "We all had our movie-fed war fantasies" (D 194), Herr writes, making clear that everyone in Vietnam - soldiers as well as correspondents - came there with a particular, media-induced, idea of what war would be like. The 1945 World War II movie $A$ Walk in the Sun (D 46), the 1959 post-apocalyptic 'World War III' movie On the Beach (D 70), the 1958 film adaptation The Quiet American (D 210), and the 1966 Western Nevada Smith (D 60) are some of the explicitly referred to films which have shaped this vision of war. On top of these, a longer passage deals with Fort Apache (1948), starring John Wayne, which, according to Herr, is "more a war movie than a Western, Nam paradigm" (D 46).

Taking the US actor as a major source of false ideas about war, Herr selfexplanatorily calls the 'gleeful' anticipation for going to Vietnam a "John Wayne wetdream" ( $D$ 20), again stressing the eroticism involved. Correspondingly, Tobey C. Herzog labels the "shaping [of] the romantic illusions about Vietnam embraced by the young American combat soldiers" as the "John-Wayne-Syndrome" (19). Turning to another Wayne movie, Herr explains that The Green Berets (1968) - theoretically "the first film to address the [Vietnam] war explicitly" (Gustainis 138) "doesn't count" as a war movie since it practically "wasn't really about Vietnam, [but] about Santa Monica" (D 188). While this comment specifically laments the 'Hollywoodness' of The Green Berets, it also points to the general unsuitability of Vietnam as a sujet for mainstream cinema:

In any other war, they would have made movies about us ... but Vietnam is awkward, everybody knows how awkward, and if people don't even want to hear about it, you know they're not going to pay money to sit in the dark and have it brought up. (ibid.)

Hence, in the late 1960s, John Wayne's California/Western-version of the Vietnam War obviously constitutes the only way to make it suitable for the (American) masses (see also Dittmar 150). In a contemporary, remarkably anticipatory, 1968 New York Times review, Renata Adler positions The Green Berets within this larger context: "[It] is a film so unspeakable, so stupid, so rotten and false in every detail that it ... becomes an invitation to grieve, not for our soldiers or for Vietnam ... but for what has happened to the fantasy-making apparatus in this country" (n. pag.). Understanding filmic war representations, in general, as misrepresentations, it follows that the false expectations they fuel are eventually belied: the "Dawn Patrol fantasy would turn very ugly" (D 230) for all those "kids who got wiped out by seventeen years of war movies before coming to Vietnam to get wiped out for good" (D 209). Neil Postman's famous words, that "we are a people on the verge 
of amusing ourselves to death" (4), take on a lethally literal meaning here; "[that's] what happens to you when you pursue a fantasy until it becomes experience" ( $D$ 68).

Another dimension of the reality-movie-relation outlined by the thematization of film in Dispatches is the perception of war as a movie, even when already in the field. Relating his first combat experience, Herr admits:

We'd all seen too many movies, ..., years of media glut had made certain connections difficult. The first few times that I got fired at or saw combat deaths, nothing really happened, all the responses got locked in my head. It was the same familiar violence, only moved over to another medium; some kind of jungle play with giant helicopters and fantastic special effects, actors lying out there in canvas body bags waiting for the scene to end. (D 209)

This passage vividly demonstrates how the movies serve as a framework through which the war is experienced; a framework which, as a sort of protective mechanism, seemingly brings about a relieving distance to the atrocities witnessed. What is most striking about it is that it presents reality as yet another medium, instead of the 'antagonist' to or the 'original' of the many circulating media representations. Again, calling up the passage on war photography, seeing war with one's proper eyes does apparently not bring about clarity or illumination but is, by contrast, obscured by pre-conceived Hollywood images of war. Early in Dispatches, Herr renders a dialog with a sergeant which stresses this point: "'This ain't the fucking movies over here, you know,' he said. I laughed again and said that I knew, but he knew that I didn't." (D 22). Similarly, a shrapnel-hit Marine later swears: "I hate this movie" (D 188, original emphasis). About his own experience Herr writes: "It took me a month to lose this feeling of being a spectator to something that was part game, part show" ( $D$ 168). To realize that one is not only watching a film is an awareness that takes time, that some only come upon in retrospect, and some escape forever; "most combat troops stopped thinking of the war as an adventure after their first few firefights but there were always the ones who couldn't let that go" (D 209). These latter ones remain trapped in the understanding of war as a spectacle, denying the abiding truth: "Vietnam, not a movie, no jive cartoon either where the characters get smacked around and electrocuted and dropped from heights, ... then up again and whole and back in the game, 'Nobody Dies,' as someone said in another war movie" (D 46).

The third dimension of the reciprocity of war movies and war itself is probably the most unexpected: war imitates the movies. In a significant passage, Herr describes how the soldiers enact combat as they know it from Hollywood scenes:

You don't know what a media freak is until you've seen the way a few of those grunts would run around during a fight when they knew that 
there was a television crew nearby; they were actually making war movies in their heads, doing little guts-and-glory Leatherneck tap dances under fire .... (D 209)

Driven by "the American male's image of toughness, courage, patriotic duty, honor, and glory" (Herzog 23), these soldiers mimic stereotypical war heroes familiar with from the movies, "acting out their fantasies" (D 50), playing Cowboys and Indians. Reading the passage against Baudrillard, Brady Harrison rightly finds that this "John-Wayne-Grunt, modeled after a simulation ('the Duke') of a simulation ('John Wayne') of an obscure reality (Marion Morrison), is a perfect simulacrum" (97). Indeed, in Vietnam the real becomes the 'hyperreal' to stay in postmodern discourse, a "fucking circus" (D 220) to use Herr's words; a world where "John Wayne-ing" (James 83, Paul 317) is a verb and "just-like-in-the-movies" (D 217) an adjective - "Life-as-movie, war-as-(war)movie, war-as-life" ( $D$ 65).

\subsection{Imitation of Mass Media: The Intermediality of Dispatches}

What has been shown so far is how intermediality appears in Dispatches by means of explicit thematizations of music, photography and film. While these already perform a variety of different functions and have profound implications for the overall text, they only make up one half of what has initially been outlined as intermedial references. Intermedial imitation (Wolf) - or simulation (Rajewsky) - constitutes for the other, more implicit half which must not be ignored here. It hardly comes as a surprise that the ways in which Dispatches resembles other media are much more difficult to grasp than the ways in which it thematizes them. While the latter can be pinpointed to particular passages, even words, the former is rather an overall effect and is hence harder to sense and to localize. Also, as Wolf remarks, "intermedial imitation as an implicit reference needs some elements which render the intermediality explicit" instead of making the "defamiliarization of the medium" appear as just "a general experimental aesthetics" ("Revisited" 29). Obviously, explicit thematizations can serve as such markers of implicit imitation (cf. Rajewsky, "Light" 48). As the previous pages have demonstrated, these abound in Dispatches to such a degree that any form of implicit intermediality may be understood as such. For the remaining part of the present close-reading, the emphasis shall therefore be shifted from the level of content to that of form in order to come to an understanding of how Dispatches imitates other (mass) media: How does it employ "its own media-specific means" to simulate "a different medial system" (Rajewsky, "Remediation" 55)? To answer this question, the three previously discussed mass media will be retained as central points of reference: how does Dispatches create music-ness, photography-ness and film-ness? 
Imitating (Rock) Music

Even as a printed book, Dispatches is not entirely silent. By means of intermedial imitation it "solicits in the recipient," to use Rajewsky's words, "a sense of ... acoustic presence" ("Remediation" 55). Dispatches creates an aural dimension through imitating melodies, sounds and (spoken) language. The first of these is most effectively simulated by partially reproducing works of music in the form of citing their lyrics. In extension of the copyright page, acknowledgement is made to 17 different songs, of which single words or whole lines are being reprinted in the text (cf. $D$ vii-viii). As has been outlined in part 4.1, all of these were popular 1960s songs, the reproduction of which thus automatically lends an acoustic quality to the text: "until I heard it in my sleep ... I fell into a burning ring of fire, surrounded by strungout rednecks, ... they were afraid they wouldn't know it when they finally got it, and it burns burns burns" (D 13) - no one familiar with the Johnny Cash tune can read these lines without hearing the melody, without hearing it sung ${ }^{24}$ (see also $D$ 108, 138, 181, 234). The perpetual presence of music on the content level further amplifies this effect; "the spirit of Morrison and Hendrix and Zappa so permeate every page that you can almost hear their music blaring in the background" (Kenney n. pag.). Likewise, one virtually hears the disc jockey roaring from the radio: "moving right along here with our fabulous Sounds of the Sixties" (D 137).

Also other voices gain a particularly oral quality through Herr's marked attentiveness to dialects. The words of a German "who had lost all traces of his original accent" and replaced it with "a gruff, clipped Brooklyn-docks way of speaking" seem likewise true for Herr: "I got dis tuhriffic eah fuh langwidjis" (D 145f). This is by far not the only sentence which reads like a phonetic transcription more than like a line in a book. By means of such fine-grained quotations of oral speech, "Dispatches constantly struggles to metamorphose itself into spoken language in order to distance itself from the degraded [written] language of power" (Thompson 584). Lastly, sound is created in Dispatches by the frequent use of onomatopoeia, which makes us hear "that wrenching, resonant metal echo" of gunfire or the "noise of the rotor blades" (D 167) which are so characteristic of Herr's perception of Vietnam: "tat-tat-tat, tatta-tatta-tat" ( $D$ 187), "bbbdddrrrpp" ( $D$ 35), "whump whump whump and dit dit dit" (D 63). What Herr says about being in a chopper thus also describes the auditory impact of Dispatches: "cassette rock and roll in one ear and door-gun fire in the other" (D 9).

On top of simulating the audibility of (rock) music, Dispatches also imitates its register. Not only the persons depicted make use of expressions that obviously derive from rock music, but also the text proper. Herr tells his story "in the lingo of rock music" (Herring 153). Rock ' $n$ ' roll itself is being used as an expression for "fire from an M-16 on full automatic" (ibid.), which explains that Herr does not talk about constant entertainment when he remarks that there was "Rock around

24 Surprisingly, instead of making use of the medium's audibility by singing or even playing the lines, the audio book version mitigates this effect by completely leaving out most reproductions of song lyrics; replacing them with just the song title or omitting the whole passage. 
the clock" ( $D$ 14). Slang expressions such as "motherfucker," “jag," "suck," "stoned," "hyper," "groovy," or "dig," as well as colloquial addresses such as "Dude," "Kid," "Jive" or "Man" can be considered traces of the American 60s subculture. Moving from direct speech to free indirect discourse to indirect speech to narrative voice, they provide a fluent passage from content to form. A chapter heading like "Hell Sucks" ( $D$ 70) clearly underlines this point and contributes to the 'rock musicness' of Dispatches, which itself becomes an example of "the speaking styles of young American soldiers: fast paced, full of slang, very much shaped by popular culture" (Paredes n. pag.).

\section{Imitating Photography}

Dispatches creates a photographic visuality in at least three different ways which vary in their intensity, or degree of intermediality. The first, and probably the most literary one, is the use of figurative language: "I felt a cold fat drop of sweat start down

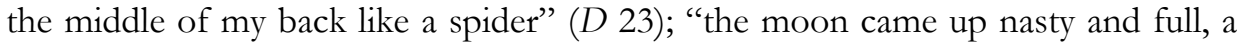
fat moist piece of decadent fruit" (D 11). Such similes, metaphors, or other figures of speech do either serve to familiarize the unfamiliar (as in "choppers fell out of the sky like fat poisoned birds" (D 14)); or, vice versa, to defamiliarize the familiar, as in the above given examples, which present something common (the moon or sweat) in a strangely new light (as a fruit or a spider). In many cases, Herr draws on imagery generated from the context of war. In the beginning of Dispatches, he describes his fear as "the Elephant ${ }^{25} \ldots$ kneeling on [his] chest" ( $D$ 5), which finds it counterpart expressed in the end as "one last chopper ... [which] flew out of [his] chest" (D 260). Here, the choice of the vehicle leads to a specific form of defamiliarization in that it implies that the allegedly familiar tenor is precisely not to be compared to the feeling of fear or relief one knows from civilian life. Regardless of such nuances, all these figures are "textual entities with a strong visual character" (Mamirovic 5).

A similar but still distinct means of suggesting a visual dimension is ekphrasis, "the verbal representation of a visual representation" (Heffernan 39). In Dispatches, many examples of ekphrastic writing can be found, such as the description of a collage ( $D$ 176f) or the constant referral to pieces of "helmet graffiti" $(D$ 226, 158) which run through the text like a golden thread - "TIME IS ON MY SIDE" ( $D$ 21), "HIGH ON WAR" (D 63), "PRAY FOR WAR" (D 27) etc. Obviously, the typesetting further enhances the visual quality of the latter such as when Herr "passed a blind man carrying a sign that read MY DAYS ARE DARKER THAN YOUR NIGHTS" (D 244f) or speaks of "enormous red letters across the front of [another] helmet: MAYHEW" (D 115). The most striking and most exhaustively discussed example of ekphrasis, however, is the map which opens the book: "There was a map of Vietnam. . . it was very old ... [t] he paper had buckled in its frame

25 As the capitalization indicates, the vehicle here is the Elephant, a bomber aircraft, rather than an elephant, the animal. Interestingly, though, even if readers miss this military meaning, the image produced remains almost the same: something big weighing heavy on your chest. 
after years in the wet Saigon heat" (D 3). In contrast to the above discussed figures of speech - which "boast semiotic unity" and are "essentially all language" - an ekphrastic passage like this one "is language replacing and "crossing' a sign system outside language" (Yacobi 94). As such, it "entails semiotic bi-polarity," which has an even stronger visual impact and makes it even 'more' intermedial (ibid.). In the case of the map, the visual representation is not only vividly described but is also taken from a framework familiar to the reader; everyone has a concept of what maps look like and can thus picture the one described more easily.

This effect is enhanced, if a specific visual representation is being referred to that is part of the reader's world; which brings us to the third means to evoke visuality: (non-fictional) intermedial individual references. The ones to contemporary and widely received photographs outlined in part 4.1, for example, are perfect demonstrations of this point. A full vivid description is not even necessary in such a case but a reference is enough to call to mind the cover of TIME magazine, the photograph in Life or other pictures of the war in any reader who is familiar with them. Reading the enumeration of "obligatory" Vietnam shots - including "the Zippo-lighter shot," and the "severed-head shot" (D 198f) - is like virtually flipping through the pages of a photo album. Any of such verbal references hence evokes a visual quality and thus "create[s] a specific image that is to be found in the text as its 'resident alien"' (Mitchell, Picture 157).

To take this thought one step further: In the case of a highly medialized event, as the Vietnam War was and is, not even a reference seems to be necessary to create such word pictures. Since the reader's perception of the verbal artifact is inextricably linked to previously conceived visual ones, the mentioning of certain keywords will suffice to elicit an image. If, for example, in a text on $9 / 11$ the words tower or dust or fireman appear, we cannot help but visualize particular, endlessly repeated, (media) images. In the context of Vietnam, most of all for the 1960s/1970s readership of Dispatches, the same holds true for expressions such as chopper, rice paddy, body bags, or napalm bomb - they inevitably recall visual icons of the war. A passage like the following makes it almost impossible not to form one of the many infamous black and white shots in one's mind's eye:

Sometimes the chopper you were riding in would top a hill and all the ground in front of you ... would be charred and pitted and still smoking ... frail gray smoke where they'd burned off the rice fields ... brilliant white smoke from phosphorous ... deep black smoke from 'palm. (D 10)

Reading these words, we subconsciously turn Herr's verbal description of his 'reality' of war into a visual representation thereof; into one of the many black-andwhite photographs we have seen from Vietnam. As if exchanging the panchromatic for the color film and changing the framing from a long shot to a close-up, Herr writes some pages later: 
I knew I hadn't seen anything until I saw this face. It was flushed and mottled and twisted like he had his face skin on inside out, a patch of green that was too dark, a streak of red running into bruise purple, a lot of sick gray white in between. $\left(\begin{array}{ll}D & 19)^{26}\end{array}\right.$

Interspersed with such verbal photographs, Dispatches "become[s] a piece of photojournalism without the pictures, [a] narrative version of Life magazine" (Herzog 79).

The book's overall structure further underlines this impression. Dispatches presents itself to us as what Vietnam presents itself to Herr: "as a series of discrete images that demand individual completion ... and reveal their possible relationships only through a process of personal absorption, connection, and invention" (Myers 150). We are confronted with "a kaleidoscopic series of snapshots" (Doherty 24), similar to the one described in Dispatches: "snaps of their families, their wives, their dogs, their cows, their cars, of Lyndon Johnson, Martin Luther King, ... the Pope, Che Guevara ... Jimi Hendrix" (D 57). The same paratactical structure informs Dispatches as a whole, which presents its many 'dispatches' as equally meaningful (or meaningless) and interchangeable. Seen in this light, Herr's vivid description of a collage turns into a most self-reflexive moment: Dispatches itself appears to be a psychedelic topsy-turvy of "wounded Marines," "newspaper headlines," "chopper[s]", "cannabis," "Mick Jagger," "American flags," and "stacked Vietcong dead" (D 176).

\section{Imitating Film}

The combination of (musical) audibility and (photographic) visuality turns Dispatches into an audio-visual experience, a movie as it were. This is most clearly illustrated through a passage which reproduces parts of "Trouble Comin' Every Day" by The Mothers of Invention. Like stage directions, the lyrics are interspersed with the reactions of the soldiers to the respective line: "You know I watch that rotten box until my head begin to hurt, (bitter funny looks passing around the room), 'And if another woman driver gets machine-gunned from her seat, ... (lip-biting, flinching, nervous laughter) ... ." (D 218). Herr here imitates a film scene in which sounds and images overlap which is just one of the many passages in which "he asks us to see Dispatches as a film instead of a book" (Harrison 89). The chapter "Hell Sucks," to name but one other example, opens with the sentence: "By 2:30 every day Saigon looked like the final reel of On the Beach" (D 70)27. Hinting at

26 Hauntingly demonstrating how history repeats itself, today's readers may feel strongly reminded of the infamous face of the "Marlboro Man from Fajullah" (2004), a U.S. Marine in Iraq, which indeed perfectly fits Herr's verbal close-up.

27 The use of film vocabulary arguably adds up to Dispatches' filmness: the war "was some scene (you found out), there was no cutting it" (D 210), to give just one glaring example. The term scene is used more than twenty times in Dispatches (e.g. D 59, 231, 240,251) and although being a word which also exists outside the realm of movies, the latter's constant presence on the content level makes readers automatically associate it with a film context. The same holds true for expressions 
Herr's "own education through war movies" as much as relying on our cinematic literacy, "Dispatches asks that the reader, a seasoned viewer of cinema and television screens, constructs a motion picture screen to capture Herr's projection of Vietnam" (ibid. 69); we have to watch it and listen to it, rather than to read it. Dispatches can therefore eventually be seen as "a surrealistic prose film" of which "Herr becomes writer, director, and principal actor" (Herzog 82). The incessant references to film further provoke such a comparison, all the more when Herr himself calls the text his "movie" (D 206, 219): "we have all been compelled to make our own movies ... and this one is mine" (D 188).

Already the title of Dispatches is suggestive of the book's fragmented, filmic overall structure. As James C. Wilson points out, "Dispatches is a book of dispatches or fragments, bits of narrative that remain diffuse and discontinuous" (45). Kurt Dittmar, in explaining his criticism of the German title translation "An die Hölle verraten" (Rowohlt, 1989), uses the same argument: "Denn der Leser wird mit einem verwirrenden Konglomerat von 'Depeschen' ... und nicht mit vordergründigen Moralismen konfrontiert" (155). Indeed, Dispatches connotes dis-junction, discontinuity and patch-work, which mirrors the war itself: "If you were one of those people who always thought they had to know what was coming next, the war could cream you" (D 13). Analogously, Herr's work does not follow a chronological, continuous order either. Time keeps moving back and forth; past, present, and future flowing into one another by means of memories, nightmares, analepses and prolepses. While one may well describe this technique in postmodern terms, it can even better be expressed in cinematic ones: The various 'dispatches' are "edited together in a rapid-paced and sharp witted montage" (Sturken 87); they are separated by "frequent jump cuts served up by the ever-present helicopter or druginduced reveries rather than the camera" (Herzog 82).

\section{Conclusion: We've All Been There}

Dispatches is a text so intricate and multi-faceted that one always has the feeling of not doing justice to its profound complexity. In combination with the broad concept of intermediality it becomes an endlessly fruitful source for literary analysis. Therefore, the previous pages are but a carefully chosen selection of significant passages which have to stand representative for a much larger whole. Nevertheless, the preceding media sensitive close reading of Herr's work has brought forth a number of valuable findings. Most broadly summarized, it has been shown, on the one hand, that via exhaustive intermedial thematization of (rock) music, photography, and film, mass media become ubiquitous in Dispatches and open up additional layers of sense making (4.1). On the other hand, it has been demonstrated that true to the dictum 'form mirrors content' - the book's own language, structure and

such as "fade out" (D 11), "flicker" (D 23), "action" (D 42, 51, 62), "stunt" (D 13), or the phrase "no preferred cut" (D 15). 
audio/-visual effect are likewise informed by mass media through means of intermedial imitation (4.2). On both levels, it has been made clear that intermediality in and of Dispatches has not only a textual but even more so a cultural dimension. As "discursive markers of larger cultural issues" (Stein 182), its intermedial references and allusions are deeply rooted in its socio-historical background, 1960s USA. However, their overall effect in Herr's work is in fact ahead of its own time. Only now that torture videos by US soldiers in Iraq can be watched on YouTube and a nation calls for an 'evidence' photo to be persuaded of Osama Bin Laden's death, the poignancy of Dispatches' concerns becomes fully evident. Illustrating the reciprocity between the media and the Vietnam War, it draws attention to the many ways in which media in general shape not only our perception of reality but even reality as such. Together, this leads to a fundamental 'mass-media-ness' of all postmodern experience - "we are all increasingly living in ... [a] media wonderland" (Herr, "We" 38).

In this postmodern wonderland, the idea of media rivalry becomes as obsolete as the distinction between reality and representations thereof; everything as closely intertwined that one can no longer be distinguished from the other. Accordingly, Herr neither presents Vietnam as a television war nor as the photographer's or the writer's war; but simply as "the first terrible postmodern war" (Jameson 44) in which all rigid categories have lost their currency. Without repeating every distinct function that each of the focused on media perform, it can be said in summary that intermediality, or inter-mass-media-lity to be precise, functions as a deconstructive means within Dispatches: it blurs the lines between high and low art, between seeing and acting, between past and present, between disgust and alluringness, and most importantly between reality and media representations. Ultimately, it thus also challenges the clear-cut distinction between soldiers and civilians; between Vietnam and the US. In so doing, to return to the opening imagery, Dispatches tears down the walls between in- and outside Plato's cave.

On top of including elements of shared cultural knowledge and dissolving the line between the 'real' and the 'mediated' war, the incapability of perceiving the reality of Vietnam runs through Dispatches as a central leitmotif. Herr himself has 'left the cave' in going to Vietnam, but experienced what Plato foresees: "When he approaches the light his eyes will be dazzled, and he will not be able to see anything at all of what are now called realities" (43). Waiting in vain for his eyes to adjust to the glaring 'light' of war, Herr finds that "night was the war's truest medium" (D 41); the only medium, it seems, he ever endowed with any form of Truth among all those which are insufficient to tell the story of Vietnam. A story in which reality is as much a construct as any representation thereof because it is "a monstrous text, collectively authored" (Thompson 583) by the people and the media alike of a whole generation. "For Herr, the Vietnam War is a symptom of the Sixties ... an essential generational experience, like trying drugs and listening to the White Album ... and it doesn't really matter whether you actually, physically participated (inhaled?) or not" (Campbell 199). In other words, it is not so much "a 
matter of 'being there' ... as a matter of being an American in the last half of the twentieth century trying to make sense of a collocation of experience and myth called Vietnam" (Beidler 266). To end on the resonating last words of Dispatches: "Vietnam Vietnam Vietnam, we've all been there" (D 260). 


\section{Works Cited}

Adler, Renata. “'Green Berets' as Viewed by John Wayne.” nytimes.com. 20 June 1968. Web. 02 Sep 2011.

Allué, Sonia Baelo. "Intermediality in Literature: Bret Easton Ellis and the MTV Novel." Literary Intermediality. Ed. Maddalena P. Punzi. Bern: Lang, 2007. 145162. Print.

Beidler, Philip. D. Re-writing America: Vietnam Authors in their Generation. Athens: U of Georgia P, 1991. Print.

Billboard. "Hot 100 - Archive." billboard.com. Web. 20 Aug 2011.

Campbell, James. "Coming Home: Difference and Reconciliation in Narratives of Return to "the World." The United States and Viet Nam from War to Peace. Ed. Robert M. Slabley. Jefferson: McFarland, 1996. 198-208. Print.

Cheeke, Stephen. Writing for Art. New York: Manchester UP, 2008. Print.

Dittmar, Kurt. "Literatur und mediale Berichterstattung als moderne Stepsister Arts: Das amerikanische Bild vom Krieg in Vietnam." Sister Arts - Englische Literatur im Grenzland der Kunstgebiete. Ed. Joachim Möller. Marburg: Jonas, 2001. 147157. Print.

Doherty, Thomas. "Full Metal Genre: Stanley Kubrick's Vietnam Combat Movie." Film Quarterly (Winter 1988): 24-30. Web. 10 Aug 2011.

Donovan, Robert John, and Ray Scherer. Unsilent Revolution: Television News and American Public Life, 1948 - 1991. Washington DC: Wilson, 1993. Print.

Eicher, Thomas. "Was heißt (hier) Intermedialität?" Intermedialität - vom Bild zum Text. Eds. Ulf Bleckmann and Thomas Eicher. Bielefeld: Aisthesis, 1994. 1128. Print.

Fabian, Rainer, Adam, Hans Christian and Rolf Gillhausen. Bilder vom Krieg: 130 Jahre Kriegsfotographie, eine Anklage. Hamburg: Gruner, 1983. Print.

Fish, Lydia M. "General Edward G. Lansdale and the Folksongs of Americans in the Vietnam War." American Folklore Society (Oct-Dec 1989): 390-411. Web. 20 July 2011.

Genette, Gérard. Paratexts: Thresholds of Interpretation. Cambridge: Cambridge UP, 1997. Print.

Gumbrecht, Hans Ulrich. "Why Intermediality - if at all?" intermédialités 2 (Fall 2003): 173-178. Print. 
Gustainis, J. Justin. American Rhetoric and the Vietnam War. Westport: Praeger, 1993. Print.

Hallin, Daniel C. The Uncensored War. Berkeley: U of California P, 1989. Print.

Hamilton, Robert. "Shooting from the Hip: Representations of the Photojournalist of the Vietnam War.” Oxford Art Journal 9.1 (1986): 49-55. Web. 07 July 2011.

Heffernan, James. "Ekphrasis and Representation." New Literary History 22.2 (Spring 1991): 297-316. Web. 27 June 2011.

Herr, Michael. Dispatches. New York: Vintage, 1991. Print.

-. "Michael Herr: We've All Been There." Interview with Eric J. Schroeder. Vietnam, we've All Been There. Westport: Praeger, 1992. 33-50. Print.

—. First Kill. Interview with Coco Schrijber. Docsonline. 2001. Web. 28 Aug 2011.

Herring, George C. "Vietnam Remembered." The Journal of American History (June 1986): 152-16. Web. 01 Aug 2011.

Herzog, Tobey C. Vietnam War Stories: Innocence Lost. London: Routledge, 1992. Print.

Heusser, Martin. "Introduction.” Mediality/Intermediality. Eds. Andreas Heusser, Martin Fischer and H. Andreas Jucker. Tübingen: Narr, 2008. 11-13. Print.

Higgins, Dick. “Intermedia.” 1965. Leonardo (2001): 49-54. Web. 21 May 2011.

Hörner, Fernand, Harald Neumeyer and Bernd Stiegler. Praktizierte Intermedialität: Deutsch-französische Porträts. Bielefeld: Transcript, 2009. Print.

Hoskins, Andrew. Televising War: From Vietnam to Iraq. London: Continuum, 2004. Print.

James, David E. "Rock and Roll in Representations of the Invasion of Vietnam." Representations 29 (Winter 1990): 78-98. Project Muse. Web. 19 May 2011.

Jameson, Frederic. Postmodernism, or, the Cultural Logic of Late Capitalism. Durham: Duke UP, 1991. Print.

Kenney, Joe. “Apocalypse Now, the Book.” 30 May 2003. Web. 01 Aug 2011.

Mamirovic, Bojana. "Image and Text in Advertising." Diss. 2009. HeiDok. Web. 11 Sep 2011.

McLuhan, Marshall. Understanding Media. 1964. Cambridge: MIT P, 1995. Print.

- War and Peace in the Global Village. 1986. Madera: Ginko, 2001. Print.

Melling, Philip H. Vietnam in American Literature. Farmington Hills: Twayne, 1990. Print. 
Mitchell, W.J.T. “Interdisciplinarity and Visual Culture.” Art Bulletin (1995): 540544. Print.

—. Picture Theory. Chicago: U of Chicago P, 1995. Print.

Moninger, Markus. "Vom 'media match' zum 'media crossing." Crossing Media. Eds. Christopher Balme and Markus Moninger. München: Leipodium, 2003. 733. Print.

Müller, Jürgen E. "Intermedialität als poetologisches und medientheoretisches Konzept. Einige Reflexionen zu dessen Geschichte." Intermedialität. Theorie und Praxis eines inter-dis₹iplinären Forschungsgebiets. Ed. Jörg Helbig. Berlin: Schmidt, 1998. 31-40. Print.

-. "Intermediality and Media Historiography in the Digital Era." Film and Media Studies 2 (2010): 15-38. Web. 17 July 2011.

Myers, Thomas. Walking Point. 1988. Ebrary. Web. 03 Sept 2011.

Oosterling, Henk. "Sens(a)ble Intermediality and Interesse - Towards an Ontology of the In-Between.” Intermédialités 1 (Spring 2003): 29-46. Print.

Paech, Joachim. "Artwork - Text - Medium. Steps en route to Intermediality." 2000. uni-konstanz.de. Web. 30 July 2011.

-. "Intermedialität. Mediales Differenzial und transformative Figurationen." Intermedialität. Ed. Jörg Helbig. Berlin: Schmidt, 1998. Print.

Paredes, Raymund. "Michael Herr." georgetownuniversity.edu. Web. 15 June 2011.

Paul, Gerhard. Bilder des Krieges - Krieg der Bilder. München: Schöning, 2004. Print.

Plato. The Republic. Trans. Benjamin Jowett. Chicago: Great Books, 1956. Print.

Postman, Neil. Amusing Ourselves to Death: Public Discourse in the Age of Show Business. 20th anniversary ed. New York: Penguin, 2006. Print.

Preuss, Rudolf. Intermedia: Künstlerische Experimente und Vermittlungsprozesse. Vol. 12. Dortmund: Dortmunder Schriften zur Kunst, 2011. Print.

Punzi, Maddalena P. Literary Intermediality. Bern: Lang, 2007. Print.

Rajewsky, Irina O. "Intermediality, Intertextuality, and Remediation: A Literary Perspective on Intermediality." Intermédialités 6 (Fall 2005): 43-64. Print.

—.Intermedialität. Tübingen: Francke, 2002. Print.

—. "Intermedialität 'light?" Intermedium Literatur. Eds. Erika Greber and Roger Lüdeke. Göttingen: Wallstein, 2004. 27-77. Print.

Ryan, Marie-Laure. Narrative across Media. Lincoln: U of Nebraska P. 2004. Print. 
Schröter, Jens. “Intermedialität.” Montage.av (February 1998): 129-154. Web. 01 July 2011.

Schwenkel, Christina. The American War in Contemporary Vietnam: Transnational Remembrance and Representation. Ebrary. 2009. Web. 01 Aug 2011.

Sielke, Sabine. "Memory, Intermediality, and the (Cognitive) Sciences: ReCognizing Cultural Studies." American Studies as Media Studies. Ed. Frank Kelleter and Daniel Stein. Heidelberg: Winter, 2008. 157-167. Print.

Sontag, Susan. Regarding the Pain of Others. 1. ed. New York: Giroux, 2003. Print.

Spanos, William V. The Errant Art of Moby Dick. Durham: Duke UP, 1995. Print.

Spielmann, Yvonne. "Intermedialität und Hybridisierung." Intermedium Literatur. Eds. Erika Greber and Roger Lüdeke. Göttingen: Wallstein, 2004. 79-102. Print.

Stein, Daniel. "From Text-Centered Intermediality to Cultural Intermediality." American Studies as Media Studies. Heidelberg: Winter, 2008. 181-190. Print.

Sturken, Marita. Tangled Memories. Berkeley: U of California P, 2002. Print.

Thompson, Jon. "Ferocious Alphabets: Michael Herr's Dispatches." The Massachusetts Review 43.4 (2002): 570-601. Web. 05 Aug 2011.

Wagner, Annette. Postmoderne im Adolesženz̧roman der Gegenwart. Berlin: Lang, 2007. Print.

Weisstein, Ulrich. "Literature and (Visual) Arts - Intertextuality and Mutual Illumination." Intertextuality: German Literature and Visual Art from the Renaissance to the 20th Century. Eds. Ingeborg Hoesterey and Ulrich Weisstein. Columbia: Camden, 1993. 1-19. Print.

Wilson, James C. Vietnam in Prose and Film. Jefferson, N.C.: McFarland, 1982. Print.

Winkelmann, Sabine. Intermedialität in Eugene O’Neill's Dramen. Würzburg: Königshausen, 2004. Print.

Winthrop-Young, Geoffry. "Hardware/Software/Wetware." Critical Terms for Media Studies. Ed. M.B.N. Hansen and W. J. T. Mitchell. Chicago: U of Chicago P, 2010. 186-196. Print.

Wolf, Werner. "Intermedialität: Ein weites Feld und eine Herausforderung für die Literaturwissenschaft.” Literaturwissenschaft: intermedial-interdisæiplinär. Eds. Herbert Foltinek and Christoph Leitgeb. Wien: Akademie der Wissenschaften, 2002. 163-193. Print.

—. "Intermediality Revisited." Word and Music Studies. Amsterdam: Rodopi, 2002. 13-35.Print. 
—. "The Relevance of Mediality and Intermediality to Academic Studies of English Literature." Mediality/Intermediality. Eds. Andreas Fischer, Martin Heusser and Andreas H. Jucker. Tübingen: Narr, 2008. 15-43. Print.

—.The Musicalization of Fiction. Amsterdam: Rodopi, 1999. Print.

Yacobi, Tamar. "The Ekphrastic Figure of Speech." Text and Visuality - Word \& Image Interactions 3. Eds. Michèle Hannoosh, et al. Atlanta: Rodopi, 1999. 93101. Print. 



\title{
The 'War on Terror' in Contemporary Hollywood Cinema: Ridley Scott's Body of Lies and Jeffrey Nachmanoff's Traitor
}

\author{
Dennis Edelmann
}

\section{Introduction}

According to Andrew Martin, "Hollywood [...] has shaped, for many of us, the way we perceive contemporary history and the rest of humanity" (112). If this is true, the importance of given Hollywood films dealing with contemporary social, economical, or political issues is evident, and thus renders the analysis of them necessary for an understanding of the discourses they are part of. In this context, a topic that arguably ranks among the most controversial of recent years is the American fight against terrorism under the Bush administration (2001-2009).

The following analysis will show that in the wake of the September 11 attacks, President Bush established a rhetoric and strategy that became characteristic of the so called 'war on terror' and has a lot to say about the American self-understanding and perceived role in the world at the time. Accordingly, it will also be documented how Hollywood initially adhered to the notion of a fight of 'good vs. evil', in which the U.S. action's were at all times deemed necessary, appropriate and morally unquestionable.

After that, this analysis will then also show that with the continuous exposition of details about the way this conflict was being fought, it was slowly revealed that the U.S. did not to occupy the transcendental moral higher ground it had always claimed to have. As will be described, Hollywood slowly but surely started to address the topic more critical in form of releases that questioned the general right- 
eousness of American actions and called for a change in strategy and a different approach of the fight in the first place.

In this context, a closer look will be taken at Ridley Scott's Body of Lies and Jeffrey Nachmanoff's Traitor. Both films express the need for a change in attitude and strategy in the fight against terror and do so in form of an authentic and realistic portrayal of American attitude to and contact with Middle Eastern culture and religion. With an entertaining mixture of action and suspense, which supports the underlying conveyance of themes and messages, they are examples of a process, which ultimately saw popular culture revealing simplistic binary oppositions to "no longer suffice, no matter how adamantly the American government [...] insist[ed] that they do" (Schopp/Hill 37).

\section{The American Self-Image After 9/11}

\subsection{The 'War on Terror', or 'Good vs. Evil'}

With an almost exclusively civilian death toll at close to 3,000, and 6,000 more injured, the events of September 11, 2001 were the single most devastating hostile attack on U.S. soil in its entire history (9/11 Commission Report). As such, they were sure to have a significant impact on both U.S. foreign and domestic politics.

In reaction to the attacks, President George W. Bush and his administration very quickly established a clear-cut binary opposition of a morally superior U.S. being the eternal 'good' and terrorists around the group al-Qaeda being what threatened it, namely the embodiment of 'evil'. In his address to a joint session of Congress and the American people on September 20, 2001, Bush was sure to stress that nothing less than the very essence of American values and beliefs was now at stake as "enemies of freedom [had] committed an act of war against our country" (The White House September 2001). His speech foreshadowed a rhetoric that was to become characteristic of the Bush administration in the following years, as he carefully maintained the dichotomy of 'we' and 'they', and the battle of 'us vs. them'. At the same time, the speech hinted the far-reaching political and military reactions that could be expected from the U.S.

While the president generally saw "freedom and fear [...] at war", he also made clear that for the U.S. in particular "our war on terror begins with al Qaeda, but it does not end there" (The White House September 2001). Thus, for the first time he used what was to become a very controversial term, namely the so-called 'war on terror'. He left no doubt that the strategy it labeled was now the top-priority of both foreign and domestic U.S. policy and would remain so for many years to come.

However, the mere phrasing of the term, which Cynthia Weber would later describe as having emerged from "combining clash-of-civilizations arguments with cowboy posturing" (20), already revealed a fundamental misconception of the 
entire conflict's nature on part of the Bush administration. In essence, "the phrase identified terrorism as America's new enemy [and] implied an objective of victory conquest or suppression of terrorism" (Zelikow 103). But, by doing so, it failed to acknowledge the fact that "terrorism is a tactic and not an enemy or adversary [and that] it can never be completely eliminated, only managed and controlled" (Martin/Andrew 5). Thus, the logic behind Bush's rhetoric already displayed itself to be dangerously wrong. Nevertheless, the deliberately populist term would remain a legitimizing tool for military, intelligence and police actions at home and abroad for many years to come. Regardless of its flawed nature and despite scholars like Noam Chomsky even denouncing it as "propaganda", believing that if the U.S. were to abide by their own definition of terrorism, they would themselves be revealed as "a leading terrorist state" (Chomsky $47 \mathrm{f}$.).

Still, as problematic as the Bush administration's rhetoric can be regarded today, at the time, it hit the right tone for a U.S. public still frozen in a state of shock and that had mutual desire for retaliation, waiting for Bush to fulfill his promise that 'evil' could and would be destroyed.' A prospect, which would quickly take shape in the form of the Afghanistan War, which started in October 2001, and which, only two years later, would be complemented by the Iraq War. Both wars, whose major combat operations were filed under the names 'Enduring Freedom' and 'Iraqi Freedom', respectively, were aimed at securing the 'good' and ultimately civilization itself (The White House October 2001, December 2005, January 2009), since "evil was to be feared and constantly attacked" (Birkenstein/Froula/Randell $16)$ in order to "defend [...] the freedom of people everywhere" (The White House October 2001).

As Richard Crokartt observed, the roots of such thinking and as such the basis for the Bush administration's rhetorical strategy date back to the Jeffersonian Enlightenment, most notably to the Declaration of Independence, which promotes "life, liberty and the pursuit of happiness" and "hold[s] these truths to be selfevident" (Declaration of Independence). To Crokartt, this "presumed self-evidence of the value of and meaning of freedom" is an integral part of the American identity, while "the extension of freedom to others is part of America's 'great mission" (178). The fact that the Bush administration embraced this attitude is evident in various documents such as the 2002 National Security Strategy, which states: "The great strength of this nation must be used to promote a balance of power that favors freedom. [...] And this path is not America's alone. It is open to all." (National Security Strategy 2002)

Thus, it was up to other nations to follow on a mission "we did not ask for [...] but will fulfill" (The White House October 2001) and whose sole initiator could only be the U.S.; a fact of which Bush would remain strongly convinced until

1 Polls showed approval of Bush's presidency to have risen from $57 \%$ to $87 \%$ after $9 / 11$ (New port/Carroll 2002). 
the end of his presidency: "If America does not lead the cause of freedom, that cause will not be led." (The White House January 2009)

In conclusion, America's morally higher ground and the righteousness of all its actions in the fighting of terrorism were deemed unquestionable, self-evident, and only appropriate in reaction to $9 / 11$. Ultimately, the 'good' that was omnipresent in the U.S. strategy even justified war, since it allowed for America to extend its values and beliefs to the Middle East, in order to protect itself by "defend[ing] its own freedom by using liberty to transform nations from bitter foes to strong allies" (The White House January 2009).

\subsection{Bush's Doctrine in Hollywood}

Often times, popular culture picks up on the events that occur and the themes that circulate within its society. In this context, the mere magnitude of a war necessarily occupies a prominent position in the work of film-makers, authors, and artists, especially in America:

Popular culture in the United States is where war comes from and where it is made possible - even desirable - and it is where it ends up, as the lived experience of war is fed back to us in displaced forms and narratives (Martin 108).

A long tradition of Hollywood movies dealing with the various wars the U.S. has engaged in and numerous examples of fictitious as well as factual war scenarios it could engage in shows that this interaction must be taken for granted, especially when it comes to the medium of film.

In this context, the nature of a given portrayal of acts of war relies as much on the individual topic as it does on the particular movies genre. On the one hand, works such as Francis Ford Coppola's Apocalypse Now and Steven Spielberg's Saving Private Ryan show real-life war for the horror they are/were. On the other hand, fictional tales of attacking aliens like Roland Emmerich's Independence Day and a given story around the likes of Bruce Willis and Arnold Schwarzenegger pictures America or the typical white, male American (action) hero as all that stands in evils way. Of course, the latter kind fit Bush's doctrine in the 'war on terror' perfectly, at a time when some believed "the cinema [to be] as much a battlefield in this war as were the ruins [of 9/11] and the cities and countrysides of the soon-to-be bombed Afghanistan, and, later, Iraq" (Weber 1).

According to Mathew B. Hill and Andrew Schopp, the Bush administration was very well aware of the influence the medium film could have on public opinion. Quoting Slavoy Žižek and Susan Faludi, ${ }^{2}$ they sum up its efforts as follows:

2 For a detailed analysis of the cooperation between Hollywood and the Bush administration in the aftermath of 9/11 cf. Susan Faludi, The Terror Dream: Fear and Fantasy in Post-9/11 America 
[T] November of 2001, the White House met with Hollywood executives to explore how Hollywood films could help in sending the "right ideological message" about the "war on terror" and to determine how Hollywood could "help 'communicate' - or rather, market - the new war on terror to the American people" (Schopp/Hill 14).

Thus, naturally, the early stages of the 'war on terror', and, as declared inevitable parts of it, the Afghanistan and Iraq Wars, were accompanied by a range of movies that affirmed the righteousness of American military actions and embraced the theme of an American-led fight of 'good vs. evil'.

For example, a surge of comic adaptations including Sam Raimi's Spiderman series (2002, 2004, 2007), Tim Story's Fantastic Four (2005) and Bryan Singer's Superman Returns (2005) repeatedly addressed the eternal fight of the all-American super hero against arbitrary villains and evil forces. In allegedly more realistic settings, works such as John Moore's Bebind Enemy Lines (2001) and Antoine Fuqua's Tears of the Sun (2003) portrayed the U.S. and its soldiers as humanitarians ready to override international boarders and treaties whenever deemed ideologically required.

In addition, the post- $9 / 11$ atmosphere saw a reinvigoration of a genre, which Mathew B. Hill terms the "techno-thriller":

Indulging in American fantasies of military power and technological achievement, the techno-thriller often features male American heroes using advanced technology and the tools of the military and intelligence establishment to respond, often violently, to threats against their country (Hill 128).

This type of character is most prominently displayed in such figures as Tom Clancy's Jack Ryan, protagonist of films like John McTiernan's The Hunt for Red October (1990), Phillip Noyce's Clear and Present Danger (1994), and ultimately Phil Alden Robinson's The Sum of All Fears (2002). Interestingly, being the only one released after $9 / 11$, the latter most clearly pictures him as the intelligent and determined savior of America and even world peace.

But, as Hill concludes, the one figure that is most characteristic of the genre's "post-September 11 descendant" and as such "one of the more popular means of representing this war [on terror]" (128), is the hero of Robert Cochran and Joel Surnow's TV series 24 (2001-2010), Jack Bauer (Kiefer Sutherland). While each episode of the series is designed to follow one in 24 hours of a day in the life of the member of a (fictional) L.A. Counter Terrorist Unit, Bauer himself is portrayed as the hero who is able to fight his evil counterparts based on the ability to think and fight just "like them, without remorse and without restraint" (Hill 134).

(New York: Henry Holt, 2007) and Slavoy Žižek: Welcome to the Desert of the Real (London: Verso 2002). 
Accordingly, in his fight Bauer time and again struggles with laws and moral obstacles, which, eventually, he is willing to readily bypass in order to stop a given terrorist attack. He simply does whatever is necessary, regardless of having to act against some of the very cornerstones of the American democracy he is trying to rescue and defend, namely the freedom from torture, habeas corpus and due process. It is just this attitude that makes evident the fragility of the concept of American morality in this conflict:

Glorification of these characters as the pinnacle of American heroism in the War on Terror [...] suggests an implicit rejection of such democratic ideals as unnecessary, untenable, or undesirable when facing a determined enemy such as Al Qaeda (Hill 143-144).

Still, such a hero and his sometimes (highly) questionable measures in the fighting of terrorism remained popular ${ }^{3}$ and for quite some time Hollywood would not risk questioning the self-evident dichotomy of 'good vs. evil' in the 'war on terror', let alone even touch upon the topic in form of a major release. ${ }^{4}$

It would require some time, several failures to actually catch (top-)terrorists, the (questionable) modification of laws, and the uncovering of a few very controversial details of the handling of suspected terrorists and prisoners of war to have parts of the general U.S. public's mood change and allow for a more critical discourse and with it some less biased Hollywood movies to be released.

\section{Rethinking the Image}

\subsection{American Duplicity}

As previously described, the post-9/11 atmosphere for quite some time defied the questioning of the Bush administration's ideological and military reaction to the attacks. Eventually, "Americans came to feel that criticism of the Bush administration's action was supportive of terrorism" (Cawelti 210) and "self-assured nationalism and patriotism replaced critical discourses seen as immoral [...], substituting moral uncertainty with moral certainty" (Weber 20-21).

Accordingly, even such measures as the 2001 USA PATRIOT Act which included several severe changes to American legislation in the name of the 'war on terror' were readily adopted. Designed "to deter and punish terrorist acts in the United

3 In 2002, Kiefer Sutherland was rewarded with a Golden Globe for Best Actor in a TV series and with a viewership of 13.7 million for the 2005-2006 season, 24 ranked 24 in the I.T.R.S. report (ABC 2006).

4 Naturally, Hollywood did not necessarily support the Bush doctrine for reasons of propaganda,but rather for economical ones, since a more critical addressing of the topic would have meant risking a box office failure. 
States and around the world, to enhance law enforcement investigatory tools, and for other purposes" (PATRIOT Act 2), it included a range of controversial alterations of and additions to U.S. Code. Its institution, however, did not evoke much controversy in the post-9/11 atmosphere of fear and only seemed to alarm scholars like Mary N. Layoun, who saw it to have "drastically compromised" the rights of "citizen and noncitizen alike", all "in the name of security against terror" (48).

Nevertheless, the general mood in the American public slowly but surely changed, as the ongoing wars in Afghanistan and Iraq continuously took a heavy toll on human lives on both sides, with American forces seemingly unable to establish the promised peace and democracy in the region. While in both countries, the Bush administration had prematurely declared major combat operations to be over (The White House 2003, Rumsfeld 2003), news of U.S. soldiers and local civilians being killed by suicide attacks and car bombs on an almost daily basis proved the actual wars far from over. Especially in Iraq, where in 2004, "the US military stated that they had lost control over many major towns and cities", which, eventually, led to "murmured parallels with Vietnam" (Oliver 40). In addition, the fact that the Bush administration ultimately failed to present any evidence for the initial justification for the Iraq War in the first place, namely the claim "that Saddam Hussein now has weapons of mass destruction" (The White House August 2002), aroused more and more suspicion about the legitimacy of certain measures in the "war on terror'.

The image of a self-evident and unquestionable moral superiority apparent in these measures further crumbled as details about prisoner treatment and intelligence-gathering procedures were made public. The most prominent examples included (the pictures of) prisoners being tortured at the Abu Ghraib prison in 2004 (Grajeda 219), "the open ended detention of prisoners without trial [at] Guantanamo Bay" (Crokartt 184), as well as "the revelation that the CIA had been using secret locations in a variety of countries to interrogate suspected terrorists" (Crokartt 170), a procedure to become known as extraordinary rendition ${ }^{5}$.

Ultimately, all these developments cast a conspicuous shadow on the whole 'good vs. evil' paradigm, as "US actions as narrated in unofficial stories about the war on terror increasingly marked the Bush administration's [rhetoric] as both hypocritical and dangerous" (Weber 89).

\subsection{Criticism in Hollywood}

As the general criticism of Bush's agenda slowly grew Hollywood too started dealing with the controversial topic of the 'war on terror' more critically and more openly. Admittedly, Steven Spielberg's Minority Report (2002) had already somewhat

5 For a detailed description of leaked CIA procedures cf. Horton, Scott. "New CIA Docs Detail Brutal 'Extraordinary Rendition' Process”. The Huffington Post 28 Sept. 2009. Eds. Adriana Huffington, Roy Sekoff and Timothy L. O’Brien. Web. 9 August $2012<$ http://www.huffing tonpost.com/2009/08/28/new-cia-docs-detail-bruta_n_271299.html>. 
criticised the concept of pre-emptive punishment in possible relation to the motivations for the War in Iraq and Doug Liman/Paul Greengrass' Bourne films (2002, 2004, 2007) had left room for the possibility that not all figures in American intelligence were of the generally 'good' nature. Also, while Sam Mendes' Jarhead (2003) was set in the (first) Gulf War, the timing of its release and its telling of the disillusioning experience of a U.S. soldier in a conflict in the Middle East had it appear as a likely (negative) comment on current U.S. wars in the region. Andrew Niccol's Lord of $W$ ar (2005) had even denounced the U.S. as one of the world's largest and therefore most ruthless arms dealers altogether.

But no film directly addressed the country's atmosphere after 9/11 or the 'war on terror' and its moral predicaments. Admittedly, Stephen Caghan's Syriana (2005) could be claimed to have been the very first major film to deal with the topic critically, but at the time, it did not spark a change of thinking in Hollywood. On the contrary, with Oliver Stone's World Trade Center (2006) and Paul Greengrass's United 93 (2006), Hollywood even seemed to continue its adherence to the Bush doctrine in reminding the American people in a most realistic and horrifying manner of just what the reason and legitimacy for this ongoing and difficult war had been and still were.

It was not until late 2006 before Irwin Winkler's Home of the Brave initiated a surge of dramas that directly and critically approached the topic, which included Paul Haggis' In the Valley of Elah (2007), Robert Redford's Lions for Lambs (2007), Brian de Palma's Redacted (2007), and Gavin Hood's Rendition (2007). In addition, 2008 saw the release of another two movies that dealt with the issue and which were of a more spectacular nature, namely Ridley Scott's Body of Lies and Jeffrey Nachmanoff's Traitor. The following analysis will take a closer look at each of them and show exactly how they achieved to address the topic in a previously unparalleled realistic and critical manner.

\section{Ridley Scott's Body of Lies}

In Body of Lies, which is the adaptation of the eponymous best-selling novel by journalist and author David Ignatius of 2007, Ridley Scott pictures the struggle of CIA-operative Roger Ferris in the fighting of terrorism emerging from the Middle East, starring Leonardo DiCaprio as Ferris and Russell Crow as his superior, Ed Hoffman. The action thriller follows its protagonist around various countries of the Arab world, as he is continuously trying to cope with the predicaments that the ideologically impregnated agenda of the 'war on terror' embraced by Hoffman present on his efforts of gathering intelligence in order to stop future terrorist attacks. In this context, a closer look at the film's opening sequence already offers an insight on the different elements with which it comments on the general U.S. attitude towards Middle Eastern culture apparent in its counter-terrorism strategy. 
The movie starts off with a black screen stating a quote from W.H. Auden's poem September 1, 1939, which reads: "I and all the public know, what all schoolchildren learn. Those to whom evil is done, do evil in return". Then, a low drumbeat sets in and a cut to an aerial view of a side street places us in what is supposed to be Manchester, England. What follows is a close-up of an old, grey-bearded man wearing the traditional Muslim headgear taqiyah who gives a determined speech in Arabic, which the subtitles reveal to be the claim of responsibility for past and future terrorist attacks on Americans exercised in order to "avenge the American wars on the Muslim world".

Notably, the word 'Islam' is most clearly distinguishable for the non-Arabic speaker and is accompanied by the setting in of the sound of an Arabic flute, as the camera zooms out and shows his utterances to be a video message to a group of young terrorists emerging from a TV next to one of them preparing a meal and another building a bomb. Also, the spheres of the old man and the young terrorists in the house in Manchester are clearly separated in colors, as the former appears in a warm and slightly brown palette, while the latter is of a rather cold blue and gray tone.

Next, an increasingly dynamic soundtrack underlines a panorama shot of the street around the house having been sealed off by police and a few rapid shots of them preparing to storm the house filmed with a hand-held camera. We follow the police inside, $3 / 4$-shots of them alternate with close-ups of the terrorists speaking Arabic, before music and background sounds die down completely for the terrorists (aware of the coming police) to utter a last "Allāhu Akbar" ("God is great"). Then, a massive explosion pictured from various angles in both panorama shots and close-ups destroys the house, sends debris flying right at us, shatters glass and has people screaming terribly. Needless to say, the terrorists blew themselves up and by doing so also killed the police officers. The camera zooms out displaying destruction and thick smoke rising from the ruins, as again, the sound of an Arabic flute lingers frighteningly over the scene. The screen fades to black and displays the film's title within a rapid collage of unidentifiable aerial images, and the melody is joined by bits of radio conversation in English.

Now, while the use of traditional Arabic instruments and melodies as introduced in this opening sequence will be both a method for and a sign of the portrayal of Middle Eastern culture, the different color patterns employed throughout the movie will also continuously distinguish between the locations that stand in for it and others like the U.S. Also, as is the case here, international locations and terrorist attacks on them will secure the world-wide significance of the story. The different camera movements, the angles, the type of cameras employed and the rapid cutting in between them will make sure to have the movie appear as the action thriller it is designed to be, with the extensive use of aerial images being of notable peculiarity.

The fact that already the terrorists are pictured to have reasons for their actions that are a little more complex than simply emerging from 'pure evil', shows that, 
while not trying to justify their actions, the film will nevertheless try to somewhat display these motivations. In addition, the initial quote immediately suggests that the following movie will blur the lines of right and wrong, as it assumes that just as in World War II, both sides in this conflict are bound to do 'evil'6. Thus ultimately, this introduction hints that the film will paint a more sophisticated picture of morality in this conflict, which critic Peter Travers conceived as the deserved "hard kick in the teeth [...] to American duplicity" (2008).

\subsection{Technical and Stylistic Aspects}

As numerous documentaries and commentaries included in the movie's Blu-ray steel book edition suggest, director Ridley Scott wanted its look and sound to be as realistic as possible, in order to give the film an aura of authenticity ("Master of the Craft: Ridley Scott"). In this context, lighting was deliberately kept as minimal and naturalistic as possible in an effort to almost exclusively make use of lamps and other light sources that were already present on location. For example, yellow street lamps in scenes designed to be located in Middle Eastern countries were not altered, the grim atmosphere of torture scenes is in part created by the use of only a few flashlights or fluorescent tubes, and in the majority of daylight scenes only the sun illuminates the characters and the action.

In terms of location, Scott's emphasis on authenticity is evident in the extensive use of real outdoor sites, especially in scenes set in the Middle East. The fact that the nature of these places could not be more distinct, ranging from the desert, illegal junkyards and small alleys in poor neighborhoods to actual government buildings ${ }^{7}$, results in each location having a different look to it, which perfectly serves the particular scene's atmosphere. At no time does this kind of portrayal feel unnatural or exaggerated, and it is safe to assume that the average American viewer will not even realize that they were exclusively shot in Morocco, which stood in for all Arab countries like Iraq, Jordan and the emirate of Dubai. Of course, the exchange and transformation of street signs and the use of appropriate costumes according to the particular country or region to be displayed intensify this effect.

While other geographical spheres such as Europe and the U.S. are more commonly featured in form of indoor locations, the film makes sure to clearly distinguish it from the Arab world and the employment of different color patterns for the two makes sure to establish them almost as opposites. As the action cuts back and forth between the two, it is obvious that a cold gray and blue tone used for the West remains in stark contrast to a warmer earth-colored, golden, and brownish "toast" (Scott, "The Color of Toast") that is used for the Middle East.

6 With regard to WWII, Tony Sharpe described Auden's poem as "a didactic historical analysis of what has happened" (2007: 23).

7 Allegedly, Scott's repeated shooting of a major picture in Morocco granted him the right to use the rooms of the Moroccan Department of Interior's building to stand in as the headquarter of the Jordanian intelligence Service ("Master of the Craft: Ridley Scott"). 
Considering the camera work and cutting, the rapid alternation of angles, paired with the use of handheld camera footage, quick camera movements and debris and blood flying directly at the cameras makes sure to have the film's action scenes look spectacular and gripping. At the same time, here again Scott paid great attention to detail, with real explosions being hardly enhanced by digital effects and every dent in a car's bodywork being in the right place ${ }^{8}$. The one feature that stands out in terms of the way the movie is shot, however, is the continuous use of aerial images, which often times introduce new locations and constantly complement phone conversations between Ferris and Hoffman.

While such footage most notably displays the constant surveillance of Ferris and his operations by Hoffman, despite the latter being thousands of miles away physically, it also somewhat underlines the technical superiority of the U.S. in this conflict. Designed to resemble the images of unmanned, remotely-controlled drones termed 'predators', of which some 250 are allegedly in use over the Middle East according to Scott's remarks in the commentary, theses aerial shots are used to an extent to which they almost become a character of their own throughout the movie ("Commentary", Scene 3). With Ferris repeatedly looking up at it and sometimes actually addressing it directly by asking Hoffman and the drone's operators to back out to not draw too much attention on him, it is indeed a character which is always present, looking at and lingering over the action.

Considering the cast and their preparation, Scott also made sure to create an authentic atmosphere by working with many actors from the Middle East and having the Western actors learn to speak in proper Arabic when needed. For example, the actress playing Ferris' acquaintance Aisha apparently was the first Iranian woman to star in a major Hollywood film and Leonardo DiCaprio allegedly pronounced his Arabic lines in various dialects so well that it even surprised his language assistant (Scott, "Uneasy Alliance"). Also, regarding the importance of the work of local intelligence services like the Jordanian one, the fact that author David Ignatius had himself met the actual head of the Jordanian secret service and could thus vouch for the authenticity of its fictional counterpart Hani Salaam (Ignatius 2009), awards Scott's portrayal credibility.

Finally, the sound and soundtrack of the movie naturally play an important role for its themes and the atmosphere of a given scene. Explosions and gunshots are loud and horrifying and each time the action gains pace, the soundtrack is sure to go along accordingly, with rocking electric guitars and pounding drums competing with the omnipresent Arabic instruments. As is the case in the introductory sequence, the latter are commonly featured throughout the film, often times aurally placing us in the Middle East, but more importantly serving as device for creating suspense. In this context, the melodies of the flute, or santoor, continuously serve as the menacing background music for terrorist speeches, as well the building up to

8 The documentary "Controlled hostility: stunts and special effects" shows Scott himself hammering the hood of a car, in order to make sure it looks like it was hit by large pieces of debris. 
an aftermath of their attacks. Admittedly, such reduction could be regarded as slightly controversial and would probably tempt film scholars like Corey K. Creekmar who regards the entire soundscape of Hollywood movies dealing with the "war on terror' as "limited and conventional" and only mediating "cultural difference" (91), to claim it only affirms stereotypes.

But, although Body of Lies does in fact use such aural elements and their interaction with distinctively used color patterns in order to establish a certain difference to Western culture, the careful attention paid to the authenticity with which the Arab world is portrayed already rescues it from being stereotypical. Ultimately, such stylistic devices only serve to underline the movie's general themes and messages.

\subsection{Characters, Themes and Messages}

Given the complex nature of the movie's storyline, its themes and messages are best analyzed through its protagonist Roger Ferris. His relation to and interaction with the other major characters serves to explain his character development, and on a broader scale needs to be regarded as a clear statement on the U.S. attitude and strategy in the 'war on terror'. In this context, the relationship to his boss is of particular importance.

The first sequence after the introductory scene already quite strongly establishes the difference between the two. We are in Samarra, Iraq, the current location of operation for Ferris, who is introduced by a panning shot from his feet ending in a close-up of his bearded face. The cut to a few shots of him sitting by while a man is being tortured to death obviously picture some of his memories and thus immediately suggest that he is "already reflecting" and "constantly looking inward" (Scott, "Commentary" Scene 2), struggling with the morality of the measures he has to take as CIA operative. All this is complemented by Hoffman's voice from the off, calmly elaborating on the legitimacy of U.S. presence in the region and the need for its continuation. His utterances display themselves to be a report he is initially dictating to his computer while at home wearing pajamas and bathrobe, shots of which alternate with close-ups of the troubled Ferris.

Hoffman is then shown to give said report to a group of people, which appear to be either his superiors or other influential figures in Washington. This time, his speech goes on accompanying horrifyingly realistic images of U.S. soldiers being attacked on patrol in what is probably an Iraq city, while he is coolly summarizing the terrorists' goals: "They want the universal caliphate established across the face of the Earth and they want every infidel converted or dead." He briefly mentions the difficulty of differentiation between enemy and friend and then quickly stresses the need for intelligence operations to continue in order to keep the U.S. and the world safe, barely squeezing this plea for further support into what little time his counterparts seem to have. 
Thus, this first sequence powerfully pictures the fundamental difference between Hoffman, who is the calculating and confident personification of the Bush administration's ideology, and Ferris, who believes enough in the righteousness of American actions to do his job, but not enough to free himself from doubting the necessity of exercising morally questionable measures.

The film takes great care to constantly uphold this difference, repeatedly cutting back and forth between the spheres of Hoffman and Ferris, which, as mentioned earlier, are nicely distinguished by different color patterns. In addition, their phone conversations usually have Ferris right in the middle of some operation, chase or even shootout, while Hoffman is casually eating cereal, taking his kids to school, or watching his daughter's soccer game. The closest he gets to the action is indifferently watching it on computer and television screens displaying images of aerial surveillance. This results in a complementing opposition of dramatic and loud background sounds and music for Ferris and a calmer soundscape (and in part even the absence of such) for Hoffman.

Naturally, these stylistic devices add to their particular remarks, with Ed repeatedly and dismissively rejecting any criticism of the nature of his operations and the physical and moral dangers these put Ferris in, all the while displaying him to be of shockingly indifferent arrogance toward Middle Eastern culture and also the respect that Ferris has for it. Examples include the justification of not rescuing a local informant as he was merely "a terrorist a-hole, who turned out to be coward who wanted to go to Disneyland", the greeting of Ferris on a visit in Washington, D.C. by asking him if he enjoyed civilization as for being "back from the sandbox" and the explanation of him running multiple operations in secret even from Ferris in context of having to act quickly: "I ain't got time to play patience, Sidi, patience and sit around eating couscous."

Ferris in return grows sicker and sicker of Hoffman's attitude and the trouble it means for him as being the one in the field who has to react to it. While he continuously utters doubts about the practice of retrieving intelligence from informants and then leaving them to be tortured and killed by the terrorists they gave away, it is mostly the difference of perspectives in this fight that enrage him and which he believes Hoffman fails to acknowledge:

I am thinking straight. You're not, alright? You can't because you're a million fucking miles away. I'm here Ed, every day. And I see the unnecessary travesties of this war that the rest of you backstabbing political fucking bureaucrats only look at pictures of.

Thus, the contradiction of the U.S. approach embodied by Hoffman, which one critic described as "a creature of flabby immorality [...] acting like the master of the Middle Eastern universe" (Turan 2008), while his actor Russell Crowe sees him as "symbolic for American policy" ("Debriefing"), and A.O. Scott even as an analogy to George W. Bush himself (2008), is what forms the core problem of the 
relationship to Ferris. It is this difference in attitude that is very much apparent in the way they each deal with prospective local allies.

After the first operation in Iraq has almost killed him, Ferris is send to Jordan in order to contact the head of the Jordanian secret service, Hani Salaam. In this context, while Hoffman disrespectfully refers to Hani's intelligence by characterizing him as not being "your run-of-the-mill fingernail puller", Ferris is shown to be much more aware of the necessary respect with which someone like Hani needs to be met. For example, much to Hani's appreciation, Ferris immediately awards him "a personal honour" (Forbes 188) by addressing him with the traditional title of pasha. Also, whenever Hani tries to explain that he is as much an enemy for the terrorists as are the Americans he is helping, Ferris finishes the religious quote that describes this circumstance in perfect Arabic, ending reassuringly: "[W] are together in this house of war, Hani Pasha, yes."

The fact that Hani is very much satisfied to see in Ferris someone that is "smarter than the Americans who are usually sent to Amman", showing respect for his elders and speaking Arabic, suggests that it is this kind of approach that is needed on part of the Americans in order to successfully cooperate with local intelligence services. At the same time, Hani's entire appearance, including clothes and every move, gesture and utterance, convey a strong aura of pride and confidence, which led critic Mick LaSalle to see in him "a character of conscience and refinement, set up in contrast to his slovenly American counterpart [Hoffman]" (2008). Accordingly, there is absolutely no doubt about the fact that it is he who is in charge of operations here. Repeatedly calling him "my dear", Hani makes sure to make Ferris understand that he should better not lie to him, as the seriousness of the statement is underlined by its repetition captured in a close-up of Hani's determined facial expression. This results in a seemingly intimidated Ferris having to realize that mutual trust is what is most important for their cooperation.

Needless to say, Hoffman's approach toward Hani is of a very different nature. While, as usual, he is operating from a room full of TV screens and computer monitors, Hoffman seemingly very much enjoys his running of multiple operations that both surprise the unaware Ferris, and at the same time act against Ferris' and Hani's agreements. Of course, whenever Ferris tries to make him understand the importance of the promises he has made to Hani, Hoffman could not care less, with his ongoing addressing of Ferris as "buddy" appearing more patronizing than ever. At the same time, he fails to realize the consequences that his actions have for Ferris on the ground, who, as we learn from the fact that Hani has him witness the "punishment" of one of Hoffman's men, is put in great danger by Hoffman's indifference. Finally, he leaves no doubt that he simply does not care about what Ferris repeatedly tries to stress, namely the fact that they need to earn Hani's trust in order to get his help: 
Ferris: $\quad$ Ed, listen, Hani does not trust you. Arabs will only help you if they trust you.

Hoffman: What, are you moving here? I don't care about cultural in security issues. I don't care if Hani trusts me or not.

In this context, this arrogance toward the necessary respectful treatment of local allies is most evidently displayed in the way Hoffman meets Hani on the rare occasion of being in the Middle East himself. Despite having been told otherwise by Ferris in advance, Hoffman shows no sign of respect in giving no greeting whatsoever to Hani before going straight into asking for intelligence on a prospective informant. To the embarrassment of Ferris, he does not even say the informant's right name, and in an effort of stressing his power threatens to have the U.S. president call the Jordanian king to resolve the matter. Hani, however, is not at all tempted by Hoffman trying to talk down to him. He calmly refers to him being the king in matters of intelligence, and more generally relates to the necessity of operations remaining secret, refusing to give up any information to the utterly disrespectful Hoffman.

Symbolically expressed by Ferris translating Hani's Arabic 'no' to Hoffman, it is quite clear that Hoffman's approach could be seen as the exact opposite of Ferris', and as such doomed to fail. While his belief of Hani being "bright, but arrogant” is rightly suggested by Ferris to apply to himself, Hoffman's attitude is pictured as not at all suitable for this environment. It seems as though it takes someone like Ferris, who much better understands local culture, with its values and beliefs, to respectfully and thus successfully cooperate with people like Hani.

In this context, the fact that Ferris emerges into the local culture to an extent that surpasses the need to operate in secret is most notably displayed in his relationship to the local nurse Aisha. While this love story was allegedly designed "as sub story for Women's rights in the Islamic region" (Scott, "Commentary" Scene 15), the fact that -compared to the book- director Scott changed the woman Ferris meets from being an American working in a refugee camp to a local woman altogether, hints that it must be seen as symbolic for Ferris development. Adding to such details as his perfect Arabic, his wearing of a beard much like the locals' and sometimes the odd sign of something like his Coke bottle being the only one with Arabic inscription in an American military hospital, this story-within-the-story pictures just how much Ferris is ultimately embracing Middle Eastern culture. As a result, he more and more finds himself struggling with the want of not having to lie to Hani and rescuing local informants from torture and death, while at the same time having to work with Hoffman in order to get to top-terrorist Al-Saleem.

Frustrated by the fact that Hani does not want to cooperate with him, Hoffman carries out another operation behind Ferris' back, which leads to a safe house with alleged terrorists being abandoned and one of Hani's informants (which Hoffman also wanted to get to) disappearing. But again, Hoffman refuses to admit 
any mistakes and answers Ferris' complaints by claiming that his actions, as opposed to Hani's, are part of the bigger picture in the world-wide fighting of terrorism: "Hani's interests extend only to his little fiefdom. Mine are global." Of course, such phrasing once more displays just what little respect Hoffman has for local allies like Hani and to what extent he believes in his own (moral) superiority.

Interestingly, though, it is Ferris who then comes up with the plan of faking a terrorist attack in order to attract Al-Saleem's attention and doing so without the knowledge of Hani. As he has an innocent local architect look like the terrorist responsible for an attack on a U.S. military base in Turkey, the victims of which are bodies from the local morgue, Ferris himself displays to be ready to take highly questionable measures in this fight. But, as opposed to Hoffman, he is very much enraged by not being able to protect the alleged terrorist he fabricated from being caught and killed by the real ones. Thus, he does have a moral conscience, a fact which is also evident in how much he hates having to admit to Hani that he has lied to him. Hani himself is more upset about the lie than the failed attempt to get closer to Al-Saleem, and his refusal of helping Ferris, who in the meantime discovered that Aisha has violently been abducted, by now feels almost deserved, considering the numerous times Hani has asked for Ferris' sincerity.

In addition, Hoffman, who only sees the possibility of getting to Al-Saleem in the context of Aisha's abduction, finally proves unable to secure or rescue Ferris. While Ferris lets himself be taken hostage in exchange for Aisha, the dust that is blown up by the terrorists' jeeps circling him in the desert deprives Hoffman of his so far effective tool of aerial surveillance. The fact that Hoffman is only able to utter a hardly convincing "sorry, buddy" as he cannot further aid Ferris, proves that ultimately, he cares as little about Ferris' fate as he does about the ones of informants. In the end, the metaphorical 'body of lies' that Ferris has created comes back to punish him and it becomes clear that he should have rather trusted in Hani than in Hoffman.?

This notion is also evident in the appearance of Hani's informant during the terrifying scene showing Ferris almost getting killed by the terrorists. Placed sitting at a table opposite of a camera in front of a flag with Arabic caption, the scene shows Ferris and Al-Saleem in climactic conversation, while a grim atmosphere results from the use of only a few flashlights as illumination in an otherwise dark cellar. While Al-Saleem rejects any criticism of his actions being against his religion and terrorism in general as a mere slave to capitalism, it is mostly his calm manner that has him appear utterly menacing. As he openly reassures Ferris in perfect English that the sole purpose of this situation is to kill Ferris in front of the camera, we can be as sure as Ferris himself that this scene, which ultimately resembles the horrible videos of actual beheadings of terrorists' hostages, will have Ferris dead in

9 Of course, in this context the film's tagline "Trust no one. Deceive everyone." appears very much ironic as it is just this attitude that leads to its protagonist's doom. 
the end. It is only the sight of Hani's informant standing among the terrorists and a quick flashback to his 'recruitment' that has us hope for a rescue of Ferris.

However, just as Ferris, we cannot be entirely sure about whether or not he is going to be saved. Admittedly, Ferris has gained new confidence by this sight and even tempts Al-Saleem to lose his composure for a moment in cutting off one of Ferris' fingers. But at the same time, Al-Saleem leaves no doubt about the fact that nobody is going to rescue him, cuts off another one of his fingers announcing "welcome to Guantanamo", and then exits the room for Ferris to be straightened out on the table. Slow-motion shots of the terrorists holding down Ferris, who is screaming with pain and struggling for his life, alternate with flashbacks of him witnessing the torture of prisoners himself, and shots picturing the situation from the point of view of the terrorists' camera suggest that he is about to die after all.

Of course, in this context, the pairing of these images, as well as the mentioning of the U.S. detention and abuse of prisoners in Guantanamo Bay clearly gives a nod towards the immoral use of torture being a measure that renders both sides in this conflict 'evil'. Accordingly, the fact that throughout the entire movie the main terrorist is shown as being a calm, calculating and intelligent family man rather than a mad 'evildoer', does not render his or more generally all terrorists' actions less despicable or even justified. It does, however, suggest more complex reasons behind them than those that were given by the Bush administration. According to producer Donald Deline, the filmmakers' aim was to express just this to counter simple demonization: "It was important to show how people's different realities create these divides. You really need to be able to understand both sides. [I]t will help toward understanding and having a dialogue." (2009)

The agonizing suspense is finally dissipated by soldiers storming in shooting the terrorists and saving Ferris. However, it is the calm-as-usual Hani entering the scene that displays to have saved him, and not Hoffman. Accordingly, Hani is also the first one to visit him in the hospital, all the while quite obviously enjoying his superiority over Hoffman in this situation: "Edward could not find you. Not with all his aircraft, all his people, all his money and joie de vivre." Moreover, he has Ferris realize that it was his informant who granted him access to Al-Saleem and with it the rescue of Ferris, while he also tricked Ferris into letting himself be taken hostage in the first place, all resulting in the final capture of Al-Saleem. Naturally, we feel sorry for Ferris as for having been played on, but the efficiency of Hani's (sometimes admittedly questionable) methods also leaves us with the notion of the possibility that the work of local intelligence services can be more effective than that of its American counterparts. ${ }^{10}$

In a final conversation with Ferris, it then becomes clear that Hoffman is unable to understand the value of the respectful cooperation with locals and will always cling to a notion of American foreign policy that is simplistic and wrong.

10 The opinion that Americans do not know enough about the region and culture of the Middle East, itself the self-proclaimed main message of his book, is also most evident in the Blu- Ray extra "David Ignatius: Author Provocateur". 
While he promises Ferris a future job that involves "no sunscreen" and "no couscous", he fails to understand Ferris' suggestion of the fundamental problem being that people like him see nothing to like in the Middle East. In addition, Ferris clarifies that he should better not mistake his idea of American values and the necessary manner with which these need to be defended to be that of all Americans:

$\begin{array}{ll}\text { Hoffman: } & \text { Ain't nobody likes the Middle East, buddy. There's } \\ \text { nothing here to like. } & \text { Hmm. Well maybe that's the problem right there, } \\ \text { Ferris: } & \text { isn't it Ed? Good luck on winning this war, Ed. I } \\ \text { hope everyone thinks you did it all by yourself. } & \\ \text { Hoffman: } & \text { You walk out on me, you know what that means. } \\ & {[\ldots] \text { Means you're giving up on America. }} \\ \text { Ferris: } & \text { Just be careful calling yourself America, huh, Ed? } \\ \text { Hoffman: } & \text { Nobody is innocent in this shit Ferris! }\end{array}$

Thus, ultimately, Ed presents himself to be the embodiment of an arrogant, selfrighteous U.S. attitude and strategy that neither functions well in this region of the world, nor is to be understood as representative of every American's self-image. At the same time, he also ultimately admits that there are morally questionable measures taken on all sides.

The movie ends with Ed eating sushi while indifferently ordering to stop monitoring Ferris buying sweets in a market, with rapid shots of a continuously zooming-out aerial surveillance as the last images before the credits start to roll. On the one hand, this suggests a promising future for Ferris as having finally escaped the 'body of lies' around him, symbolized by the end of Hoffman's constant surveillance. On the other hand, it also leaves us with the revelation that Ed will not for a moment consider any of what Ferris has said to him, much less change his attitude. Rather, U.S. mistakes and failures will continue as long as a fundamental change in the ideological approach of the conflict that is the 'war on terror' is not made. This impression is exactly what Jeffrey Nachmanoff's Traitor also addresses.

\section{Jeffrey Nachmanoff's Traitor}

With Traitor, first-time director Jeffrey Nachmanoff pictured another film that is centered around the notion of the lines of 'good' and 'evil' being prone to blur easily in a conflict as complex as the 'war on terror'. Released about two months earlier than Scott's Body of Lies, ${ }^{11}$ Traitor is largely based on an idea of executive

11 The fact that the two films were produced and released at almost the same time is the reason why this analysis does not treat them chronologically and does not assume them to have had much influence on each other concerning style or themes. 
director Steve Martin, better known for his status as comedian, and was elaborated by Nachmanoff. Allegedly relying on the knowledge of numerous academics, authors, as well as espionage and intelligence experts (Nachmanoff, "Interview"), the movie pictures Don Cheadle as Samir Horn, a U.S. undercover agent, who is constantly torn apart by the mutual adherence to his Islamic religion and the duty to his country.

While "Horn might have the honor of being the first Muslim action hero in an American big budget film" (Harmanci 2008), the film feeds mostly on leaving open the possibility of him being a double agent. It does so in cutting back and forth between his immersion into a terrorist cell and an FBI unit around agents Roy Clayton (Guy Pearce) and Max Archer (Neil McDonough) chasing him around the globe. With Horn going as far as executing a terrorist attack himself, it takes until about half way into the movie before we can finally be sure that he has not switched sides.Even then, the fact that the FBI chasing him remains unaware of his real intentions further fuels the action and makes sure that the general theme of lies and deception that is central to any spy story is explored to the utmost.

Of course, as in Body of Lies, the movie's action scenes, including Horn and the terrorists violently being freed from prison in Yemen and repeated explosions of their bombs killing innocent civilians, look and sound spectacular and ensure it also is a gripping action thriller. But, at the same time, long conversations about the nature and justification of both the terrorists' and the American measures taken in this conflict, result in it being what critic Josh Rosenblatt described as follows:

[A] rare Hollywood creature: an action picture with ambiguity, a blockbuster with more questions than answers, a shoot 'em up thriller with a sense of moral and geopolitical ambivalence (2008).

Accordingly, the film also contains numerous slower paced scenes, which seem to aim at taking a look insight the belief system that underlies the actions of such terrorist groups as al-Qaeda. While it does not at all justify them, it does, just like Body of Lies, try to somewhat display them, suggesting their emergence to be highly complicated and not as simplistic as the Bush administration demonized them to be. In addition, with one of its major questions also being how far one is willing and morally allowed to take this fight, it gives direct nods toward the U.S. itself sometimes conducting highly questionable measures. Thus, ultimately, the film expresses a message, which Horn, asked by his wife to tell her the truth about his intentions, summarizes as this: "The truth is, it's complicated." 


\subsection{Technical and Stylistic Aspects}

With a budget of about 22 million dollars, Traitor cost less than a third of how much was spent for Body of Lies. ${ }^{12}$ As a result, its look is naturally somewhat different. In Body of Lies, careful attention was paid to the constant use of multiple cameras, from which Ridley Scott switched back and forth in order to be able to show numerous angles, mostly during action scenes. By doing so, he could then cut quickly from one to another and have a given scene appear fast-paced and spectacular. Of course, in order to employ this technique, Scott needed multiple camera crews operating at the same time, all the time.

For Traitor, on the other hand, director Jeffrey Nachmanoff often only used one or two cameras at a time, with cuts between them being significantly less frequent As a result, the entire movie appears slightly slower in pace, often times allowing actor Don Cheadle to make use of the smallest gesture or facial expression to have us wonder about his character's intentions during the many long close-ups of him. In addition, Nachmanoff claims to have used only a very small crew for most scenes, in order to be able to film his protagonist using only a handheld camera that follows him around the various locations ("Commentary" Scene 2).

In this context, the use of a smaller crew apparently allowed for the employment of a filming technique Nachmanoff terms "guerilla filming" ("Commentary" Scene 6), and which consists of simply going to actual places such as crowded streets in Marseille or the London underground to film without official permission to do so. Naturally, a scene that has been filmed this way does have a slightly more authentic look to it, as it is likely that the 'use' of actual pedestrians as extras will result in a given location appearing more natural than it would after having been fabricated to look a certain way. Accordingly, while the film, just as Body of Lies, used Morocco as stand-in for Yemen and thus the general Middle East, it makes sure to portray its locations in a most authentic way.

In accordance to an authentic portrayal of the Arab world which Nachmanoff and the producers claim to have aimed at (Nachmanoff, "Interview"), Traitor, much like Body of Lies, was careful to cast many actors from the Muslim community. Examples include British actress Archie Panjabi (Samir's wife), long-time Bollywood actor Alyy Khan (Fareed), and most notably French-Moroccan actor Said Taghmaoui (Omar). Also, Nachmanoff paid great attention to detail concerning the right representation of the Arabic language in having his protagonist speak proper Arabic, while in the Blu-Ray's commentary he even apologizes for some of the extras not talking in a proper dialect ("Commentary" Scene 3). Although Nachmanoff's claim to have talked to numerous authors and academics in order to authentically represent the Arab world cannot actually be verified, the fact that just like Ridley Scott, he was very keen on not falling into stereotypes of Arabic por-

12 IMDB estimates the budget of Body of Lies at about 70 million dollars. 
trayal, suggests, that he is very well aware of the necessary credibility that his display needed to convey.

As mentioned before, the movie, like Body of Lies, tries to pair this authenticity with entertainment in form of action in order to be what producer David Hoberman coins "a thinking man's thriller" ("Interview”). But, compared to Body of Lies, this action element seems even less important, as it deliberately takes a somewhat subordinate role to the mystery around Samir and thus ultimately the general topic of the movie, which director Nachmanoff believes to be a character drama within the framework of a modern political subject ("Interview"). Accordingly, concerning its images, Traitor is also less of a techno-thriller than Body of Lies in that it does not at all include a comparable amount of images of aerial surveillance suggesting a significant technological superiority on part of the U.S. in this conflict. Rather, the one image that seems most characteristic is the close up of Samir, who, as opposed to Roger Ferris, is never backed-up by a superior monitoring him.

Interestingly, the movie also uses different color patterns in order to distinguish the geographical location of a given scene. It does so in a very similar way to Body of Lies, with action set in the Middle East being of a kind of warm yellowish/brownish beige tone, and its American counterparts being significantly colder in a bluish gray. While critic Reyhan Harmanci believes this use of color patterns to simply be "bowing to convention" (2008), it nevertheless is very important for the distinction of the two cultural spheres. Of course, on a more pragmatic note, it helps to not get confused about the complexity of the plot, but more importantly, it maybe even subconsciously reminds us of a certain difference between them that is both origin of and fuel for some of the movies' themes and messages.

In addition, this alleged cultural difference is enhanced by the use of Middle Eastern instruments and melodies in the soundtrack. But, as opposed to Body of Lies, it is not mostly used in order to aurally place us in the geographical region. Repeatedly underlining close-ups of the thoughtful and seemingly self-reflecting Samir, the sounds of this music also symbolically represent his ongoing moral struggle resulting from being caught in between his religion, which is deeply rooted in Middle Eastern culture, and the duty to his country, itself rooted in American culture.

\subsection{Characters, Themes and Messages}

After the roll of the opening credits and the film's title presented along with kaleidoscopic images of oriental structures, we are introduced to the main character Samir through a flashback to his childhood. His growing up in Sudan of the late 1970 s is depicted as peaceful and faithful, as he is shown to pray and play chess with his father, all the while joyful African-style music is playing in the soundtrack. But suddenly the atmosphere changes, as he has to witness his father being killed by a car bomb, leaving him alone in the face of terror. The close-up of his terrified self as a boy cuts to the grown-up Samir, resolutely driving through a city in 
Yemen in what is supposed to be the "present day". We follow him into a terrorist safe house and witness him easily countering suspicions about his intentions in claiming to want to sell them explosives and also show them how to use them without blowing themselves up "unintentionally". A warm greeting by what appears to be the older terrorist leader suggests Samir has known him for a while, before suddenly a police raid sends them all fleeing. Some of the terrorists, including the older man, get shot, while Samir is knocked out, the screen fading to black just like his conscious.

Of course, this opening sequence strongly establishes the mystery that is Samir's identity as deeply rooted in his biography. The movie leaves open the possibility of him being a double agent of some kind right from the start, since he could easily be acting in order to avenge an American-led attack on an alleged religious fanatic. After all, the backgrounds behind the car bomb that killed his father are never revealed, the only other direct reference to it in the entire movie being an FBI agent causally saying it remains unclear what side was behind it. At the same time, his perfect English and the slight mocking of the terrorists' actions also suggest him having come into contact with Western, or rather American culture. Thus, despite the fact that he is seemingly not at all intimidated by the terrorists' suspicions about him being a possible traitor (much like the film's title already suggested), we cannot be sure about his actual intentions. Ultimately, we are left to figure out what side he is on, with the notion of truth in the movie already showing itself to be as complicated and even twisted as the initial kaleidoscopic images symbolically suggest reality to be.

The following interrogation of Samir by the two FBI agents Clayton and Archer, who were previously shown to be part of the raid that resulted in his capture, then further adds to the mystery around his character. Asked about the reason for trying to sell explosives to terrorists, Samir again leaves open the possibility of being anti-American:

Samir: I sell them to whoever can afford to buy. Like the United States government.

Archer: $\quad$ Only ours don't kill innocent people.

Samir: $\quad$ Oh yeah, they do, genius. People just usually have darker skin.

Of course, we later learn that he needs to disguise himself from the FBI in order to operate undercover, but the disapproval of the idea of the U.S. always doing 'good' will remain part of his character. As such, it is one of the film's first nods towards the duplicity inherent in American policy.

This notion is also symbolically expressed in form of the fundamentally different characters of the FBI agents Clayton and Archer. A few shots of them among the local police prior to the previous raid already showed Archer to be an ignorant cowboy refusing to give up his gun, while Clayton was introduced as much more 
aware of the necessity of meeting the locals with respect. Symbolically nicely separated by wearing black and white shirts, respectively, Archer and Clayton were thus shown as almost opposites concerning the ability of understanding the local culture. This impression endures as some of his utterances reveal Archer to be utterly disrespectful towards Middle Eastern culture, rendering him the arrogant American similar to Ed Hoffman in Body of Lies.

For example, he apologizes for hitting Samir during investigation saying "I must have forgotten my Bill of Rights at home", mocks a suicide bomber who survived by ridiculing the prospect of waking up in paradise, rejects any efforts of trying to learn Arabic by claiming to be only picking up "your basic jihadi", and never once doubts that Samir could be anything but a terrorist. Clayton, on the other hand, is portrayed as much more sensible and not near as narrow-minded. He understands the value of putting psychological rather than physical pressure on suspects, and puts into perspective Archer's views on suicide bombers referring to the $\mathrm{Ku}$ Klux Klan burning crosses as an example of Christianity also having "more than one face". In addition, he is revealed to be a minister's son having gained a $\mathrm{PhD}$ in Arabic studies and for a long time seems to doubt that Samir is merely a terrorist. Thus, ultimately, this difference between the two agents, which their actors Neil McDonough and Guy Pearce perceive to symbolize the 'old' and the 'new' FBI ("Interview"), is necessarily also a statement on a needed change in strategy in the gathering of intelligence on possible terrorist attacks.

The film also criticizes another aspect of the work of intelligence agencies, namely the lack of communication between them, which often times complicates their individual efforts or even renders them impossible. This notion, which Nachmanoff regards as one of the movie's central themes ("Interview"), is most evidently displayed in the scene picturing different members of various intelligence agencies in a meeting in Washington, D.C. Here, Clayton shares information on a possible terrorist attack about to take place inside the U.S., only for another agent (his identity is not revealed) to admit that his agency has long known about an imminent threat. A short argument about the need of sharing information sparks until another man in suit steps in and reassures the White House's wishfor "everybody working together on this". Thus, evidently, the movie quite strongly suggests that these agencies are not nearly as efficient as they could be if they would only manage to work together. Of course, this is also expressed in Samir having to remain undercover even from the FBI for fear of being exposed as American undercover, while the one person that knows about his real intentions, a freelance agent for the CIA named Carter, never admits having an agent inside the terrorist network.

Again, the manner with which this agent emerges into the terrorist cell is of course what generates the most suspense in the movie. In this context, it is most of all Samir's strong Islamic belief that is interesting, as it not only attracts the terrorists' attention, but at the same time continuously has us wonder about whether he actually is an American undercover agent after all. Having refused to cooperate 
with Archer and Clayton in the beginning, he is imprisoned in Yemen, where ongoing shots of him in prayer, and the defending of an old man against bullies by referring to God being the only one able to decide over life and death, show him to be just as religious as the locals, if not even more so. His strong belief catches the attention of Omar, the young terrorist that had initially doubted his intentions of wanting to sell them explosives in the first place, who slowly realizes the value of both Samir's intelligence and his religious submissiveness. The conversations they share over playing chess show them to have a mutual influence on each other.

On the one hand, we see Omar trying to remind Samir of jihad being his duty, referring to the Americans also once having been terrorists to the British. The fact that he does not explicitly reject this idea, despite, as we know, having formerly been a U.S. soldier, shows that Samir is struggling with an inner conflict of different belief systems. All we are allowed to see are repeated close-ups of Samir, who seems to constantly be in a state of doubting his own actions, and we still cannot be sure at this point whether or not he might be tempted to actually join the terrorists for real. At the same time, their talks also have Omar thinking, who we learn was educated in a boarding school in Switzerland, is dreaming in English, and sometimes does not feel at home speaking his own language. Naturally, this comes as a surprise not only to Samir, but also to us as it leaves a very tiny possibility of Omar not being the stereotypical fanatic terrorist he first appeared to be. Ultimately, their relationship already suggests the further blurring of the lines of 'good' and 'evil' that the movie aims at.

Just how much Omar values their friendship is evident in him taking Samir with him when they are freed from prison. They board a ferry to Marseille and Omar invites Samir to join his terrorist cell, but asks him not to "decide lightly" as their "path is not for everyone". Once more, a cut to a close-up of Samir apparently considering the consequences this will have for him leaves us unable to decide whether he is just playing his role to stay undercover, or if he is actually thinking about becoming a terrorist. In the end, he does join Omar, but the way he encounters his superior, Fareed, hints that his belief in Islam is so strong that ultimately it will not allow him to kill civilians, which is the very aim of the terrorists he now surrounds himself with. Deeply confused by Fareed claiming the drinking of alcohol a necessity in order to blend in, Samir refers to a fundamentally wrong interpretation of the Quran, and is once more pictured as much better understanding their mutual religion.

Nevertheless, the extent to which Samir proceeds to actively take part in the terrorists' actions once more has us doubt his intentions. For example, in a scene that shows just how persuading the terrorists can be in luring young men into becoming suicide bombers, mixing the fun of playing soccer with the ongoing preaching of a necessary fight against the U.S., Samir joins actively. Admittedly, his claim that a man, who is not afraid to die can never be defeated, no matter how big the empire he is fighting, is more moderate than Samir's previous utterance, who accused Americans of having "spill[ed] the blood of innocent Muslims for dec- 
ades". However, it is just as convincing, a fact which is symbolically expressed by a young French boy summarizing the argument as follows: "America has planes, missiles and bombs. But we have God on our side." Thus, with the boy then becoming a prospective executer of an attack, Samir is partly responsible for the 'creation' of such a suicide bomber.

Accordingly, the central question more and more becomes how far Samir is willing and able to go in case he is actually an American undercover agent. The movie continues to uphold the mystery around his intentions, alternating scenes showing Samir inside the terrorist cell with sequences of Clayton and Archer questioning his mother and wife and gathering background information on him.Although it is not clear whether Clayton fully believes in him being a terrorist, Samir nevertheless becomes a prime suspect for the FBI, while Fareed is pleased to have his own investigation on him also suggesting that he really is one of them. What adds to further confusion about Samir is the fact that he himself comes up with the plan of how to execute an attack on the American consulate in Nice. He does so pushing to have the terrorist cell take action, despite the initial plan including the boy as suicide attacker having failed.

At the same time, however, Samir insists on the use of a remote detonator, and combined with the tiny nod he gives the boy towards escape from getting killed for the exposistion of the imminent attack, this still leaves the possibility of him wanting to avoid any casualties whatsoever. Then again, he could not stop the boy getting killed and the determination with which he builds, plants the bombs, and eventually pulls the trigger once more raises the question of whether an undercover agent would go this far. The fact is we still cannot tell, since Don Cheadle's acting skills simply leave open the possibility of his character being able to be both 'good' and 'bad'.

What finally gives him away, then, is his reaction to the news about the attack he carried out having killed eight people. Despite claiming that his shock about this outcome is merely due to the fact of having hoped to kill many more, his facial expression suggests that he really is terrified by his own actions. This notion is also evident in him quoting Martin Luther King when Omar once more tries to remind him that their actions as terrorists are for the benefit of their people and religion. Eventually, it is clear that while a close-up lingers on the utterly sad and seemingly self-reflecting Samir, his embracing of the value of finding something worth dying for (as expressed in his quoting of one of the most famous American free rights activists) is not meant to be the joke Omar perceives it to be. Evidently, for him such a cause is not the terrorists' actions, which to him are clearly based on a wrong interpretation of their religion, but much rather the stopping of them.

As the next scene reveals, what is the most troubling for Samir is not the need to play his role of determined terrorist, but the need to act against the values of his religion in order to uphold this cover. Taking great caution not to be followed, he meets with Carter, and it is revealed that the bomb Samir set off was not supposed to actually kill anybody. Instead, a few corpses should only make it look real, ren- 
dering this measure very much similar to the staged bombing in Body of Lies. In this context, Carter seems hardly concerned by the outcome of having killed a few construction workers, claiming they could not control everything and reassuring Samir of such measures being necessary in order to further advance inside the terrorist cell and ultimately get to top terrorist Nathir. Thus, what he fails to understand is that he puts Samir into a situation of incredible struggle between duty and religion, with shots of him in desperate prayer for forgiveness stressing the seriousness of him now being responsible for having killed innocent civilians.

Nevertheless, Samir goes on and meets Nathir, who is portrayed as calm and thinking strategically, describing terrorism as "theatre" which is performed for the American people in order to provoke an American military reaction that will in turn generate more support for the terrorists. In this context, Samir is supposed to arrange the bombing of dozens of overland buses going through the U.S. on the same day, an attack designed to have Americans everywhere in fear. Of course, this means that Samir once more has to decide just how far he can and needs to go as American undercover with a strong Islamic belief. Again, Carter is not near as concerned as he is, as is evident in their second conversation. While Samir is deeply troubled by the possible need of giving the terrorists actual bombs in order to keep his cover, Carter once more expresses his willingness to take any given measure in order to stop them in the long run:

$\begin{array}{ll}\text { Samir: } & \text { How far are you willing to take this? We've got } \\ & \text { blood on our hands. We've killed innocent people. } \\ \text { And if we stop now, they'll have died for nothing. } \\ \text { Carter: } & \text { This is a war. You do what it takes to win. } \\ & \text { You know what you sound like, right? } \\ \text { Samir: } & \text { We're the good guys. } \\ \text { Carter: } & \text { Oh, I know. } \\ \text { Samir: } & \text { Remember who you answer to. } \\ \text { Carter: } & \text { I answer to God, we all do. }\end{array}$

Thus ultimately, Carter, whom his actor Jeff Daniels understands to be symbolic of "the old spies [...] blending in while doing whatever it takes" ("Interview"), is pictured to be just as convinced about the righteousness of questionable measures being required to be taken in this 'war on terror' as is Ed Hoffman in Body of Lies. As Samir rightly mentions, this is an attitude that renders him no different from the 'evil' he is fighting. To Samir, only God is the one true 'good' and neither side should be claiming to act in order to defend a self-declared superior version of it.

As the further plot shows, Samir is willing to fight for his beliefs, even if it means having to cooperate with the terrorist for a while longer, with his cover requiring him to both lie to his wife and deceive Clayton and the FBI. Accordingly, he travels around the country and hands out bombs to prospective suicide attackers and eventually cannot show any emotions when Omar kills Carter, who bursts 
into a meeting of him and Omar. Rather, he has to even be happy about being put on the FBI's high value target list, since it means that his cover is not yet blown, despite him having met his wife, which Fareed perceived to be a sign of him being an unnecessary liability. In the end, the film cleverly plays with elements of dramatic irony and leaves open the possibility of Samir again killing innocent civilians in order to remain undercover. After all, it is only the last twist, which shows him to have put all bombers on the same bus, that finally also reveals to the other characters what we already knew: he never wanted to kill anybody in the first place, only Nathir and Fareed.

More importantly, though, the last conversations with him show Samir to not have given up on Omar understanding the wrong in what the terrorists do. As their talk about the need of resisting temptation shows, Omar really seems to reflect somewhat:
Omar:
You know, it's true what they say, war is the lesser jihad. To overcome temptation, to live rightly, that is the great jihad.
Samir: Is that what we've been doing? Did you ever ask yourself that?
Omar: $\quad$ Sometimes. But Nathir is the leader and my duty is to follow.

Thus, Omar is intelligent enough to see that the term jihad "has had other, more temperate, inflections in Islamic history" (Crokartt 77). But at the same time, he feels the need to follow his leader in accepting a wrong, more aggressive interpretation. Naturally, Samir tries to convince him to see this abuse of their mutual religion, an effort which is pictured one last time during the stand-off of the two that follows Samir having shot Nathir and Fareed.

In an emotional discussion that has Samir rejecting his status as traitor by claiming that such men only use them for their faith and that it is them who are the traitors for having betrayed Islam, Omar slowly seems to accept this truth. After Samir first drops his gun, the initially mad Omar also lowers his, but is then shot by the entering police. Thus, the movie leaves open the possibility of Omar eventually being able to see how terrorists misuse faith and faithful men for their purposes, while Samir is pictured to be the only one able to interpret Islam correctly.

Admittedly, all this could very well be interpreted as suggesting that the movie's main message is that the terrorists simply misinterpret their religion and that it is therefore still morally right to fight them with questionable measures and be content as long as they are killed in the end. But the very last scene sheds a different light on the matter. After Samir had also been wounded badly whenever the police led by Clayton and Archer stormed the previous scene and mistook him for one of the terrorists, we follow Clayton meeting him on the street after his recovery. Clayton congratulates him on finally being free and asks him to further 
help him in his efforts of finding and fighting terrorists, as "this fight is far from over". Samir, however, elaborates on the gravity of him having had to make "choices about people's lives" and tries to have Clayton understand that the contradiction of duty and his religion is evident.

He refers to what Ahmad Ghazali identifies as "one of the hadiths (sayings)" of the Prophet Mohamed (105), in saying that the killing of innocent civilians amounts to the killing of all humankind. Clayton tries to counter this by claiming that the Quran "also says that if you've saved a life, it's as if you've saved all mankind", and even proclaims Samir a hero. But Samir rejects this label and refuses to go on helping Clayton. Thus, ultimately, the fact that he honorably served his country does not matter near as much to him as the fact that the measures he had to take in order to do so put him into deep trouble with his religion. In the end, he recognizes Clayton's efforts at trying to understand his situation and meet him with respect, but at the same time stresses the need to approach the whole matter differently in the first place. A notion, which is symbolized in their final farewell in Arabic:

Clayton: As-salaamu 'alaykum.

Samir: Wa 'alaykum salaam. And you should start the conversation with that.

Thus, the "conversation" that is the treatment of and the approach toward Middle Eastern culture and religion needs to be started differently by the U.S. Ultimately, as the final images of the film consist of close-ups of the sun-bathed Samir praying, aurally underlined by an Arabic flute's melody, it becomes clear that the movie symbolically expresses the fact that this is the main element to be reconsidered in the American strategy in what is the complex conflict of the 'war on terror'.

\section{Conclusion}

Both Ridley Scott's Body of Lies and Jeffrey Nachmanoffs Traitor contain various themes and messages that critically shine a light on the Bush administration's approach towards its "war on terror". Above all, they reject the notion of a simplistic binary opposition of the eternal 'good' U.S. and the purely 'evil' terrorists, in that they show that both sides engage in actions that are morally and ethically wrong. They do so by documenting just what it means to fully embrace and adhere to Bush's ideology.

In this context, it has been shown that characters like Ed Hoffman, Max Archer and Carter are utterly determined and confident about the righteousness of even the most questionable moral measures necessarily having to be taken in order to find and stop, or rather kill the terrorists. At all times, they see it a necessary 'evil' to engage in such measures and not for one moment consider the fact that in the 
end, they render themselves on the wrong side of the 'good vs. evil' dichotomy. In addition, they show a strong ignorance toward the local Middle Eastern culture and are at no time concerned with the reactions that their arrogant and insensitive behavior will necessarily provoke. Thus ultimately, they must be seen as the embodiment of a U.S. strategy that ignorantly pursues its goal of obliterating terrorism, all the while unconcerned "with the consequences of its manner of doing so" (Rajaee 72).

Of course, both films also express this blurring of the lines of 'good' and 'evil' in form of their protagonists' moral struggles. While Roger Ferris is experiencing an inner conflict that stems mostly from the unscrupulousness of his boss, who has not near as much respect as he has for the local culture into which he more and more emerges, Samir Horn struggles even more with what he has to do as U.S. undercover due to his strong Islamic belief. What they both have in common is that they are much more critical about the measures they are forced to take in the fighting of terrorism than are their superiors. Unlike the protagonist of the TV series 24 and thus the typical hero of the post-9/11 (techno) thriller, they do not readily put aside all moral conscience to 'get the job done', but are displayed to be much more aware of the importance of actually remaining on the side of the moral 'good'.

In the end, they refuse to further engage in this fight against terrorism, as they cannot stand the way it is exercised anymore, both left to deal with the moral consequences of their previous actions. As such, their character developments need to be understood as a direct criticism of the duplicity inherent in the Bush administration's strategy, which Cynthia Weber attributes to be "so insistently self-referential (e.g. we believe we are doing the morally right thing, so we are moral)" (162).

Also, in an effort to counter a simplistic demonization, the two films show the terrorists to have more complex reasons for their actions than Bush had claimed them to have. While these are not portrayed as justified, they nevertheless are shown to partly be fueled by the above mentioned insensitivity with which the U.S. behaves in this conflict. ${ }^{13}$ Accordingly, both movies seem to be a plea for a change in attitude and strategy on part of the Americans. On the one hand, Body of Lies strongly suggests that the cooperation with and respectful treatment of local allies is indispensable in order to succeed in the fighting of terrorism and to do so in a way that does not further generate an atmosphere of resentment toward U.S. operations in the Middle East. On the other hand, Traitor pictures both the failure of U.S. intelligent agencies to work together and, more importantly, the necessity of understanding Middle Eastern culture and Islamic religion better in the first place, in order be able to overcome what Robert Ricigliano and Mike Allen regard as a critical flaw in U.S. policy: "the failure to target the root causes that motivate terrorists and facilitate their actions" (92).

13 For a detailed analysis of the counterproductive results of American public diplomacy in the Middle East cf.Zaharna, R.S. Battles to Bridges: U.S. Strategic Communication and Public Diplomacy after 9/11 (Palgrave Macmillan 2010). 
The most important aspect of the way all these themes and messages are presented is the authenticity with which both films picture them and which, in the case of Traitor, tempted critic Roger Egbert to describe it as "com[ing] uncomfortably close to reality" (2008). As has been shown, both movies put great emphasis on an appropriate representation of the Arab world and are careful not to fall into stereotypes. Of course, they establish a visual and aural difference in between the spheres of the West and the Middle East, but the way these are presented results in much more than simple 'clash of civilization' portrayals. Essentially, their stories rather seem to be aiming at a mutual understanding and the start of a respectful dialogue. In doing so, the two films can be regarded as not being part of what James Castonguay describes as a "limited repertoire of images of, and narratives, about Arabs and Islam before and during the war on terror", which allegedly "served to keep much of the U.S. ignorant about Arab and Islamic culture" (152).

Rather, Body of Lies and Traitor form part of a number of Hollywood movies released between 2006 and 2008 that addressed the 'war on terror' in a way that shed a light on America's narrow view on it, while at the same time displaying its own, 'evil' actions in this fight, ultimately exposing the Bush administration's rhetoric as populist and simplistic. Despite the fact that they remained commercially unsuccessful, ${ }^{14}$ a circumstance which Jeff Birkenstein regards as resulting from them "hit[ting] too close to the truth to be enjoyed as entertainment" (70), these films publicized a less biased view on American strategy. In a political context, these films must naturally be put into perspective of the 2008 Presidential Election, which eventually saw Barack Obama become the current President of the U.S. But in a historical context, such films are also part of a form of criticism that dates back as far as the principles which the Bush administration so rigorously claimed for itself. After all, the Declaration of Independence also states that it is the people's duty to throw off any government that "becomes destructive" of certain rights like life and liberty (Declaration of Independence).

Of course, with the American fight against terrorism far from over, it remains to be seen whether or not the current and future administrations will follow a less ideologically impregnated strategy. In the end, it seems likely that some of the central themes and messages of Ridley Scott's Body of Lies and Jeffrey Nachmanoff's Traitor remain highly topical and will possibly do so for many years to come.

14 IMDB estimates their gross at about 23 million dollars for Traitor and about 40 million dollars for Body of Lies, compared to estimated budgets of 22 million and 70 million dollars, respectively. Thus, despite a change in atmosphere, releasing a major film critical to the Bush administration's behavior in the 'war on terror' still meant taking a great economical risk. 


\section{Bibliography}

\subsection{Films Cited}

24. By Robert Cochran and Joel Surnow. Perf. Kiefer Sutherland, Carlos Bernard and Mary Lynn Rajskub. Fox Network, 2001-2010. 20th Century Fox, 2010. DVD.

Behind Enemy Lines. Dir. John Moore. Perf. Owen Wilson and Gene Hackman. 20th Century Fox, 2002. DVD.

Body of Lies. Dir. Ridley Scott. Perf. Leonardo DiCaprio, Russell Crowe and Mark Strong. Warner Home Video, 2009. Blu-Ray.

Clear and Present Danger. Dir. Philip Noyce. Perf. Harrison Ford and Willem Dafoe. Paramount Home Entertainment, 1998. DVD.

Fantastic Four. Dir. Tim Story. Perf. Ioan Gruffudd and Michael Chiklis. 20 th Century Fox, 2005. DVD.

Home of the Brave. Dir. Irwin Winkler. Perf. Samuel L. Jackson, Jessica Biel, Brian Presley and Curtis Jackson. MGM, 2006. DVD.

In the Valley of Elah. Dir. Paul Haggis. Perf. Tommy Lee Jones, Charlize Theron, Susan Sarandon and Josh Brolin. Warner Home Video, 2007. DVD.

Jarhead. Dir. Sam Mendes. Perf. Jake Gyllenhaal and Jamie Foxx. Universal, 2005. DVD.

Lions for Lambs. Dir. Robert Redford. Perf. Robert Redford, Meryl Streep and Tom Cruise. United Artists, 2008. DVD.

Lord of War. Dir. Andrew Niccol. Perf. Nicolas Cage, Ethan Hawke and Jared Leto. Lions Gate, 2006. DVD.

Minority Report. Dir. Steven Spielberg. Perf. Tom Cruise, Colin Farrell and Jessica Harper. Dreamworks Video, 2002. DVD.

Redacted. Dir. Brian de Palma. Perf. Patrick Carroll and Rob Devaney. Magnolia, 2008. DVD.

Rendition. Dir. Gavin Hood. Perf. Jake Gyllenhall, Reese Witherspoon and Meryl Streep. New Line Home Video, 2008. DVD.

Spider-Man. Dir. Sam Raimi. Perf. Tobey Maguire, Kirsten Dunst and Willem Dafoe. Sony Pictures Home Entertainment, 2002. DVD.

Spider-Man 2. Dir. Sam Raimi. Perf. Tobey Maguire, Kirsten Dunst and James Franco. Sony Pictures Home Entertainment, 2004. DVD. 
Spider-Man 3. Dir. Sam Raimi. Perf. Tobey Maguire, Kirsten Dunst, Topher Grace and James Franco. Sony Pictures Home Entertainment, 2007. DVD.

Superman Returns. Dir. Bryan Singer. Perf. Brandon Routh and Kevin Spacey. Warner Home Video, 2006. DVD.

Syriana. Dir. Stephen Caghan. Perf. George Clooney, Matt Damon and Jeffrey Wright. Warner Home Video, 2006. DVD.

Tears of the Sun. Dir. Antoine Fuqua. Perf. Bruce Willis and Monica Bellucci. Sony Pictures Home Entertainment, 2003. DVD.

The Bourne Identity. Dir. Doug Liman. Perf. Matt Damon and Franka Potente. Universal, 2003. DVD.

The Bourne Supremacy. Dir. Paul Greengrass. Perf. Matt Damon, Brian Cox, Julia Stiles and Franka Potente. Universal, 2004. DVD.

The Bourne Ultimatum. Dir. Paul Greengrass. Perf. Matt Damon, Joan Allen and Scott Glenn. Universal, 2007. DVD.

The Hunt for Red October. Dir. John Mc'Tiernan. Perf. Sean Connery, Alec Baldwin and Sam Neill. Paramount, 1998. DVD.

The Sum of All Fears. Dir. Phil Alden Robinson. Perf. Ben Affleck and Morgan Freeman. Paramount, 2002. DVD.

Traitor. Dir. Jeffrey Nachmanoff. Perf. Don Cheadle, Guy Pierce, Jeff Daniels and Neil McDonough. Anchor Bay Entertainment, 2008. Blu-Ray.

United 93. Dir. Paul Greengrass. Perf. J.J. Johnson and Gary Commock. Universal, 2006. DVD.

World Trade Center. Dir. Oliver Stone. Perf. Nicolas Cage, Micheal Peña and Maggie Gyllenhaal. Paramount, 2006. DVD.

\subsection{Works Cited}

Birkenstein, Jeff. "An Early Broadside: The Far Rights Raids Master and Commander: The Far Side of the World." Reframing 9/11: Film, Popular Culture and the War on Terror. Eds. Birkenstein, Jeff, Anna Froula, and Karen Randell. New York: Continuum, 2010.

Birkenstein, Jeff, Anna Froula, and Karen Randell. Introduction. Reframing 9/11:

Film, Popular Culture and the War on Terror. New York: Continuum, 2010. 
Castonguay, James. "Intermedia and the War on Terror." Rethinking Global Security: Media, Popular Culture, and the "War on Terror". Eds. Petro, Martin, and Andrew Martin. New Brunswick: Rutgers, 2006.

Cawelti, John G. Afterword. Reframing 9/11: Film, Popular Culture and the War on Terror. Eds. Birkenstein, Jeff, Anna Froula, and Karen Randell. New York: Continuum, 2010.

Chomsky, Noam. 9-11: Was There an Alternative? New York, Seven Stories Press, 2011.

Creekmar, Corey K. "The Sound of the "War on Terror."' Reframing 9/11: Film, Popular Culture and the War on Terror. Eds. Birkenstein, Jeff, Anna Froula, and Karen Randell. New York: Continuum, 2010.

Crockatt, Richard. After 9/11: Cultural Dimensions of American Global Power. New York: Routledge, 2007.

Crowe, Russell. "Debriefing." Body of Lies. Dir. Ridley Scott. Perf. Leonardo DiCaprio, Russell Crowe and Mark Strong. Warner Home Video, 2009. BluRay.

Deline, Donald. "Field Operation: The Terrible Room." Body of Lies. Dir. Ridley Scott. Perf. Leonardo DiCaprio, Russell Crowe and Mark Strong. Warner Home Video, 2009. Blu-Ray.

Daniels, Jeff. "Interview." Traitor. Dir. Jeffrey Nachmanoff. Perf. Don Cheadle, Guy Pearce, Jeff Daniels and Neil McDonough. Anchor Bay Entertainment, 2008. Blu-Ray.

Faludi, Susan. The Terror Dream: Fear and Fantasy in Post-9/11 America. New York: Henry Holt, 2007.

Forbes, A. Gruar. The Empires and Cities of Asia. London, Virtue: 1873.

Ghazali, Ahmad. "Radical Islam, Terrorism, and the Impact of September 11 on the Muslim Community." The War on Terror in Comparative Perspective: US Security and Foreign Policy after 9/11. Eds. Miller, Mark J., and Boyka Stefanova. New York: Palgrave MacMillan, 2007.

Grajeda, Tony. "Picturing Torture: Gulf Wars Past and Present." Rethinking Global Security: Media, Popular Culture, and the "War on Terror". Eds. Petro, Martin, and Andrew Martin. New Brunswick: Rutgers, 2006.

Hill, Mathew B. "Tom Clancy, 24, and the Language of Autocracy." The War on Terror and American Popular Culture: September 11 and Beyond. Eds. Schopp, Andrew, and Mathew B. Hill. Madison/Teaneck: Fairleigh Dickinson University Press, 2009. 
Hoberman, David. "Interview." Traitor. Dir. Jeffrey Nachmanoff. Perf. Don Cheadle, Guy Pearce, Jeff Daniels and Neil McDonough. Anchor Bay Entertainment, 2008. Blu-Ray.

Ignatius, David. "Author Provocateur: David Ignatius.” Body of Lies. Dir. Ridley Scott. Perf. Leonardo DiCaprio, Russell Crowe and Mark Strong. Warner Home Video, 2009. Blu-Ray.

Layoun, Mary N. "Visions of Security: Impermeable Borders, Impassable Walls, Impossible Home/Lands?" Retbinking Global Security: Media, Popular Culture, and the "War on Terror". Eds. Petro, Martin, and Andrew Martin. New Brunswick: Rutgers, 2006.

Martin, Andrew. "Popular Culture and Narratives of Insecurity." Rethinking Global Security: Media, Popular Culture, and the "War on Terror". Eds. Petro, Martin, and Andrew Martin. New Brunswick: Rutgers, 2006.

McDonough, Neil and Guy Pierce. "Interview." Traitor. Dir. Jeffrey Nachmanoff. Perf. Don Cheadle, Guy Pearce, Jeff Daniels and Neil McDonough. Anchor Bay Entertainment, 2008. Blu-Ray.

Nachmanoff, Jeffrey. "Commentary." Traitor. Dir. Jeffrey Nachmanoff. Perf. Don Cheadle, Guy Pearce, Jeff Daniels and Neil McDonough. Anchor Bay Entertainment, 2008. Blu-Ray.

—. "Interview." Traitor. Dir. Jeffrey Nachmanoff. Perf. Don Cheadle, Guy Pearce, Jeff Daniels and Neil McDonough. Anchor Bay Entertainment, 2008. Blu-Ray.

Oliver, James K. "US Foreign Policy after 9/11: Context and Prospect." The War on Terror in Comparative Perspective: US Security and Foreign Policy after 9/11. Eds. Miller, Mark J., and Boyka Stefanova. New York: Palgrave MacMillan, 2007.

Petro, Martin, and Andrew Martin. Introduction. Rethinking Global Security: Media, Popular Culture, and the "War on Terror". New Brunswick: Rutgers, 2006.

Rajaee, Bahram M. "US Foreign Policy and Radical Islam." The War on Terror in Comparative Perspective: US Security and Foreign Policy after 9/11. Eds. Miller, Mark J., and Boyka Stefanova. New York: Palgrave MacMillan, 2007.

Ricigliano, Robert, and Mike Allen. "Cold War Redux." Retbinking Global Security: Media, Popular Culture, and the "War on Terror". Eds. Petro, Martin, and Andrew Martin. New Brunswick: Rutgers, 2006.

Scharpe, Tony. W.H. Auden. New York: Routledge, 2007.

Schopp, Andrew, and Mathew B. Hill. Introduction. The War on Terror and American Popular Culture: September 11 and Beyond. Madison/Teaneck: Fairleigh Dickinson University Press, 2009. 
Scott, Ridley. "Commentary." Body of Lies. Dir. Ridley Scott. Perf. Leonardo DiCaprio, Russell Crowe and Mark Strong. Warner Home Video, 2009. BluRay.

-. "Controlled Hostility: Stunts and Special Effects." Body of Lies. Dir. Ridley Scott. Perf. Leonardo DiCaprio, Russell Crowe and Mark Strong. Warner Home Video, 2009. Blu-Ray.

-. "Master of the Craft: Ridley Scott." Body of Lies. Dir. Ridley Scott. Perf. Leonardo DiCaprio, Russell Crowe and Mark Strong. Warner Home Video, 2009. Blu-Ray.

—. "The Color of Toast." Body of Lies. Dir. Ridley Scott. Perf. Leonardo DiCaprio, Russell Crowe and Mark Strong. Warner Home Video, 2009. Blu-Ray.

—. "Uneasy Alliance." Body of Lies. Dir. Ridley Scott. Perf. Leonardo DiCaprio, Russell Crowe and Mark Strong. Warner Home Video, 2009. Blu-Ray.

Weber, Cynthia. Imagining America at War: Morality, Politics, and Film. New York: Routledge, 2006.

Zelikow, Philip. "U.S. Strategic Planning in 2001-02." In Unceratin Times: American Foreign Policy after the Berlin Wall and 9/11. Leffler, Melvyn P., and Jeffrey W. Legro. Eds. Ithaca/London: Cornell University Press, 2011.

Žižek, Slavoy. Welcome to the Desert of the Real. London: Verso 2002.

\subsection{Online Sources}

ABC Television Network. I.T.R.S. Ranking Report. May 31, 2006. Web. 9 August 2012. <http://web.archive.org/web/20070310210300/http://www.abcmedia net.com/pressrel/dispDNR.html?id=053106_05>.

“Body of Lies." IMDb.com 2008. Web. 9 August 2012. <http://www.imdb.com/ title/tt0758774/>.

Ebert, Roger. Rev. of Traitor, dir. Jeffrey Nachmanoff. Chicago Sun-Times Online 26 Aug. 2008. Web. 9 August 2012. <http://rogerebert.suntimes.com/ apps/pbcs.dll/article?AID=/20080826/REVIEWS/808269997>.

Harmanci, Reyhan. Rev. of Traitor, dir. Jeffrey Nachmanoff. San Francisco Chronicle Online 27 Aug. 2008. Web. 9 August 2012. <http://www.sf gate.com/movies/article/Movie-review-Traitor-3197662.php>.

Horton, Scott. "New CIA Docs Detail Brutal 'Extraordinary Rendition' Process". The Huffington Post 28 Sept. 2009. Eds. Adriana Huffington, Roy Sekoff and 
Timothy L. O’Brien. Web. 9 August $2012<$ http://www.huffingtonpost. com/2009/08/28/new-cia-docs-detail-bruta_n_271299.html>.

LaSalle, Mick. Rev. of Body of Lies, dir. Ridley Scott. San Francisco Chronicle Online 10 Oct. 2008. Web. 9 August 2012. <http://www.sfgate.com/mo vies/article/Movie-review-Muddled-Body-of-Lies-3191302.php>.

National Archives and Records Administration. The Declaration of Independence: $A$ Transcription. Web. 9 August 2012. <http://www.archives.gov/exhibits/ charters/declaration_transcript.html>.

National Commission on Terrorist Attacks on the United States of America. The 9/11 Commission Report. August 21, 2004. Web. 9 August 2012. <http://www.9-11commission.gov/report/911Report_Exec.htm>.

Newport, Frank and Joseph Carroll. Despite Sharp Increase in Bush Approval Since 9/11, Race Gap Persists. Gallup News Service Online Jan. 8, 2002. Web. 9 August 2012. < http://www.gallup.com/poll/5158/despite-sharp-increa sebush-approval-since-911-race-gap-persists.aspx $>$.

Rosenblatt, Josh. Rev. of Traitor, dir. Jeffrey Nachmanoff. The Austin Chronicle Online 29 Aug. 2008. Web. 9 August 2012. <http://www.austin chronicle.com/calendar/film/2008-08-29/662580/>.

Scott, A.O. Rev. of Body of Lies, dir. Ridley Scott. The New York Times Online 9 Oct. 2008. Web. 9 August 2012. < http://movies.nytimes.com/2008/10/ 10/movies/10lies.html>.

The President of the United States of America. The National Security Strategy of the United States of America. 2002. Web. 9 August 2012. <http://nssarchive.us/ NSSR/2002.pdf>.

The White House: President George W. Bush. "Address to a Joint Session of Congress and the American People." September 20, 2001. Web. 9 August 2012. <http://georgewbush-whitehouse.archives.gov/news/releases/2001 /09/20010920-8.html>.

-. "Presidential Address to the Nation." October 7, 2001. Web. 9 August 2012. $<$ http://georgewbush-whitehouse.archives.gov/news/releases/2001/10/2001 1007-8.html>.

-. "President Bush Announces Major Combat Operations in Iraq Have Ended." May 1, 2003. Web. 9 August 2012. <http://georgewbush-whitehouse.arch ives.gov/news/releases/2003/05/20030501-15.html>.

-. "President Bush Delivers Farewell Address to the Nation." January 15, 2009. Web. 9 August 2001. <http://georgewbush-whitehouse.archives.gov/ news/releases/2009/01/20090115-17.html>. 
-. "President Discusses Iraqi Elections, Victory in the War on Terror." December 14, 2005. Web. 9 August 2012. <http://georgewbush-whitehouse.arch ives.gov/news/releases/2005/12/20051214-1.html>.

-. "Remarks by the Vice President to the Veterans of Foreign Wars 103rd National Convention." August 26, 2002. Web. 9 August 2012. <http://georgewbushwhitehouse.archives.gov/news/releases/2002/08/200 20826.html>.

“Traitor." IMDb.com 2008. 9 August 2012. < http://www.imdb.com/title/ $\mathrm{tt} 0988047 />$.

Travers, Peter. Rev. of Body of Lies, dir. Ridley Scott. Rolling Stone Online 10 Oct. 2008. Web. 9 August 2012. <http://www.rollingstone.com/movies/ reviews/body-of-lies-20081010>.

Turan, Kenneth. Rev. of Body of Lies, dir. Ridley Scott. Los Angeles Times Online 10 Oct. 2008. Web. 9 August 2012. <http://articles.latimes.com/2008/ oct/10/entertainment/et-body10>.

United States Congress. PATRIOT ACT. 2001. Web. 9 August 2012. $<$ http://www.gpo.gov/fdsys/pkg/PLAW-107publ56/pdf/PLAW-107publ56. pdf $>$.

United States. Dept. of Defense. Office of the Assistant Secretary of Defense (Public Affairs). News Transcript May 1, 2003. Web. 9 August 2012. $<$ http://www.defense.gov/transcripts/transcript.aspx?transcriptid=2562>. 



\title{
The Construction of Identity and Identification in Tim Minchin's Storm
}

\author{
Lennart Brieger
}

\section{Introduction}

\subsection{Storm and Identities}

Tim Minchin's beat poem Storm is an account of the clash of two people's world views. The narrator of the text and his wife ${ }^{1}$ visit friends for dinner, and a fifth person called 'Storm' is also invited. It soon turns out that the narrator's and Storm's opinions on the nature of knowledge, truth, spirituality and other issues seem to differ fundamentally, and thus, an argument that constitutes most of the content of the poem ensues.

The conflict between the two stubbornly defended, mutually exclusive world views in Storm seems to show that the two opponents are not simply in disagreement over the issues they discuss. Rather, their persistence appears to indicate that the topics argued over are of far more importance to them than other topics might be. Their opinions on the issues, thus, seem to matter to them as if they were not only part of their views of the world, but part of their self-conceptions - their identities, one might say. Thus, it could be argued that the displayed argument is not just one of contesting ideas, but of seemingly irreconcilable identities. 1 The narrator will be referred to as male, as he explicitly mentions his "cock" (Minchin 177),
meaning his penis. 
However, a third identity is involved in the quarrel. While perceiving Storm, the recipient of the text is inevitably confronted with both the views of the narrator and those of Storm. The way in which he or she evaluates their claims probably does not merely depend on his or her identity, but also on the way both the characters and their arguments are presented in the text. Since the account of the happenings at the dinner party is entirely delivered from the perspective of the narrator, it is rather subjective and seemingly aims to convince the recipient of the correctness of the narrator's views.

The purpose of this paper is to examine how certain elements of the text can influence the reader's identity, by causing him or her to agree with the narrator ${ }^{2}$. Specifically, the role of the narrative structure and the capacity of poetic qualities of Storm, mostly imagery, to influence identification by giving the reader pleasure will be examined. The narrative structure is of interest because of the inevitable subjectivity of the narration that arises from the narrator's rendering of it. The narrator's point of view may certainly serve to show things, happenings and people from a certain perspective (Petersen 2), thereby showing them in a certain light to the recipient of the text, which may influence his or her views and identity in a certain way. Furthermore, "Poetry is something for everyone to enjoy" (Nelson 1), and poetic aspects of the text thus can presumably make the reader more readily accept and assume opinions that are expressed in a way that gives him or her pleasure. As Paul Bloom states, "we tend to like those who give us joy." (137-138), and perhaps we can even identify with them.

\subsection{The Transcription}

An obstacle that had to be cleared in order to conduct a literary analysis of the effects of Storm on the reader's identity is that the poem has, as yet, not been published in written form, but only as performed by Minchin himself on CD and DVD. It has, however, also been released on the internet as part of a video entitled Tim Minchin's Storm the Animated Movie, where Minchin recites the poem and the plot is simultaneously shown as an animated film, accompanied by music. It is this version of Storm that has been transcribed for the purpose of this paper and that will be examined here. A complete analysis of the text, performance and possibly even the music in the background of the performance, would exceed the aims of this paper by far. Therefore, the analysis will focus on what is said in the transcribed text, not on how Minchin recites the poem ${ }^{3}$.

2 A different approach would be to examine the narrator's rendering of the events for instances of self-subversion, which might indeed prove fruitful, yet will scarcely be done here for the sake of conciseness.

3 The transcription, it must be admitted, is certainly influenced by the performance. Breaks in the recitation have mostly been deemed to mark the end of a line, as have rhyming words. Since rhythm and metre are barely considered in this analysis, however, their possible misrepresentation should not matter greatly. The animations in the video as well as the music have not been taken into consideration here, except for passages where the text is displayed as part of the animation. 


\subsection{The Approach of the Analysis}

The analysis of Storm's possible influence on the recipient's identity will begin with the establishment of a theoretical framework that describes how identity construction might work psychologically. This will include an examination of why people identify at all, what part of the mind identity comprises, how it is constituted, and how its formation can be influenced. Based on this framework, the relationship between the recipient and the text, particularly the narrator will be discussed and assessed.

Then, the influence of the narrative structure of Storm on the recipient's inclination to identify with elements of the text will be examined, following Petersens categorisation of the features of narrative systems. Here, especially the consequences of the narrator's positioning with regard to both the narrated and the recipient will be inspected, as well as the ways in which he narrator (who is both a character and the narrating medium) can be characterised by analysing his rendition of the story.

Following that, the capability of pleasure derived from art, particularly from poetry, to elicit the reader's identification with views expressed in Storm will be investigated on the basis of Bloom's ideas on the workings of pleasure. Furthermore, instances in the poem will be examined, where lyric devices (imagery, specifically) may serve both to illustrate thoughts and emotions represented in the text and to make the reader more open to identifying with those sentiments by displaying them in a pleasurable way.

Finally, conclusions about Storm's capability to influence its recipient's identity construction will be drawn and different approaches to how the text might be received and processed will briefly be envisaged.

\section{An Applicable Theory of Identity Construction}

\subsection{The Subject}

To analyse the effects of any text on a reader's processes of identification with characters or views represented in that text, a theoretical framework that shows how identity construction works is needed. To establish such a framework it is vital to consider what exactly identity formation is considered to be. Is it simply the social process of blending in with a certain group of people as sociologists may think? Is identity formed when agreeing or disagreeing with someone politically, as a political scientist might argue? Is it a result of education and socialisation, a temporary psychological state, or is it something inherent, transcendental like the soul perhaps - or simply genetic - and therefore unchanging? In this paper, the process

Naturally, knowledge of both the animations and of the music may have influenced the transcription subconsciously, yet to no extent that has been detected or appeared relevant. 
of identity formation will be viewed as a psychological process. This means that it takes place on the theoretical level of what will be called the subjects. For now, 'identity' ${ }^{5}$ will simply be deemed a certain state of mental organisation, since a more detailed definition of identity will be developed over the course of this chapter. The same applies to 'identification', which, until it is defined more thoroughly, shall simply denote the process of assuming an identity.

A precise, widely agreed-upon definition of what the term subject actually denotes does not seem to exist. According to Luke Ferretter, "the concept of the subject is one in which an individual human being is believed to be the independent origin of their own thoughts, actions and emotions" (88). Thus, it could be argued that every human being is psychically also a subject. This notion seems to be in accord with Louis Althusser's remark that the term "subject" has been used simply as a different name for what used to be called "soul" (Althusser 115-116), which further suggests that the subject is a unified entity and the very core of what constitutes a human mind.

But Althusser also remarks that a "concrete subject", which is always already a part of an individual human being, only becomes a proper, conscious subject when it is hailed or "interpellated" by what he calls "ideology" (118). He elaborates that the subject is somehow hailed by ideology just like someone on the street might be hailed by a police officer, and that this hailing leads to the subject gaining awareness of its own existence. This may sound confusing - especially because he describes this process as always having happened already, which in conclusion seems to mean that it never happens any more $^{6}$. But what is important for the analysis conducted in this paper is the notion that the subject may not just inexplicably exist with no origin in an unchanging form. The suggestion is that the subject is constituted or 'made', be it through Althusser's 'ideology' or otherwise. Since it has been implicitly presumed for the purpose of this paper that identity, too, is somehow formed rather than simply present (the object of study being identity formation), the constitution of the subject may well have an influence on identity construction - a possibility that should be kept in mind when the theoretical basis for a literary analysis of identity formation is compiled.

Jacques Lacan believes that the subject "does not function as the center of human thought and action, but [. . . inhabits the mind as an elusive agency, controlling yet uncontrollable" (Nobus 61). Lacan thus not only challenges the idea that the subject is the fixed core of the human mind, but also suggests that it should not be thought of as a unified entity or construct. He rather sees it as a

4 Italics will be used when a technical term is first introduced.

5 The inverted commas in this paragraph indicate that the word will be used as a loosely defined term, until its technical meaning is given.

6 Frankly, it seems as though Althusser either works with a few assumptions that he did not make apparent, or that some of the context of his musings has been lost in translation. Luckily, his concept of interpellation was reformulated by Stuart Hall and is in that form explained later in this chapter. 
loose, vague, largely unconscious "agency," a force that subtly influences human thoughts, emotions and actions.

However interesting Lacan's notion of the impalpable, "elusive" subject may be, not regarding the subject as a somewhat unified being would probably make for a very vague theoretical basis for an analysis of identity formation. If the subject were not unified and ascertainable, then how could it be affected by a text like Storm and how would one determine which mental processes it affects? Yet simply ignoring the idea that the subject may not exist purely in its own right could unnecessarily narrow the applicability of the theoretical groundwork for the analysis. Perhaps, then, a compromise can be found, which neither renders the concept of the subject inapplicable in a literary analysis, nor excludes the possibility that the subject may not be a unified, indissoluble, completed entity.

The relatively recent psychological theory of the 'dialogical self seems to provide such a compromise. In dialogical self theory (DST) the so-called self "becomes a "mini-society", more technically speaking a "dynamic multiplicity of I-positions" (Hermans and Gieser 2). This means that the self can be imagined as a space in which the $I$ and different I-positions exist ${ }^{7}$. Within this conceptual space of the self, the I "is able to move from one position to the other in accordance with changes in situation and time" (2), while "dialogical exchanges among positions can develop" (ibid.) as well. This means that not only the positioning of the I, but also the I-positions themselves can change and shift, making the self dynamic, yet unified as could be said of a society of people.

The idea of the subject or I and subject-positions or I-positions as being embedded in the self includes the notion that the subject is the core part of a unity (the self), yet still capable of radical change and multiplicity (occupying diverse, possibly even contesting subject positions). Therefore, these concepts of the subject and the self will be used as part of the theoretical framework for identity formation employed in this paper.

\subsection{The Need to Identify}

Now that a workable definition of the subject has been established, its role in the process of identity formation must be considered.

In everyday speech the use of the word 'identity' implies that a person or a group of people 'has' some sort of identity. This means that identity is always something that belongs to someone or is ascribed to them. By the same token, 'identification' (not in the sense of 'pass' or 'credentials') usually implies that there

For the purpose of this paper, "the I" will be considered to be synonymous with "the subject", since Stuart Hall uses the terms "subject" and "subject position" in his article on identity construction as well, but does not elaborate on the origin of his terminology. Links between Hall's terminology and DST may exist, but have not been researched in the context of this paper, because such specific inquiries into the history of psychoanalysis and psychology were deemed too extensive for establishing a theoretical basis for a literary analysis of Storm. 
is someone who identifies with someone or something, an 'identifier' who 'takes' an identity, so to speak. The aim of this paper is to examine how recipients of the text under consideration are influenced to identify or not to identify with the narrator. Hence, it seems reasonable to assume that in a theory of identity formation, too, there must be someone or something that 'has' an identity or undergoes a process of identification. Following Stuart Hall's notions on identity and identification, that someone or something will be considered to be the subject. However, the assumption that the subject is the part of the conceptualised mind that 'has' or readily 'takes' an identity implies that the subject is not only vaguely capable of assuming an identity or identities but that it has an inherent tendency or even a need to do so - otherwise, why would it assume one? In theories of personal identity and identification this need is often simply presumed to exist, perhaps because considering it a given seems commonsensical. Hall, too, does not seem to mention why identities arise and why identification occurs, but only how. It seems, though, that an analysis of how Storm influences its recipient's inclination to identify with either the narrator or Storm can hardly be conducted without at least a basic understanding of the need for identity. After all, that need could be precisely what is influenced within the recipient's mind by Storm.

A rather convenient explanation for the need for identification can be extrapolated from Judith Butler's claim that gender identity "is performatively constituted" (Butler 1990: 25). This means that gender identity formation does not entail intentionality or volition from the subject, but, more or less, simply 'happens' due to restrictions (regarding gender) of the language used by the subject to narratively construct its gender identity. A generalisation of Butler's explanation to include identity formation in general, rather than just the formation of gender identity, would hence state that identity is imposed onto the subject by the language of selfnarration. Justifiable as that thought might be, for an analysis of identification in Storm it would mean that the recipients' inclination to identify with the narrator or not to do so - entirely depends on each individual recipient's personal use of language for self-narration. This would make it almost impossible to make any generalising statement at all about the influence of Storm's literary properties on a model recipient, because every recipient would most likely be fundamentally differently affected by the text. Furthermore, while a subject may not intentionally undergo identification, the process still does take place and there still is no explanation what purpose it serves. The question of why identification occurs therefore remains.

In their article "The Need to Belong: Desire for Interpersonal Attachments as a Fundamental Human Motivation", Roy F. Baumeister and Mark R. Leary evaluate "a hypothesized need to form and maintain strong, stable interpersonal relationships [. . .] in light of the empirical literature" (497). In their inquiry they "found evidence for a basic desire to form social attachments" (520) and they conclude that "the need to belong can be considered a fundamental human motiva- 
tion" (521). Presumably, then, the subject's presumed need to identify is simply part of that innate human need to belong.

However, part of Baumeister's and Leary's hypothesis is that the need to belong is only fulfilled within a "temporally stable and enduring framework of affective concern for each other's welfare" (497). Consequently, the subject's processes of identity formation would also have to result in the assumption of temporally stable identities which contribute to the fulfilment of the need to belong with someone or something. If so, how can a relatively short text like Storm influence a recipient's identification process even though the text is probably not perceived frequently and despite its influence on the recipient - in all likelihood - not being as continuous as an interpersonal relationship 8 ?

Sigmund Freud claims that "identification may arise with every perception of a common quality shared with some other person who is not an object of the sexual instinct" (680). Thus, as it is the subject which identifies, the important question here is not whether or not assumed identities will be stable, but rather whether or not they appear to provide enduring stability to the subject. Because "identifications belong to the imaginary" (Butler 1993: 68) and identities "arise from the narrativization of the self' (Hall 4), the subject's inclination to assume a certain identity must depend on how stable that identity is imagined to be. The subject has no way of 'knowing' how stable an identity is going to be, so it is most likely to adopt one which seems to provide stability in the subject's 'imagination', regardless of whether it actually does, or not ${ }^{9}$. This way of looking at the subject's inclination to identify also makes it possible to examine potential influences of the literary properties of Storm on the recipient's tendency to identify or not to identify with the narrator and his views. For example, if a point of identification provided in Storm is somehow presented in a way that makes it seem stable and preferable to other potential points of identification, then the subject's affinity to that point may increase.

\subsection{The Mechanics of Identity Formation}

Having established what part of the mind of the recipient undergoes processes of identity formation (the subject) and what purpose such a process may serve (the fulfilment of an inherent need to belong) still does not explain how exactly the assumption of an identity might work. An important hint towards the functioning of identificatory processes can be found in the aforementioned quotation by Stuart Hall. He states that identities "arise from the narrativization of the self". If the "narrativization of the self" can be imagined as a constantly ongoing discourse

8 Unless, perhaps, one were to occupy oneself with Storm over a period of several months.

9 As already mentioned, Judith Butler, for instance, suggests that identities and identifications are performative. Speaking of the subject's "imagination" and the subject not "knowing" something is therefore only a way of clarifying why imagined stability is important and not to suggest any kind of intentionality based on reasoning within the subject. 
within the mind, it seems logical to conclude that identity formation, too, is never finished as a process and that "identity is never a fixed core" (Brah 142), but developing and changing. Homi $\mathrm{K}$. Bhabha notes that "identity is never an a priori, nor a finished product; it is only ever the problematic process of access to an image of totality" (51), which further suggests that identities are not only capable of changing occasionally, but permanently in the process of alteration, always being imagined and re-imagined.

Hall, who in his essay "Introduction: Who Needs 'Identity'?" presents a comprehensive theory of the mental mechanics of identity formation, states that identities and identification are widely seen among theorists "as a construction, a process never completed - always "in process"” (2). He also claims that identities are "constantly in the process of change and transformation" (4), and again it can be seen that identities are not stable, but can only ever provide an illusion of stability.

When put into context with the theoretical framework of the subject established so far, the notion of identity as being shifting and unstable suggests that the nature of identity is similar to that of the self: dependant on the positioning of the subject. Although Hall does not directly employ the concepts of dialogical self theory, he argues that "identities are, as it were, the positions which the subject is obliged to take up" (6), and he thus presupposes a spatial concept of the mind that is apparently similar to the one in DST. An identity can thus be described as the combination of the subject and all subject positions occupied by it, while identification is "a process of articulation" (3), meaning the attachment of the subject to a few specific, interrelated subject positions. It should be stressed again, though, that this attachment - this identification - is "a process never completed - always 'in process" (2). The changing and non-unified nature of identity thus arises from its dependence on the ever shifting identifications that constitute it. Similarly, identifications can be considered to be "in process" both because the subject positions they encompass, according to DST, can change and develop and because the subject may pick different subject positions to occupy as well. This means that some understanding of the external and internal influences that regulate identifications is required to examine what different aspects of Storm might reinforce or weaken the recipient's inclination to identify.

\subsection{Interpellation, Exclusion and the Other}

Any process of identification, Hall argues, is elicited through the "hailing of the subject by discourse", which he calls "interpellation" (6). Contrary to Althusser's use of the term, Hall's "interpellation" is not an effect of ideology, but of discourse, which means that what is really to be considered in the analysis of Storm is how specific literary and discursive practices can "hail" - or interpellate - the subject of the recipient to make it occupy specific subject positions. One factor that seems to influence the effectiveness of interpellation has already been named: the imagined stability of the subject positions which the subject might prospectively oc- 
cupy. Another variable apart from the imagined foothold that identities provide appears to affect the subject's inclination to identify as well.

Hall states that "throughout their careers, identities can function as points of identification and attachment only because of their capacity to exclude" (4). He elaborates that "they emerge within the play of specific modalities of power" and that they are "the product of the marking of difference and exclusion" (4), which suggests that any process of identity construction must also involve the exclusion of something that is explicitly not part of that identity.

Other theorists, too, have pointed out the crucial role which exclusion as well as the establishment of imagined hierarchies play in identity formation. Jonathan Rutherford, for instance, remarks that "it is within their polarities of white/black, masculine/feminine, hetero/homosexual, where one term is always dominant and the other subordinate, that our identities are formed" (10) and Bhabha argues that "to exist is to be called into being in relation to an otherness" (44). Consequently, one might assume that the potency of interpellation is increased if the prospectively assumed identity seemingly involves a stronger repudiation of that which is marked as different - the so-called other.

It could admittedly be argued that exclusion and differentiation do not influence the inclination to identify directly. Instead, quite possibly, rigorous differentiation from an imagined constant other produces a similarly constant relationship to that other. Since such a stable relationship must somehow be part of the self, its establishment also leads to the stabilisation of the self, which could then be seen as the ultimate cause of identification. Rutherford mentions that "it is the threat of the dissolution of self that ignites the irrational hatred and hostility as the centre struggles to assert and secure the boundaries, that construct self from non-self' $(11)^{10}$, and while this comment shows that exclusion to some extent matters because it leads to the stabilisation of the self, it also suggests that exclusion very prominently occurs even during the construction of the self, and hence during the shaping of identity. As the analysis of Storm will focus on the formation and assembling rather than just the preservation of identities, exclusion will be considered as a different effect of interpellation than self-stabilisation.

Particularly in the context of an analysis of Storm, notions of identity being constructed from difference provide an interesting view upon identity formation, since the narrator's and Storm's views are displayed as being mutually exclusive. Possibly, therefore, their identities are to some degree based on the exclusion of their respective other. Hall states that identification "requires what is left outside, its constitutive outside" (3) and that identity is constructed "through the relation to

10 Rutherford's "self", it should be pointed out, is not the self used in DST or in this paper, as his "non-self" seems to denote what here will be called the other. The crucial difference between the two conceptions of the term "self" is that the other here will be considered to be part of the self, while the "non-self" in Rutherford's terminology seems to be the opposite of and outside the "self". This difference in terminology does not change the fact that otherness - whether within or outside the self - serves to stabilise the self. "Centre" here seems to mean the subject, the core of the self. 
the Other" (4). Since the only account of the argument in Storm is given by the narrator, Storm and her views may come to represent such a constitutive outside or constitutive other to the reader as well. To examine how the narrator's biased portrayal of Storm may influence the recipient's inclination to identify with the narrator, it is necessary to locate the place of the other in relation to the self and the subject.

In DST "the other, as real, imagined or remembered, can be addressed as an $I$ position as part of an extended self' (Hermans and Gieser 8). In fact, the term "extended self" here denotes precisely such a concept of the self, where the other is not considered to be outside the self, in contrast to the "Cartesian self, which is based on a dualistic conception, not only between self and body but also between self and other" (3). If, as stated in the quotation above, the "other" denotes a subject position (or, possibly, a set of subject positions) within the self, however, then how is it different from other subject positions within the self? The answer is that the other, while part of the self, is explicitly not part of identity. In fact, as far as they have been defined in this paper, this is the main difference between the abstract concepts of self and identity: the self includes the other, identity specifically does not. Thus, the other denotes a subject position that cannot be occupied by the subject, unless an assumed identity is fundamentally restructured and a different other emerges. As identities are shifting and constantly revised, one other can presumably be substituted for another over time. To be able to apply the notion of the other as being excluded from identity in the analysis of Storm, it should prove useful to make a few practically oriented assumptions about the nature of the other.

Firstly, although Hermans and Gieser state that the other "can be addressed as an I-position" (8), it should be more appropriate to see it as a set of subject positions rather than just as one here. The reason for this assumption is that the narrator in Storm, it seems, is not simply critical of one feature of Storm, but of quite a few of them, for instance her tattoos (Minchin 23-27, 242-243), her opinion about the legitimacy of alternative medicine (85-94) and her alleged lack of consideration for the other people at the dinner party (62-72). Since the recipient's inclination to identify with the narrator's views may not depend merely on the demotion of one, but of several features ascribed to Storm, it seems reasonable to see each of those features as a separate subject position. After all, the presumed multiplicity of subject positions within the self allows for such an assumption.

Secondly, the other is not only that which is excluded because it is seen as contesting or even threatening to identity. There are also what Hermans and Gieser call "significant others [. . .] who play a role in one's self temporarily or for a longer period" and who "serve as promoter positions" (17). Such significant others serving as promoter positions can, for instance, include family members, teachers, friends and images of divinity (ibid.): entities that simply cannot be incorporated into identity because their otherness is a necessary condition for their existence. After all, one cannot, realistically, be one's own parent. To the recipient of Storm, the narra- 
tor may to some extent function as a promoter position, thereby being part of the other, yet not necessarily subjected to the establishment of "a violent hierarchy" (Hall 5) that places the recipient's identity above that part of the other. This observation further justifies the previously made assumption that the other consists of multiple subject positions. Moreover, it shows that while there are parts of the other that are pointedly excluded and seen as a threat to identity, there are also such parts that make up milder contrasts to it, merely facilitating "coherence and organization in the self" (Hermans and Gieser 17) and in identities by allowing an individual to realise the boundaries of his or her identity.

\subsection{Short Summary: Identity Formation}

Now that an adequate theoretical framework for the analysis of identity formation in Storm has been developed, it seems appropriate to sum up its most important points. The conceptual space of the mind in which identity is formed is the self, which is inhabited by the subject and subject positions that represent elements of an individuals mind: feelings, traits, pieces of knowledge, opinions, ways of thinking, relationships to others and connections to the environment. In order to stabilise and organise the self, the subject occupies certain subject positions, which leads to the constitution of an identity. The attachment of the subject to a particular set of related subject positions is called identification. Processes of identity formation are performative and identities are ever shifting and do not actually provide long-lasting stability for the self and the subject, but are nonetheless 'imagined' to do so. The more stabilising or constructive a subject position seems, the more likely it is to be identified with. Interpellation is the process of making the subject 'aware' of a potentially assumable subject position and making it likely that the subject will occupy it. Subject positions that are not or cannot be occupied are part of the so called other and can be strongly opposed, even contrary to identity - or simply distinct from the subject positions that are incorporated into identity. Certain parts of the other can influence the self as promoter positions and thereby help with the organisation and structuring of identity and the self, promoting or demoting certain subject positions (i.e. altering the effects of interpellation). The marking of the other as different serves the purpose of ascertaining the boundaries of identity and therefore furthers the constitution of identity.

\subsection{Narrator and Recipient}

Now that the theoretical structure of the mind, the aims, mechanics and strategies of identity formation and how they may apply to the relationship between the recipient and the narrative have been discussed, a few assumptions made about the model recipient in light of the analysis of Storm must be pointed out. 
Firstly, in the following analysis, only the recipient's conceptual internal space will be considered. Thus, neither the narrator himself, nor any other character occurring in Storm will be viewed as a subject within a self. This is due to the fact that, as Niklas Luhmann remarks, "from the perspective of each subject, every other one possesses merely a derivative, constituted, constructed existence" (Luhmann xli). The problem is that "every subject conceives of itself as the condition of all the others" (ibid.), which in context with the established terms underlines the notion that there can only be one subject within each self 11 . Consequently, the recipient's observation of the characters in Storm might enable him or her to deduce that they probably view themselves as subjects as well, but the reader himself can only see them as others ${ }^{12}$. Hence, the influence of Storm on the recipient is that of others on a subject, not of subjects on a subject.

Secondly, when speaking of 'the recipient's' perception of a text, this obviously involves a generalisation. However, despite the fact that every individual reader reacts to and experiences a text differently, this generalisation is, to an extent, justified, because, as Petersen states, no reader of a fictional text is identical to him- or herself as a real person (20). He elaborates that a reader becomes a "fictional reader" ("Fiktional-Leser", ibid.) ${ }^{13}$ when he or she enters the fictional realm of the text, which means that the reception mechanisms which the reader uses in the real world are replaced by those that function in the fictional world (ibid.). These reception mechanisms of the fictional world oblige the fictional reader to perceive everything within it as true (ibid.), because it cannot be established within the reader's mind if its entire design - everything that is said about it - is constantly doubted. Petersen also acknowledges that this does not mean that the real reader's individual personality is abandoned completely (21), and he accepts that the interpretation of a fictional text depends both on the recipient and the text itself (36). For instance, if a real reader of Storm is entirely opposed to the narrator's views and behaviour, he or she is unlikely to agree with him wholeheartedly within the fictional world, since it would mean the incorporation of part of the other into identity and, thus, a destabilisation and reorganisation of the self. Nonetheless, the factor that actually determines the reading of the text, Petersen argues, is the text itself and not the reading subject, because the fictional reader usually has little choice but to accept everything presented within the fictional world (which he or she is part of) as true (ibid.). This general acceptance of the fictional world as being true, which all fictional readers must have to some extent, justifies the assumption that certain effects of Storm apply to more than just a fraction of its recipients' identification processes.

11 Unless, perhaps, in certain cases of mental illness, where it seems as though multiple personalities inhabit one mind. That thought is speculative, however.

12 'Others' meaning different parts of the overall other in the recipient's self.

13 Unless a different source is stated, translations of Petersens terms are devised by the author of this paper and the respective original is given and referenced in parentheses. 


\section{How the Narrative and Narrative Techniques Elicit Identification}

\subsection{Time and Space}

This first part of the analysis of Storm will focus on the narrative system of the text. Petersen's book on narrative systems (Erzählsysteme) provides a thorough and useful basis for examining the narrative structure and its potential influences on the reader.

First of all it should be mentioned that, in accord with Petersen, the narrator will not be seen as identical with the author, but instead viewed as a part of the fictional world of the narration, a medium devised by the author (16). Hence, the author is the creator of the narrative structure of the text, but not part of it (16) and therefore not too important when the reception of a fictional text's narrative is examined.

Petersen states that one major property of fictional texts that allows the reader to identify with characters portrayed in them is the lack of time and place (8). This does not mean, of course, that the setting of a fictional text does not matter, but because the real reader becomes a fictional reader within the narrative system, he or she is automatically 'transported' to the time and place of the fictional world. Discrepancies between the reality of the reader and the fictionality of the text thus do not necessarily keep the reader from assuming the views of characters, because the reader's individuality is partially deleted (ibid.).

Petersen also mentions that this only works if the fictional world is described with the same linguistic signs as the real world of the reader (9). Thus, the setting of Storm in a London inner city "top floor flat" (Minchin 1) - no too specific type of flat, really - will probably be more readily recognised as part of the fictional world by western readers than a setting, e.g., in a yurt in the Gobi Desert. Storm is hence set in a both spatially and situationally imaginable environment in the eyes of most (western) readers which certainly facilitates their immersion into the fictional world, thereby also increasing their susceptibility to influences on processes of identification. Because the recipient can recognise the subject positions represented by the setting, they and other subject positions shown in the text are more readily incorporated into his identity (or excluded from it and therefore still constitutive of it through otherness).

The time of the events in Storm, quite like the spatial setting, does not seem too remote for contemporary readers to imagine. Admittedly, no specific date is mentioned in the text, but the reference to Michael Jackson (148), for instance, suggests that the story takes place sometime around the turn of the twentieth century. Furthermore, Storm is narrated in the present tense, which of course does not automatically imply that the text is set in the reader's real present, but at least gives the impression of relative synchrony with the real world and a sense of relevance to the reader. Petersen mentions several different capacities in which the present 
tense ("Präsens") occurs in (German) literature (21-30), but it seems that its use only has distinct effects when combined with other tenses to create a contrast of some sort.

In Storm, the tense of the narration does not change and therefore a more indepth analysis of how the use of the present tense influences the recipient will be omitted here. Suffice it to say that both the setting and the tense of the narration facilitate the fictional reader's orientation in the fictional world, making him or her more susceptible to other influences of the narrative.

For instance, the narrator remarks that Storm, "like her meteorological namesake" (Minchin 71), does not consider how her comments might annoy the rest of the people at the dinner party. Thus, he portrays Storm as being inconsiderate and impolite in the context of civilised company. If the setting were not a flat in contemporary London, however, but, for example, a tent in the camp of some ancient barbarian tribe, Storm's lack of consideration would presumably appear in a different light. In that case, the reader might not be certain whether Storm is disregarding the prevalent social etiquette or not and therefore hesitate to agree with the narrator's opinion that Storm is behaving rudely. The actual setting of Storm does not provide reasons to doubt the narrator's judgement to such an extent, and so, it serves to raise the recipient's responsiveness to interpellation by Storm.

\subsection{The Form of Narration}

\section{Forms of Narration and the Fictional}

Petersen categorises the components that make up narrative systems according to the different relations between the narrated, the narrator and the reader which they describe. He calls the ontic ${ }^{14}$ connection between the narrator and the narrated the form of narration (")Erzählform»", 53) and here distinguishes between the I-form, the he-form and the you-form (53-65). In Storm the I-form is used, because the narrator refers to himself as "I" and is a figure in the story, which means that the reader receives an overtly subjective account of the events. The I-form could thus simply serve to represent the narrator's view of the fictional reality as indisputably correct, since the reader, as mentioned before, generally has to assume that most of that which is said about the fictional world is true. Hence, if the narrator states that Storm's arguments for alternative medicine are invalid, then the reader can only doubt the truth of that statement by drawing upon his or her real life knowledge or

14 "Ontic connection" ("ontische Verhältnis", 53) seemingly means the relation in which the entities exist to each other (i.e. is the one part of the other or are they separate, perhaps even opposite?). The term is presumably employed by Petersen because he also describes other connections between the narrator and the narrated (for instance how the narrator is able to view the narrated, as opposed to where he stands in relation to it). The exact meaning of the term was deemed inconsequential for this paper, since it becomes clear from Petersen's text what exactly he means by form of narration, and since the term does not reoccur to any noteworthy extent. 
opinion on the matter (or by finding signs within the story which reveal that the narrator may be wrong).

Within the realm of the fictional, the narrator's descriptions and judgements mostly remain uncontested as long as they are not logically flawed or otherwise challenged inside the fictional world. Indeed, as long as the I-narrator in Storm does not gravely undermine his own credibility, the reader cannot contest his account without referring to the real world and thereby also disrupting the perceived fictionality of the text. Consequently, he or she would presumably cease to be a proper fictional reader, because the fictional reader is part of the fictional world that is then subverted.

On the level of the reader's self, the denial of the fictionality of the text could mean that some element of it may have been deemed a threat to the recipient's understanding of the real world (and to his or her current identity) and that whatever it was that unsettled the reader is part of his or her other. It can thus be said that if an element of the fictional world of Storm is recognised by the recipient as being a part of his or her other, identification with that subject position is unlikely to occur. Instead, perhaps, the text must promote subject positions which are either already loosely incorporated into the recipient's identity or which are created while reading. For instance, someone who reads Storm might be rather religious and spiritual like Storm is, yet unaware of the narrator's notion that "Science adjusts its views based on what's observed" (Minchin 164), while "Faith is the denial of observation so that belief can be preserved" (165). Hence, this statement by the narrator will presumably not make the reader stop being religious, but it could make him or her aware of the idea that some religious people can be bigoted. This might make the recipient consider him- or herself to be religious, still, but specifically not in a bigoted way. Thus, hypothetically, the new subject position of 'not being bigoted' or maybe of 'being open-minded' might arise and become a part of the reader's identity.

\section{The Experiencing I and the Narrating I}

The problem that elements of the fictional world may represent parts of the recipient's other and therefore be unavailable for incorporation into his or her identity is not necessarily a unique effect of the I-form of narration, but could arise in a particularly biased narration in the he- or you-form as well. What is distinct about the I-form, Petersen argues, is that it renders both the narrating I and the experiencing I recognisable (56). This distinction is particularly prominent when an I-narrator tells a story that lies in the past and comments on it from a later perspective, as Petersen demonstrates (56).

Although Storm is narrated in the present tense and although most of the account seems to be given from the perspective of the experiencing I, it could be argued that the duality between narrating and experiencing I can be spotted here as well. After Storm releases a tirade of spiritualist arguments which are dismissed as 
"vacuous crap" (Minchin 123) by the narrator, he speculates, "Maybe it's the Hamlet she just misquothed / or the fifth glass of wine I just quaffed, / but my diplomacy-dyke groans / and the arsehole held back by its stones / can be held back no more." (124-128) While it is possible that the notions of the "diplomacy-dyke" and the "arsehole held back by its stones" are part of the way the experiencing I perceives and processes the situation at the time when it occurs, the reflections upon the cause of the outburst that follows - Storm's misquoting of Shakespeare or the excessive consumption of alcohol - seem like additions made by the narrating I. Considering that the experiencing $\mathrm{I}$ is described as being absolutely stunned and infuriated by Storm's words, not to mention intoxicated by the wine, it simply seems unlikely that he would be able to reflect so soberly upon the cause of the rant which he is about to release. There can be no certainty, of course, as to whether these sentiments originate from the experiencing I or the narrating I, but at least it becomes clear that this passage and others like it are ambiguous when it comes to the bipolarity of the I-narrative.

The capacity of the I-narration to show both the experiencing I's and the narrating I's perspective and evaluation of events in the story may have significant effects on the recipient's inclination to identify with the narrator. It could be argued that the I-narration appears to be more objective than even a he-narration which displays only the perspective of one character. Thus, if the I-narration shows events both from the perspective of the experiencing I at the time when they take place and from the perspective of the narrating I at the time when the story is narrated, then the former perspective may seem more subjective, but the latter will probably seem more considered and self-reflective. After all, it is still the same person speaking, but presumably at a later time, and the narrating I can potentially provide thoughts on a situation which the experiencing I may not have had when that situation occurred. This degree of self-reflection - self-evaluation even - exhibited by the narrating I may make the narrator seem more sincere and trustworthy, which is why instances where the narrating I can be detected can make the narrator appear more reliable, honest and objective to the reader. As this effect is made possible only in the I-form, it can be concluded that this form of narration helps to firmly ground the fictional reader in the fictional world and to encourage his or her acceptance of the it, thus making him or her more prone to incorporate subject positions presented in the text into his or her identity.

\section{The I-Form in Storm}

As mentioned before, there is the problem in Storm that the narrating I never appears to occur indubitably, but only ever in ambiguous instances. However, it also seems as though the I-form's trust-enhancing self-reflectivity can still emerge, since a sense that the narrating $I$ is potentially self-observant and somewhat critical towards its own actions is likely to come across nonetheless. 
The narrator notices, for instance, that his hostess throws him a warning glance to make sure that he does not burst into one of his "rare, but fun, rants" (Minchin 62-64). Although this particular piece of self-description may seem rather selfsatisfied, it still shows that the narrator - either as the experiencing or narrating I is by no means unaware of his shortcomings, which makes his account seem more honest, if in this case perhaps also a little self-congratulatory.

Another similar example can be seen when he casually describes an utterance which he makes at an early point during the dinner party as "some un-hippily empirical comment" (37-38). Storm is previously in the text described in a way that may suggest that she is a hippie (22-31), but it does not seem as though the narrator is convinced of this or aware that his comment is pointedly "un-hippily" when he makes it. At the time, he presumably simply stated his opinion and only became aware of his comment's "un-hippily" nature once he noticed that Storm disagrees with him, which would indicate that it is the perspective of the narrating $I$ that is given here, rather than that of the experiencing I. Neither does he describe more specifically what his comment entails which may indicate that he does not even remember it in sufficient detail. Again, this would suggest that the view of the narrating $I$ is presented which, due to its self-reflectivity, makes the entire narrative seem more thoroughly thought through and reliable. This facilitates the recipient's potential identification with subject positions presented in the text, since it also makes those subject positions seem reliable and stabilising in the recipient's imagination.

A problem with the assumption that the time of events precedes the time of narration in Storm is of course that the text is narrated in the present tense, which seems to indicate that the time of the events and the time when they are narrated are the same. Realistically, however, one would also intuitively assume that the narrator cannot be part of the events and recount them at the same time (except while writing a diary, perhaps), and Petersen states that the epic present tense has the same function as the epic past tense (24). Hence, the notion that the experiencing I's perspective is an earlier one than that of the narrating I seems appropriate here.

\section{Personality}

One further aspect of the form of narration mentioned by Petersen is that the more subjective the narration is, the more prominent the personality ("Personalität") of the narrating I becomes (59). In Storm, as demonstrated, the narrating I does not figure very prominently and thus does not actively comment on the events, even though it becomes apparent enough to indicate some self-reflection on the part of the narrator. The account therefore seems somewhat neutral and factual and not as if the narrator was trying to impose his opinion on the reader.

Later in the poem, of course, the narration consists mostly of the experiencing I's direct speech, which is directed at Storm, but perceived by the reader as well. 
Thus, the experiencing I's opinion may still be imposed on the reader, but since the narrating I (who is closer to the recipient than the experiencing I, because he is the medium who relays the information) does not have such a direct influence, it presumably does not make the recipient uncomfortable by trying to force an opinion on him or her. A more urging attitude towards the reader and a more overt personality of the narrating I might contest the reader's identity to a degree where identification with the narrator's viewpoint would be prevented because it would be perceived as a threat to the stability of the recipient's self. Interestingly, many of Storm's comments quoted by the narrator seem far more absolute and forward than the narrator's account, which may cause the reader to perceive Storm's views as a threat to his or her identity rather than the comparatively mild seeming narrator. When the narrator begins to quote himself as an acting character later in the text, this impression might shift to some degree, as he, too becomes quite urgent and offensive.

It will hopefully have become apparent in this section, that the form of narration in Storm - the I-form - serves to make the narrator seem reliable and honest in his account, thereby increasing the recipient's inclination to incorporate the narrator's views into his or her identity as subject positions. It could therefore be seen as a tool to establish the narrator, who is an other in the self of the reader, as a promoter position that is able to influence the organisation of the recipient's self and identity.

\subsection{The Narrator's Point of View}

According to Petersen, the form of narration describes the connection between the narrator and the narrated (53), and so does the point of view of the narrator ("Standort des Erzählers", ibid.), but on a spatial and temporal level. Petersen also makes mention of the issue that in the English-speaking world the term 'point of view' is often used to refer to a mixture of the narrator's point of view, the narrator's perception ("»Sichtweise «", 65) (i.e. his/her capability to perceive the thoughts and emotions of characters) and sometimes even the narrator's behaviour ("Erzählverhalten", 68).

To some extent, the point of view in Storm has already been discussed, as it has been assessed in chapter 3.2 that Storm is presumably narrated slightly after the events have actually taken place. Thus, the temporal relation between the narrator and the narrated can be described as very close, but not quite synchronous.

As for the spacial distance, it has also already been pointed out that the difference between the narrating and the experiencing I is rather small and mostly ambiguous, so that the narrator is more or less identical with himself as a figure in the story and therefore very close to the happenings. This limits his overview in comparison to an omniscient he-narrator, of course, and because only the narrator's own narrow point of view is shown, it is difficult for the reader to consider the events from Storm's angle other than by interpreting the narrator's rendition of her 
behaviour and utterances ${ }^{15}$. Consequently, the point of view of the narrator makes it harder for the reader to identify with Storm's opinions, since the reader shares the perspective of the narrator and therefore observes Storm as being opposite him- or herself and possibly even as being part of his or her own other. Thus, the point of view in Storm supports the exclusion of the subject positions represented by Storm and furthers the instalment of the narrator as a promoter position within the recipient's self by putting the reader in the narrator's position.

\subsection{The Perception of the Narrator}

Petersen's category of the perceptions ("Sichtweisen", 67) of the narrator has a similar effect as the point of view, because it concerns the capability of the narrator on the one hand to describe the outer appearance of characters and on the other hand to relay their thoughts and feelings to the reader (67).

In Storm the narrator is only capable of perceiving his own inner state of mind, which, considering that he is an I-narrator, makes sense. Admittedly, Petersen mentions cases where an I-narrator is also aware of the thoughts of others (67-68), yet in Storm the thoughts of other characters are not represented in their unaltered form, but only as the narrator's interpretations of their actions. For instance, after Storm counters the narrator's "unhippily empirical comment" (Minchin 37-38), his wife "widens her eyes" (41), silently begging him to "be nice" (42), which shows that he does not actually render her thoughts, but only non-verbal communication between her and him. Similarly, when he states, "My hostess throws me a glance / she, like my wife, knows there's a chance / I'll be off on one of my rare, but fun, rants" (62-64), he does not seem to be able to describe her thoughts without receiving any external input from her to interpret. Although similar examples lead Petersen to assume that an I-narrator can also relay the inner lives of other characters (68), it is still clear that he or she has to conclude them from those character's actions. The sentiments are thus filtered through the narrator's subjectivity and therefore by no means reliable; possibly they are only phantasms of the narrator.

By only describing his own thoughts and feelings, the narrator makes it easy for the reader to empathise with him, but difficult to comprehend the motivations of other characters, especially those of Storm. The reader thus has a chance to understand and evaluate the reasons behind the narrator's actions, while Storm's motives (beyond her direct comments) remain obscure. Therefore, assuming Storm's views, or - more specifically - occupying the subject positions represented by them, will seem unproductive to the reader because they do not appear to be able to provide his or her identity with any stability or organisation due to their vagueness. Of course, large parts of the text consist of direct speech by both the narrator and Storm, so that it could be argued that Storm's motivations are to

15 Naturally, the narrator may also choose to withhold certain information, but this eventuality will not be considered here for the sake of brevity. 
some degree represented in that form. Nonetheless, as long as the narrator only reports his experience without quoting Storm, he never even speculates as to what might be driving her.

The rendering of the events at the dinner party through the narrator's subjective perception thus furthers his establishment as a promoter position in the recipient's self. Making Storm's motivations seem hard to comprehend, perhaps even incomprehensible also supports the exclusion of the subject positions she represents into the reader's other, while the subject positions favoured by the narrator are promoted. Consequently, the narrator not only installs himself as a promoter position, but already acts as one in manipulating Storm's image in the recipient's mind and in enforcing the interpellation of his preferred subject positions.

\subsection{The Narrator's Behaviour}

The category of the narrator's behaviour ("Erzählverhalten", Petersen 68) encompasses exactly what it says on the tin: it is the manner in which the narrator presents the narrated (68). It should be emphasised that this does not involve the attitude of the narrator towards the narrated, but only the question: does he or does he not evaluate and comment on the narrated, does some kind of subjectivity take effect in the narration? The three kinds of behaviour suggested by Petersen are authorial ("auktoriale"), personal ("personale") and neutral ("neutrale") behaviour (68). Neutral behaviour essentially means that the narrator neither comments on the narrated nor assumes the perspective of a character (74). The narrator in Storm is clearly not neutral, since he is actually one of the characters in the narrative and overtly subjective in his account. Hence, he must be authorial or personal.

Authorial behaviour means that the narrating medium can intervene in the narration to comment on or to assess characters, situations and other elements of the narrated (68). In Storm, this seems to be the case insofar as the narrator certainly does not reserve judgement on Storm. This being said, personal narrative behaviour may involve commentary as well, but only such that it renders the perspective of a figure in the narration, not that of the narrating medium (69). This, too, could to be the case in Storm, as the I-narrator is both the narrating medium and a character. Hence the problem prompted by Storm is once more the uncertainty whether or not narrating and experiencing I can really be separated. It has already been assumed in chapter 3.2, however, that the narration and the events do not take place synchronously and hence that the narrating I can indeed be distinguished from the experiencing I. The narrator must therefore rather be regarded as authorial, because he comments on the happenings from a subsequent and non-figural perhaps 'post-figural' - perspective.

Concerning the reader's potential identification with subject positions represented in the narration, the narrator's authorial behaviour allows for a crucial effect: it enables the narrator to address the recipient fairly directly. Whenever the narrating I comments on the narrated, that additional information is relayed to the 
reader and influences the way he or she evaluates the narrated. The narrator in Storm - as the narrating I and not the character - can thus attempt to lure the recipient into sharing his views by demoting the subject positions assigned to Storm and by elevating those represented by himself.

For instance, by mentioning that Storm, "like her meteorological namesake" (Minchin 71), does not seem to be concerned about the atmosphere at the dinner table (a comment which could be attributed to the narrating I), the narrating medium tries to convey to the reader that Storm is inconsiderate. It is also said that the narrator himself has "no intention of rocking the boat" (69), which presents him as being more socially aware and therefore superior to Storm. Similarly, the narrating I's allusion to his "rare, but fun, rants" (64) significantly takes the edge of the notion of a prospective defiant tirade against Storm, possibly even making the reader curious to know what such a rant might entail and why it might be "fun". Thus, the narrating I attempts to make what may objectively be considered rude behaviour (i.e. ranting) seem acceptable, even enjoyable, when he himself exhibits it, whilst at the same time depicting Storm's demeanour as reckless and anti-social.

On the level of the reader's self, this means that the narrating medium as a promoter position 'promotes' the subject positions represented by the experiencing I to elicit or reaffirm (depending on whether or not they are already occupied by the subject) their incorporation into the recipient's identity. This 'promotion' of certain subject positions means that the interpellation of the subject is augmented in such a way that the subject's affinity to them is increased.

As assessed in chapter 2, the two main factors that influence interpellation and the subject's inclination to occupy certain positions are the imagined stabilising effects of those positions and their capacity to exclude. In the case of Storm's alleged lack of consideration, it seems that mainly the latter takes effect, since the narrating I points out the difference between himself and Storm. By authorially disparaging the subject positions represented by Storm, the narrator causes the exclusion of those subject positions from the recipient's identity and hence, by implication, their integration into his or her other. Since the narrator represents the opposite of Storm's positions in the duality of 'considerateness' versus a lack thereof, his positions cannot be part of the reader's other as long as Storm's are, and must therefore be incorporated into identity (assuming that the reader is indeed influenced by the narrating I's interventions). Hence, the authorial narrative behaviour enables the narrator to display circumstances and characters in ways that to a considerable degree alter the recipient's conception of them including his or her tendency to identify with them. 


\subsection{The Narrative Attitude}

\section{The Attitude towards Characters}

To some extent the narrative attitude ("Erzählhaltung", Petersen 78) has already been touched upon in the previous chapter. While the category of the narrator's behaviour only describes whether or not and from what perspective the narrator comments on the narrated, the narrative attitude encompasses the narrator's posture towards the narrated (ibid.). A neutral narrative attitude thus means more or less the same as neutral behaviour: that the narrator does not express or show any kind of sentiment, but simply relays factual information and direct speech to the reader (ibid.). Since the narrator in Storm is obviously biased, he most certainly cannot be considered neutral.

Petersen states that a narrator's attitude towards the narrated, towards characters and their thinking and demeanour can be affirmative or dismissive, critical, sceptical or varying, and that it may occur to a varying degree of sophistication and clarity (ibid.). It is not only expressed in authorial interventions, but can also be extrapolated from other stylistic devices used by the narrator, for instance if a particularly ironic narrating style is assumed (ibid.). Hence, both the narrative attitude and the way it is articulated must be considered on the basis of the linguistic devices used by the narrator.

In Storm, as has already been shown, the narrative attitude can to some extent be seen in the authorial interventions by the narrating I, which are made to subtly disparage Storm and to promote the narrator's views. However, the rest of the narration is very subjective as well and comments are also made from the figural perspective of the experiencing I. For instance, the narrator mentions that "Conversation is initially bright and light-hearted, / but it's not long before Storm gets started" (Minchin 32-33), suggesting that it was to be expected that Storm would become annoying at some point. His attitude towards Storm is thus not only dismissive, but prejudiced as well, as he already anticipates her supposedly reckless behaviour. The narrator's attitude remains pejorative of Storm's allegedly stereotypical, anti-scientific arguments throughout the narration and he later compares her to a "sniper using bollocks for ammunition" (155), which also shows that his language becomes more derogatory in his later descriptions of her.

After Storm states that "You can't know anything, / knowledge is merely opinion" (34-35), the narrator discloses his "urge to ask Storm / whether knowledge is so loose weave / of a morning, / when deciding whether to leave / her apartment by the front door, / or the window on her second floor" (45-50), thereby sarcastically dismissing her utterance and even casually raising the idea of her being injured in a fall. It can thus be seen that the narrator expresses his attitude towards Storm far less subtly when he narrates from the perspective of the experiencing I. 
Since the reader, particularly on this occasion, is aware that the described sentiments belong to the experiencing I who has to resist the urge to express them, it becomes clear that these notions are very subjective. It could hence be argued that the narration seems to be rather undifferentiated which would make the narrator seem unreliable and potentially decrease the reader's inclination to share his views (unless he or she does so already and is amused by the remark). However, other readers too may recognize the experiencing I's internal response to Storm's claim as valid, since Storm - despite her disbelief in the existence of knowledge - is presumably indeed certain that leaving a second floor flat by the window instead of the door is impractical, possibly even dangerous. Furthermore, at this point in the narration recipients may have noticed (as pointed out in chapter 3.2) that one can also see the slightly more objective narrating I in Storm, which to some extent has the capability to retrospectively re-evaluate the narrated. As the narrating I in no way seems to intervene to mitigate the experiencing I's harsh thoughts, it appears as if the narrating I yet approves of them. Within the fictional world, the notion of Storm falling out of the window is thus rendered somewhat acceptable and does not necessarily lower the recipient's tendency to share the narrator's opinions.

The narrator's attitude towards himself - he is, after all, also part of the narrated as a character - is of course rather approving, but he also shows a certain degree of self-irony when it comes to his irritability in the face of what he perceives as Storm's ignorance and naivety. This can be seen in the examination of his supposedly "rare, but fun, rants" (64) in chapter 3.2, but also in his confession that he labels Storm as belonging to a group of people whose values he repudiates:

And when she says: "I'm sagittarian", I confess a pigeon hole starts to form and is immediately filled with pigeon when she says her name is 'Storm'. (28-31)

The narrator, thus, does not attempt to hide his prejudice from the reader and seems to articulate his attitude toward himself very openly and honestly which probably makes him seem like a fairly decent person in the recipient's eyes.

\section{Self-Subversion of the Narrator}

It has already been stated that the narrator keeps pointing out Storm's alleged inconsideration, whilst describing himself as being careful to bite back his annoyance at Storm for the benefit of the general mood at the dinner party. Hence, it seems that leading up to his rather rampant argument with Storm later in the poem, he feels that he has to justify his increasingly unrestrained reactions to her allegedly anti-scientific propositions. For instance, he states: 
And although Storm is starting to get my goat,

I have no intention of rocking the boat.

Although it's becoming a bit of a wrestle, because like her meteorological namesake

Storm has no such concerns for our vessel. (68-69)

He clearly does not take responsibility for his inability to pull himself together, but blames Storm for it, which suggests that he is aware of his lack of self-restraint but unwilling to admit to it. Assuming that this is the case, the reader may get the idea that the narrator is less sure of himself and of the views he holds than he seems on the surface. This might bring on doubts about the validity of his standpoint and decrease the recipient's inclination to identify with him. In other words, the subject positions represented and promoted by the narrator may seem less stabilising and justifiable, and the recipient's subject's affinity to those subject positions might falter. This also shows that if the narration in Storm is deconstructed in a certain way, instances where interpellation can actually cause the subject to turn away from the narrator's subject positions can also occur.

As shown in the previous paragraph, the narrative attitude can also be employed to draw conclusions about the narrator himself, as "every explicit statement about another character is also an implicit (often unconscious) instance of selfcharacterisation" (Nünning and Nünning 107). An even more detailed analysis of what character traits of the narrator can be derived from the narrator's attitude will be refrained from here, as it would go beyond the aim of this paper. Suffice it to say that it may indeed be possible to deconstruct more narrative features than just the narrative attitude in Storm in such a way that the narrator's position is substantially undermined.

\subsection{Modes of Representation}

\section{The Modes in Storm}

Modes of representation ("Arten der Darbietung", Petersen 80) are the different uses of language which the narrator employs to relay the narrated (ibid.). This includes the narrator's account ("Erzählerbericht", ibid.), free indirect discourse ("erlebte Rede", ibid.; translation from Nünning and Nünning 189), indirect speech ("indirekte Rede", Petersen 80), the interior monologue ("inneren Monolog", ibid.) and the dialogue or direct speech ("Dialog bzw. [. . .] direkte Rede", ibid.). As for the narrator's account, Petersen specifies that it may contain descriptions, but also hints and foreshadowing as long as the narrating medium speaks and the information refers to the narrated rather than to the narrator or the reader (ibid.). Petersen also points out that it can be difficult to differentiate between the narrator's account and free 
indirect discourse, but is of the opinion that the context usually helps to determine which mode of representation is being used (ibid.).

In Storm, the prevalent modes of representation seem to be free indirect discourse and direct speech, although there are quite a few instances where - due to the uncertainty if the narrating I's or the experiencing I's perspective is rendered it is hard to tell whether an account, free indirect discourse or even an interior monologue is at hand. Direct speech is, of course, easily identifiable ${ }^{16}$, and indirect speech does not seem to occur at all in Storm $^{17}$.

The difficulty of distinguishing between an account, free indirect discourse and interior monologue already arises in the first few lines of Storm:

Inner north London, top floor flat,
all white walls, white carpet, white cat,
rice paper partitions,
modern art and ambition,
the host's a physician,
bright bloke, has his own practice,
his girlfriend's an actress,
an old mate of ours from home
and they're always great fun,
so to dinner we've come. (Minchin 1-10)

Vera and Ansgar Nünning name "the omission of all verbs of thinking and feeling, the complete removal of any mediating instance from the narrative" and "the presentation of the character's mental processes in his or her language" (126) among the characteristics of the interior monologue. While these criteria mostly seem to apply, the "removal of any mediating instance from the narrative" is no longer given in the last line: "so to dinner we've come" (Minchin 10). The implication of the pronoun "we" is that there is an I-narrator (or at least - rather unusually something like 'we-narrators') and considering the fact that there also does not seem to be a complete "omission of punctuation" (Nünning and Nünning 126), it seems unlikely that an interior monologue is really the case here ${ }^{18}$.

16 If direct speech is considered to be the rendition of utterances in their exact wording in quotation marks, as it is here.

17 Indirect speech is here considered to be the indirect, yet faithful rendition of characters' direct statements by the narrator. However, whenever a character in Storm makes an utterance, the information is either relayed as direct speech (i.e. directly quoted by the narrator), or omitted and just hinted at. Hence, indirect speech does not seem to occur, unless, perhaps, one could spot it somewhere with considerable interpretative effort.

18 Of course, the punctuation in Storm cannot be extrapolated from its performance, which means that punctuation may indeed be left out here. Nonetheless, the occurrence of the pronoun "we" will be seen as a sufficient reason for dismissing the notion that the respective excerpt could be an interior monologue. 
Much rather, the occurrence of a narrator suggests that the quoted excerpt from Storm is a narrator's account, albeit syntactically modified. Petersen's specification that an account is concerned with the narrated rather than the narrator himself or the reader (80) also seems to apply to the quoted passage, as the narrator indeed barely shows himself and as the reader is not addressed in any way. However, the issue of whether or not the account is given by the narrating or the experiencing I arises. The speaker clearly states, "we've come", which implies that 'they' have now arrived in the previously described setting and that the experiencing I's perspective is conveyed here. This impression is supported by the fact that the entire passage barely contains any personal pronouns or verbs, which suggests that an experience rather than an organised narration is rendered. Admittedly, Petersen acknowledges that no specific stylistic qualities are linked to a narrator's account, but he also mentions that the narrative must be presented by the epic medium (80). Since the I-narrator can occur in the capacity of both the experiencing and the narrating I, he can only be fully recognised as the epic medium in the form of the narrating I otherwise he only appears as a figure in the narrated. In the aforementioned quote from the beginning of Storm that does not seem to be the case. Thus, describing the passage as an account is inappropriate as well.

Free indirect discourse, bearing some resemblance to the interior monologue, means that "the character's thoughts and feelings are generally reported in his or her own language" (Nünning and Nünning 125). Furthermore, "free indirect discourse attempts to convey the illusion of offering an immediate insight into the perceptions and internal processes of a character." (ibid.) This certainly seems to be the case in the beginning of Storm and the "loose syntax" and "signals of subjectivity" (ibid.) also seem to be given, because it is clear that the rendered thoughts and evocations belong to the experiencing I, who is also part of the action. For these reasons and because both the interior monologue and the narrator's account have been discarded, the mode of representation in the beginning of Storm is free indirect discourse.

Indeed, there seems to be an alternation of free indirect discourse and (on fewer occasions) narrator's account throughout the rest of the poem - apart from the passages that are dialogue (i.e. direct speech), that is. As mentioned before, Petersen recognises that it can be hard to tell the two alternating modes apart, yet also remarks that the prevalent mode is most often easily discernible when considering the given context (80). But once more the difficulty in Storm is that the context in many instances allows for differing interpretations, because the I-narrator's bipolarity between experiencing and narrating I is only vaguely perceptible. Generally, it seems that the experiencing I's perspective is given, which suggests free indirect discourse. However, the few examples where the narrating I's view appears to be rendered (see previous chapters) could well be seen as narrator's accounts and the fluctuating perceptibility of the narrating medium seems to be the only way to determine which mode really is at hand - hence the ambiguity. Nonetheless, the 
possible effects of the prevalence of account and free indirect discourse on the recipient's inclination to identify can be examined.

\section{Effects of the Modes}

Petersen states that the perspective of the narrator and character merge in free indirect discourse (81). In the I-narration of Storm this is more or less the case already, since the narrator is a character. However, the fact that the narrator could also just render an account rather than the perspective of the experiencing I, yet chooses not to do so, suggests that the narrating and the experiencing I are, at large, in agreement. Thus, the combination of the two modes of narration (of which free indirect discourse is prevalent) further underlines that the relationship between the narrating I and the experiencing $I$ is rather harmonious. This suggests that the narrating I, which, as has been established in chapter 3.2, seems to have a more reflected and objective view of the events, shares the experiencing I's attitudes and opinions. Hence, the narrating I's apparent objectivity is to some extent transferred to the perspective of the experiencing I, potentially making its view seem less subjective and less specific to the narrated situation. The recipient might then perceive the narrator's thoughts and feelings as more sober and profound, and become more inclined to incorporate the seemingly stabilising and wellgrounded subject positions which they represent into his or her identity.

The interplay of free indirect discourse and narrator's account is at first only interrupted in the few cases when Storm is quoted in direct speech, for instance when she claims that "the human body is a mystery! / Science just falls in a hole / when it tries to explain the the nature of the soul!" (Minchin 59-61). These exclamations in direct speech can come across as somewhat disruptive of the narrator's rendition of the events, which may subtly cause the reader to become slightly annoyed at Storm. Thus, the narrator's insistence on the use of free indirect speech and account may also serve to make Storm's comments more noticeable by way of contrast and, perhaps, more unnerving. The reader would then presumably be more inclined to dismiss Storm's views and to accept those of the narrator.

Another interesting aspect regarding the use of modes of representation in Storm is that over the course of the poem there is a shift from the narrator's recount of the happenings towards more and more direct speech by the narrator and, to a lesser extent, by Storm. With regard to the plot, this is due to the circumstance that the narrator at first only describes the setting and his internal struggle to remain calm when confronted with Storm's opinions. When Storm keeps making remarks which the narrator finds increasingly preposterous and unjustifiable, he begins to counter her claims and his initially careful argumentation gradually becomes more unrestrained and defiant, culminating in a vigorous rant that is en- 
tirely rendered in direct speech ${ }^{19}$. Thus, the narrator as a narrating medium so to speak hands over the narration to the narrator as a character over the course of the text $^{20}$.

This development may play a significant role for the identity formation of the reader. As mentioned, the use of free indirect discourse and narrator's account in the beginning of the poem makes the reader more open to identifying with the narrator's views, because they seem rather moderated and not too urging. The assertions and opinions which the narrator expresses in direct speech, however, are rather direct. Hence, the recipient presumably perceives them as quite pressurising even though they are levelled at Storm. The earlier, 'milder' passages in free indirect discourse and as narrator's accounts could thus serve to somehow align the reader's views with those of the narrator to such an extent that the later, bolder argumentation will more readily be accepted by the recipient. Also, the fact that the criticism in the rant is directed at Storm rather than the recipient maybe takes the edge off it slightly, so that it may not seem quite as vile to the reader as it presumably does to Storm, its direct target.

On the level of the self, the gradually changing influence of Storm on the reader's identity could be interpreted in the following way. At first, when free indirect discourse and narrator's account are dominant in the narration, the subject positions that are represented and promoted by the narrator are established and incorporated into the reader's identity. Later, when direct speech prevails, the then reformed identity of the reader is asserted and secured through the forceful exclusion of the subject positions represented by Storm. The narrator functions as a promoter position in both steps, first increasing the reader's subject's inclination to occupy the promoted subject positions and then supporting the organisation and stabilisation of the newly articulated identity. By the end of the reading of Storm the recipient, if this development really does take place ${ }^{21}$, may thus largely agree with the narrator.

19 As the text of Storm was transcribed from a performance, parts of the unrestrained speech could theoretically also be seen as interior monologue rather than direct speech. The choice not to do so in the transcription is based on the circumstance that the performance as well as the text itself seem to suggest that the narrator is in fact talking to Storm and not to himself (there seems to be an addressee for the rant).

20 Of course, the term 'narration' then becomes less appropriate, because the rant contains criticism rather than events. Nünning and Nünning define the term as a "superordinate account of $[. .$. events on the [...] extradiegetic level" (192), wherefore the delivery of the tirade by the narrator as a character makes it even less of a 'narration'.

21 There may be other possible developments within the reader, which will be omitted here for the sake of brevity. 


\subsection{Styles}

Petersen's styles ("Sprachstile", 81) are the manners in which an author lets his or her narrator and the characters speak (81). Petersen claims that "the more I-ish" ("je ichhafter", 83) the narrative is, the more individual and colourful the style of the narrator is. This also means that the narrator can be characterised by examining the way he or she speaks (83). In Storm, however, the entire narrative is also a poem and Petersen's only considers styles with respect to narrative and not lyric texts. Thus, the adequacy of applying Petersen's notions to poetry is doubtful, yet disregarding his ideas at this point may be rash, so a few observation shall be named.

The narrating and the experiencing I's styles do not seem to differ fundamentally. However, the experiencing I's direct speech, especially towards the end, seems more crude than the narrating I's rendering of the happenings. Since the experiencing $\mathrm{I}$ is the part of the narrator that directly interacts with Storm, his utterances are somewhat more vulgar. For instance, the frequency of the use of swearwords increases noticeably when the experiencing I begins his rant at Storm.

For the reader's inclination to assume the subject positions promoted by the narrator the effect of this increase in swearing depends on the recipient's attitude towards swearing. If he or she approves of it or even finds it enjoyable in this context, he or she will presumably identify further with the narrator's views. If he or she does not approve of swearing, however, then the reader will probably tend towards excluding the narrator's subject positions from his or her identity.

Storm's utterances throughout the text mainly appear to involve rhetorical questions like "Why take drugs / when herbs can solve it" (Minchin 78-79) and absolute statements such as "the human body is a mystery" (59). The experiencing I, during his tirade, uses a similar style as Storm, since he increasingly asks rhetorical questions and makes assertions without necessarily backing them up. For instance, he claims that "there's no such thing as an aura" (130) and does not make any attempt to justify this opinion.

A lack of evidence and explanations for such claims might make the reader wary of both Storm's and the experiencing I's opinion. However, the experiencing I's views are again supported by the narrating I's presence in the text. The narrating I does not intervene or elaborate and therefore, with its seemingly more objective view, seems to agree with the experiencing I, but not Storm. This, too, may well cause the recipient to side with the narrator rather than Storm. 


\section{How Poetry Invites Identification through Pleasure}

\subsection{Pleasure}

In the previous chapter the effects of the narrative system in Storm on the recipient have been examined. Yet the text is a poem and thus has lyric properties as well. The influence of these properties on the reader's inclination to identify will be examined on the basis of the assumption that poetry - as a form of art - can induce pleasure. The recipient's enjoyment of Storm may thus alter his or her tendency to identify with the narrator's views on a more emotional level than the already discussed narrative properties of the text seem to.

First, it must be considered what exactly pleasure does, how it works. Bloom proposes that "uniquely human" pleasures, "such as art, music, fiction, masochism and religion" (xi), are "affected by deeper factors, including what the person thinks about the true essence of what he or she is getting pleasure from" (24). Bloom bases this idea on the notion that human beings "naturally assume that things in the world - including other people - have invisible essences that make them what they are" (xii).

With respect to art he states that "displays of cleverness, discipline, strength, speed, and so on capture our interest because they reveal relevant properties of an individual" (136). This is important because a piece of art (in the case of Storm, a poem) may be considered to be precisely such a display of cleverness, wit, creativity, or some other sort of "valuable positive information about another person" (138). In Storm who that other person is depends on who is considered to speak. In the previous chapter it was assumed that the narrator is the speaking medium and for the sake of simplicity the same will be done here. Thus, it will be presumed that the "valuable positive information" is (mostly) about the narrator ${ }^{22}$, henceforth called the lyric $I^{23}$.

Another claim made by Bloom "is that we have evolved to take pleasure from virtuoso displays. This motivates us to seek out such displays, it drives us to create them ourselves, and it proves a psychological mechanism underlying our attraction to artists - they are capable of creating these objects that give us so much pleasure." (137-138) Thus, if a recipient recognises Storm as such a display, he or she is likely to gain pleasure from it. The fact that "we tend to like those who give us joy" (ibid.), then, means that someone who enjoys Storm will presumably be more in-

22 To some extent, this assumption implies that the poetic properties of the text originate from the narrator and not from the author. As mentioned before, the narrator is of course created by the author and so are the lyric elements of the poem. However, because the narrator and not the author has so far been considered to be the entity that readers may identify with, it will be assumed that the author lets the narrator and characters speak in poetic lines and that the poetry of Storm, thus, is perceived as coming from the narrator and other characters, rather than directly from the author.

23 The term lyric I was simply deemed more appropriate in the context of an examination of lyric qualities. 
clined to share the lyric I's views and therefore to incorporate the subject positions represented by the lyric I into his or her identity. This may seem commonsensical, but it is relevant nonetheless. However, why exactly should recipients appreciate Storm as an artistic display?

Bloom argues that "the perceived amount of effort" (141) that has gone into a piece of art plays a crucial role for people's assessment of it. The fact that "More effort leads to greater pleasure" (ibid.) means that in order to be appreciated by recipients, Storm must be recognised as an artistic display. An aspect of the text that might elicit this recognition is its sheer length: it is two hundred and forty-seven lines long (in the transcription used here), which for a poem is considerable, one might argue. In combination with the fact that the poem is also mostly written in rhyme, some of which may seem rather inventive - for instance the use of the end assonance ${ }^{24}$ of "favour" and "Australia" (Minchin 13-14) - the length may certainly show that a certain creative effort has been made ${ }^{25}$. Naturally, a reader may also find Storm distasteful and crude, in which case the disapproval will presumably have the opposite effect of pleasure (i.e. decrease his or her inclination to identify with presented views and beliefs).

If Storm is recognised as an artistic display, however, the recipient may gain pleasure from the text and become more inclined to accept the lyric I - even the entirety of the text - as a promoter position. Thus, the pleasure derived from Storm may serve to raise the recipient's openness for interpellation by certain elements of the content, thus indirectly affecting the reader's inclination to identify with subject positions represented in it. Furthermore, it could be argued that pleasure can also directly influence interpellation. If the joy derived from the text occurs in response to the humorous ridicule of a character, then that is an instance of exclusion. "Being laughed at is a surefire way of feeling put in your place - your place being absolutely not the place of those doing the laughing" (Medhurst 20) and thus, exclusion through ridicule, can be a strong instance of interpellation, uniting those who gain pleasure from it against those who are ridiculed.

This also happens in Storm. After a rather lengthy and conceptual explanation why so-called alternative medicine is not universally recognised as adequate, the narrator rhetorically asks Storm, "Do you know what they call alternative medicine that's been proved to work? / 'Medicine'." (Minchin 92-94). The humour - the pleasure - may here arise because suspense is built up when expectations of a complex, intellectualised answer to the question are raised. That suspense is released when the answer - in stark contrast to those expectations - turns out to be

24 Nünning and Nünning define "end assonance/vowel rhyme" as "congruence between vowel sounds only" (62).

25 Of course, rhyme is not the only poetic quality of Storm. However, the transcription used here is not meant to be a precise representation of elements like rhythm and metre. Therefore, an examination of these elements would seem speculative in this context. Rhyme and sound patterns largely remain recognisable even when the visual structure of the poem is altered and can therefore be considered here without too great a risk of inadequacy. 
blatantly simple. This play with the reader's expectations may be seen as humorous and therefore pleasurable.

The capacity of this passage to ridicule and exclude arises from a combination of the implication that Storm is naive and misinformed, and the pleasure derived from the witty way in which the narrator points this out (if it is perceived as witty). The recipient will most likely not be inclined to side with the ridiculed Storm and will therefore presumably lean towards occupying the narrator's subject positions.

\subsection{The Pleasure of Poetry}

The general recognition of Storm as art probably depends not only on the overall effort that seems to have gone into its creation. "What matters more", Bloom states, "is our intuitions about creativity and genius." (142) This means that perceived effort needs to go along with perceived originality or skill of some sort. "You need to be dazzled by the idea to be dazzled by the art" (146), and "our clashing intuitions about the quality of such artwork derive in large part from what we think of the performance. If you have a low opinion of the capabilities underlying a creation, then you will see it as bad art and get no pleasure from it" (ibid.), as Bloom puts it. Thus, it may prove useful to try to pinpoint instances in Storm where relatively creative or clever lyric devices are employed, because these may influence the reader's perception of specific views expressed in the poem.

The focus in the following analysis will be on imagery and comparisons because they can serve "to evoke the subject in a certain way or for a particular response" (Nelson 3) ${ }^{26}$, but can also give pleasure if they seem particularly inventive or appropriate. Thus, the recipient's tendency to identify with subject positions represented in Storm may in such cases be influenced both by the manner in which views are articulated, and by the emotional association of the voicing of those views with pleasure. However, this is not to say that elements other than comparisons are only capable of eliciting either pleasure or insight.

Rhyme, for instance, "is not simply an end in itself, but a way to emphasise certain words, and thus their meaning and connotations" (10). Yet, "rhyme and other special sound effects" may also "certainly add to the pleasure we receive" (ibid.) from poetry. The reason why imagery rather than phonological or structural aspects of Storm will be focused on in the analysis is that the connection between them and the argumentation in the text seems more obvious, because they "characterise the subject in ways that enhance our appreciation and understanding of it" (3). Rhyme, on the other hand, may certainly be used to emphasise words, but does not add extra meaning to them. Therefore an examination of the possible consequences of such emphasis would seem highly speculative and inadequate here.

26 The "subject" Nelson speaks of is the topic of a given piece of poetry, not the subject discussed in chapter 2 . 
Regarding rhythm and metre, the same problem occurs: "Any change in the metrical pattern usually means that the poet wishes to emphasise the word receiving the stress" (12). However, adding to the fact that stress alone does not enhance a word's meaning, the rhythm in the transcription used here cannot be considered to be entirely accurate (see chapter 1.), so an inquiry into its importance does not seem adequate here. Metaphors and similes on the other hand carry meaning of their own and are therefore easier to examine in context with the arguments put forward in the poem.

\subsection{Pleasurable Imagery in Storm}

In order not to render the analysis of imagery too lengthy, two particular examples will be examined here. The following occurs fairly early in the poem and has already been mentioned when the narrator's attitude was examined:

And when she says: "I'm sagittarian",

I confess a pigeon hole starts to form

and is immediately filled with pigeon

when she says her name is 'Storm'. (Minchin 28-31)

Firstly, why is this a metaphor? "Metaphor involves the removal of a word from its original semantic field and projection of this word onto an element from another semantic field." (Nünning and Nünning) In this case, the noun whose meaning changes is "pigeon hole", because what is meant here is not "a small recess for a domestic pigeon to nest in" or "each of a set of small open-fronted compartments in a workplace" (Oxford Dictionary of English 2005), but a prejudice about Storm in the lyric I's mind. In saying that he "confesses" that this prejudice is evoked by Storm's apparent belief in the importance of star signs, the lyric I seems to show that he feels slightly guilty for categorising her according to such a stereotype. However, the pigeon hole "is immediately filled with pigeon / when she says her name is 'Storm", which to him means that his labelling was, in fact, justified. Thus, due to the lyric I's seemingly acceptable labelling of Storm according to his prejudices about "hippies" (241), the reader might get the idea that his or her own pigeonholing of Storm is justified as well. Naturally, this can only happen if the recipient really has similar prejudices or has at least heard of the stereotypes which Storm seemingly perpetuates. The metaphor here may thus to some extent serve to illustrate the validation of the lyric I's preconceptions about Storm.

Yet the imagery may also work as a source of pleasure to the reader. As explained before, creativity and cleverness have the capability to give joy to the recipient. The use of the term "pigeon hole" in the sense in which it is employed here may well be seen as quite inventive, and the idea of it being filled with conceptual "pigeon" rather than 'pigeons' may certainly appear unusual and clever. If pleasure is evoked in the recipient in this way, his or her possible feeling of guilt 
for adhering to prejudices about "hippies" and for his or her lack of openmindedness may subside. Perhaps the pleasure might even be associated with the stereotyping of Storm, which might then be perceived as something desirable, even for readers who did not hold the stereotypes before reading the text.

The prejudices that are evoked or reinforced in this way presumably decrease the recipient's inclination to identify with Storm, since she is demonstratively categorised by the lyric I as 'other'. Furthermore, if the reader here receives pleasure from the text, he or she is likely to become more open towards incorporating subject positions represented in it into his or her identity. Since the happenings in the text are relayed through the perspective of the lyric I, most of those subject positions in it are probably the ones held and promoted by the lyric I.

It can thus be seen that metaphors both on the level of emotional pleasure and due to their capability to illustrate and explain thoughts and feelings can help to align the reader's identity with the views held by the lyric I.

The second example of imagery examined here can be seen in the following two passages. "And, try as I like, / a small crack appears / in my diplomacy-dyke" (85-87), and:
Maybe it's the Hamlet she just misquothed or the fifth glass of wine I just quaffed, but my diplomacy-dyke groans and the arsehole held back by its stones can be beld back no more. (124-128, emphasis added)

When the lyric I first says "a small crack appears / in my diplomacy-dyke", the image that springs to mind is probably that Storm, like an actual storm, is responsible for his decreasing self-control because he is annoyed at her apparent inconsideration and her allegedly false opinions. Earlier she is described as being "like her meteorological namesake", (71) and thus the comparison between her and a great storm that causes a breach in an embankment illustrates that she is allegedly responsible for the lyric I's increasing loss of self-restraint. The lyric I is displayed as a victim of his incapability to cope with the offence that Storm seemingly causes. When the "diplomacy-dyke groans / and the arsehole held back by its stones / can be held back no more", the imagery gains a third element: the "arsehole", the part of his personality which the lyric I tried to suppress.

In the metaphor, this element has not explicitly been mentioned until this point. Thus, it may serve to let the lyric I appear in a favourable light, as it suggests that he was not trying to contain himself, but that uncivilised part of himself, which somehow comes across as a separate entity here. The lyric I is to some degree portrayed as the innocent maintainer of the "diplomacy-dyke" who is helpless in the face of the natural disaster that Storm comes to represent. The implication is that he cannot be held responsible for his ensuing rudeness, and that Storm only has herself to blame for being ranted at by him. The recipient will therefore proba- 
bly deem the lyric I's following tirade to be far less inappropriate, as this reaction is to some extent justified by blaming it on Storm rather than on the narrator.

Furthermore, the maritime and meteorological imagery may - like the pigeon hole earlier - be perceived as rather creative, since it could be argued that it has a certain intricacy to it. For example, one would usually expect a dyke to protect settlements in coastal areas from floods caused by storms. In the metaphor in Storm, however, the reader soon comes to realise that the dyke is not meant to keep Storm from causing harm, but to protect her from the raging storm of the lyric I's furious rant. If the reader finds this use of imagery clever and sophisticated, then he or she will most likely derive pleasure from it, pleasure that is associated with the voice of the lyric I and thus causes a higher affinity of the recipient's subject to the lyric I's subject positions.

\section{Conclusion}

It has been made clear in this analysis that Storm seems to be laid out to convince the recipient to identify with the subject positions represented by the narrator. Both the narrative system and the use of poetic devices to evoke pleasure serve to achieve this in various ways: they elicit and support the establishment of the narrator (or lyric I) as a promoter position, they increase the reader's openness to and the potency of interpellation by elements of the text and they serve to demote Storm and her views. All of these effects certainly lead to an increased inclination of the recipient's subject to assume the subject positions promoted by the narrator by showing them in a favourable light. Especially the subjectivity created through narrative devices, but also through the ridicule of Storm serve to exclude her subject positions from being considered for identification and to render her as part of the reader's other.

Conducting a more detailed survey of the narrative situation and the lyric in Storm would likely reveal a different but equally reasonable reading of the text, since, as observed a few times, neither the effects of the narrative structure nor those of the poetic qualities of the text are unambiguous. The narrator's standpoint may well be subverted by either in many instances. Yet it ultimately seems to depend on the individual perceiving the poem whether approval and identification or disapproval and 'othering' of the narrator's subject positions occurs. Particularly the poetry of the text may well be perceived as quite unoriginal and lacking in virtuosity. For instance, the syntactic structure barely seems to differ from ordinary prose which may be seen as evidence of a lack of skill by the author. Furthermore, if the subjectivity of the narrator and his demeanour are consciously perceived and evaluated by readers, they may deem the narrator untrustworthy, presumably making them wary and unwilling to identify with the subject positions promoted by him. It could also be argued simply with regard to the argumentation of the narra- 
tor that he more than once subverts his own standpoint by contradicting his own principles ${ }^{27}$.

The aim of this paper, however, was simply to examine whether the narrative and poetic devices in Storm elicit identification with the narrator. That, it seems, is indeed the case.

27 For instance, he seems to insist that Storm's behaviour is inconsiderate, yet behaves quite similarly, perhaps even worse towards the end of the poem. 


\section{Transcript: Tim Minchin's Storm the Animated Movie}

Inner north London, top floor flat, all white walls, white carpet, white cat, rice paper partitions,

5 modern art and ambition, the host's a physician, bright bloke, has his own practice, his girlfriend's an actress, an old mate of ours from home and they're always great fun, so to dinner we've come.

The fifth guest is an unknown.

The hosts have just thrown us together for a favour, 'cause this girl's just arrived from Australia and she's moved to North London and she's the sister of someone or has some connection.

As we make introductions I'm struck by her beauty, she's irrefutably fair with dark eyes and dark hair, but as she sits, I admit, I'm a little bit wary, 'cause I notice the tip of the wing of a fairy tattooed on that popular area just above the derrière. And when she says: "I'm sagittarian", I confess a pigeon hole starts to form and is immediately filled with pigeon when she says her name is 'Storm'.

Conversation is initially bright and light-hearted, but it's not long before Storm gets started:

"You can't know anything, knowledge is merely opinion!", she opines over her Cabernet Sauvignon vis-à-vis some un-hippily 
empirical comment made by me.

Not a good start, I think, we're only on pre-dinner drinks and across the room my wife widens her eyes, silently begs me: "Be nice!"

A matrimonial warning not worth ignoring, so I resist the urge to ask Storm whether knowledge is so loose weave of a morning

when deciding whether to leave her apartment by the front door or the window on her second floor.

The food is delicious and Storm,

Whilst avoiding all meat

Happily sits and eats as the good doctor, slightly pissedly, holds court

on some anachronistic aspect of medical history when Storm suddenly insists:

"But the human body is a mystery!

Science just falls in a hole when it tries to explain the the nature of the soul!"

My hostess throws me a glance.

She, like my wife, knows there's a chance

I'll be off on one of my rare, but fun, rants, but I shan't, my lips are sealed,

I just want to enjoy the meal And although Storm is starting to get my goat, I have no intention of rocking the boat.

Although it's becoming a bit of a wrestle, because like her meteorological namesake Storm has no such concerns for our vessel. "Pharmaceutical companies are the enemy! They promote drug dependency at the cost of the natural remedies 
that are all our bodies need! They are immoral and driven by greed!

Why take drugs

80 when herbs can solve it?

Why use chemicals when homoeopathic solvents can resolve it?

I think it's time we all returned to live with natural medical alternatives."

85

And, try as I like, a small crack appears

in my diplomacy-dyke.

"By definition", I begin,

90

"alternative medicine", I continue, "has either not been proved to work, or been proved not to work.

Do you know what they call alternative medicine that's been proved to work?

'Medicine'."

"So you don't believe in any natural remedies?"

"On the contrary, Storm. Actually, before I came to tea

I took a remedy

100

derived from the bark of a willow tree, a painkiller that's virtually side-effect free.

It's got a weird name

darling, what was it again?

maspirin?

105

Er, baspirin?

Oh yes, aspirin!

which I paid about a buck for

down at the local drug store."

The debate briefly abates

110

as my hosts collect plates,

but when they return with dessert

Storm pertly asserts:

"Shakespeare said it first:

'There are more things in heaven and earth 
than exist in your philosophy.'

Science is just how we're trained to look at reality.

It doesn't explain love or spirituality.

How does science explain psychics, auras, the afterlife, the power of prayer?"

120

I'm becoming aware that I'm staring.

I'm like a rabbit suddenly trapped in the blinding headlights of vacuous crap. Maybe it's the Hamlet she just misquothed or the fifth glass of wine I just quaffed, but my diplomacy-dyke groans and the arsehole held back by its stones can be held back no more.

"Look, Storm, sorry, I don't mean to bore you, but there's no such thing as an aura.

Reading auras is like reading minds, or tea leaves, or star signs or meridian lines.

These people aren't plying a skill, they're either lying or mentally ill!

135 Same goes for people who claim they can hear God's demands, or spiritual healers who think they've got magic hands.

By the way, why do we think it's OK for people to pretend they can talk to the dead?

140 Isn't that totally fucked in the head? Lying to some crying woman, whose child has died and telling her you're in touch with the other side? I think that's fundamentally sick

Do we need to clarify here that there's no such thing as a psychic?

What, are we fucking two?

Do we actually think that Horton heard a Who?

Do we still believe that Santa brings us gifts?

That Michael Jackson didn't have facelifts?

Are we still so stunned by circus tricks

that we think the dead would want to talk to pricks like John Edward?"

Storm, to her credit, despite my derision, 
155

160 keeps firing off clichés with startling precision

like a sniper using bollocks for ammunition:

"You're so sure of your position, but you're just closed-minded.

I think you'll find that your faith in science and tests is just as blind as the faith of any fundamentalist."

"Wow, that's a good point. Let me think for a bit ...

Oh wait, my mistake, that's absolute bullshit.

Science adjusts its views based on what's observed. Faith is the denial of observation so that belief can be preserved.

If you show me that, say, homoeopathy works, then I will change my mind, I will spin on a fucking dime, I'll be as embarrassed as hell, yet I will run through the streets yelling: 'It's a miracle! Take physics and bin it! Water has memory,

and whilst it's memory of a long lost drop of onion juice seems infinite, it somehow forgets all the poo it's had in it!'

You show me that it works and how it works, and when I've recovered from the shock

I will take a compass and carve 'Fancy That' on the side of my cock."

Everyone is just staring now, but I'm pretty pissed and I've dug this far down so I figure: in for a penny in for a pound.

"Life is full of mysteries, yeah.

But there are answers out there and they won't be found by people sitting around looking serious and saying 'Isn't life mysterious?

Let's sit here and hope! Let's call up the fucking pope!

Let's go watch Oprah interview Deepak Chopra!'

If you want to watch telly, you should watch Scooby Doo.

That show was so cool, because every time there was a church with a ghoul 
or a ghost in a school

they looked beneath the mask and what was inside?

The fucking janitor or the dude who ran the water-slide.

Because throughout history

every mystery

ever solved has turned out to be

200 not magic.

Does the idea that there might be knowledge

frighten you?

Does the idea that one afternoon

on Wiki-fucking-pedia might enlighten you

205 frighten you?

Does the notion that there may not be a supernatural

so blow your hippy noodle

that you'd rather just stand in the fog

of your inability to google?

Isn't this enough?

Just this world?

Just this beautiful, complex, wonderfully unfathomable natural world?

How does it so fail to hold our attention

215

that we have to diminish it with the invention

of cheap, man-made myths and monsters?

If you're so into your Shakespeare,

lend me your ear:

To gild refined gold, to paint the lily,

to throw perfume on the violet ... is just fucking silly ...

or something like that.

Or what about Satchmo?!

'I see trees of green, red roses too ...'

And fine, if you wish to

glorify Krishna and Vishnu

in a post-colonial, condescending,

bottled-up and labelled kind of way then whatever, that's OK,

but here's what gives me a hard-on:

I am a tiny, insignificant, ignorant bit of carbon.

I have one life, and it is short and unimportant ...

But thanks to recent scientific advances 
235

I get to live twice as long

as my great great great great uncleses and auntses.

Twice as long to live this life of mine.

Twice as long to love this wife of mine.

240

Twice as many years of friends and wine, of sharing curries and getting shitty at good-looking hippies With fairies on their spines and butterflies on their titties.

And if perchance I have offended think but this and all is mended: we'd as well be ten minutes back in time for all the chance you'll change your mind." 


\section{Works Cited}

Althusser, Louis. Lenin and Philosophy, and Other Essays. 1971. New York: Monthly Review Press, 2001. Print.

Baumeister, Roy F. and Mark R. Leary. "The Need to Belong: Desire for Interpersonal Attachments as a Fundamental Human Motivation." Psychological Bulletin 117.3 (1995): 497-529. Print.

Bhabha, Homi K. The Location of Culture. London: Routledge, 1994. Print.

Bloom, Paul. How Pleasure Works: The New Science of Why We Like What We Like. New York: W. W. Norton, 2010. Print.

Brah, Avtar. "Difference, Diversity and Differentiation." "Race", Culture, and Difference. Ed. James Donald and Ali Rattansi. London: Sage Publications in association with the Open University, 1992. 126-146. Print.

Butler, Judith. Gender Trouble: Feminism and the Subversion of Identity. New York: Routledge, 1990. Print.

Butler, Judith. Bodies That Matter: On the Discursive Limits of "Sex". New York: Routledge, 1993. Print.

Ferretter, Luke. Louis Althusser. London: Routledge, 2006. Print.

Freud, Sigmund. Freud: The Major Works of Sigmund Freud. Ed. Wallace Brockway. Chicago: Encyclopaedia Britannica, 1952. Great Books of the Western World 54. Print.

Hall, Stuart. "Introduction: Who Needs 'Identity?”" Questions of Cultural Identity. Ed. Stuart Hall and Paul Du Gay. London: Sage, 1996. 1-17. Print.

Hermans, Hubert J. M., and Thorsten Gieser. "Introductory Chapter: History, Main Tenets and Core Concepts of Dialogical Self Theory." Handbook of Dialogical Self Theory. Ed. Hubert J. M. Hermans and Thorsten Gieser. Cambridge: Cambridge University Press, 2012. 1-22. Print.

Luhmann, Niklas. Social Systems. Stanford, California: Stanford University Press, 1995. Print.

Medhurst, Andy. A National Joke: Popular Comedy and English Cultural Identities. London: Routledge, 2007. Print.

Minchin, Tim, Dan C. Turner and Tracy King. "Tim Minchin's Storm the Animated Movie." Youtube. Stormmovie.net. 7 April 2011. 17 June 2012. <http://www.youtube.com/watch?v=HhGuXCuDb1U>

Nelson, Nicolas H. The Pleasure of Poetry: Reading and Enjoying English Poetry from Donne to Burns. Westport, Connecticut: Praeger, 2006. Print. 
Nobus, Dany. "Lacan's Science of the Subject: Between Linguistics and Topology." The Cambridge Companion to Lacan. Ed. Jean-Michel Rabaté. Cambridge: Cambridge University Press, 2003. 50-68. Print.

Nünning, Vera, and Ansgar Nünning. An Introduction to the Study of English and American Literature. 1st ed. Stuttgart: Klett Sprachen, 2004. Print.

Petersen, Jürgen H. Erzählsysteme: Eine Poetik epischer Texte. Stuttgart: J.B. Metzler, 1993. Print.

Rutherford, Jonathan. "A Place Called Home: Identity and the Cultural Politics of Difference." Identity: Community, Culture, Difference. Ed. Jonathan Rutherford. London: Lawrence \& Wishart, 1990. 9-27. Print. 



\section{„Göttinger Schriften zur Englischen Philologie“: Zum Konzept der Reihe}

Die Reihe „Göttinger Schriften zur Englischen Philologie“ umfasst Schriften zur Forschung aus den Disziplinen englische, amerikanische und postkoloniale Literatur- und Kulturwissenschaft, englische Fachdidaktik, englische Sprache, Literatur und Kultur des Mittelalters, Linguistik des Englischen. Veröffentlicht werden können:

- im Rahmen des 1. Staatsexamens für das Lehramt an Gymnasien verfasste Zulassungsarbeiten (Staatsarbeiten), die mit ,sehr gut' benotet wurden bzw. die mit ,gut' benotet und entsprechend überarbeitet wurden, so dass sie zum Zeitpunkt der Veröffentlichung mit ,sehr gut' bewertet werden könnten;

- im Rahmen des Magisterexamens verfasste Zulassungsarbeiten (Magisterarbeiten), die mit ,sehr gut ${ }^{6}$ benotet wurden bzw. die mit ,gut benotet und entsprechend überarbeitet wurden, so dass sie zum Zeitpunkt der Veröffentlichung mit ,sehr gut ${ }^{6}$ bewertet werden könnten;

- im Rahmen des BA-Studiengangs (Zwei-Fächer-Bachelor-Studiengang) verfasste Abschlussarbeiten (Bachelor-Arbeiten), die mit ,sehr gut ${ }^{6}$ benotet wurden bzw. die mit ,gut ${ }^{`}$ benotet und entsprechend überarbeitet wurden, so dass sie zum Zeitpunkt der Veröffentlichung mit ,sehr gut' bewertet werden könnten;

- im Rahmen der einschlägigen MA-Studiengänge (Master of Arts / Master of Education) verfasste Abschlussarbeiten (Master-Arbeiten), die mit ,sehr gut' benotet wurden bzw. die mit ,gut ${ }^{6}$ benotet und entsprechend überarbeitet wurden, so dass sie zum Zeitpunkt der Veröffentlichung mit ,sehr gut bewertet werden könnten.

Zusätzlich können in der Reihe Sammelbände beispielsweise mit den Arbeitsergebnissen aus Kolloquien oder Workshops veröffentlicht werden. Die Werke werden auf Deutsch oder Englisch publiziert. 
"What passing-bells for these who die as cattle? - Only the monstrous anger of the guns." This is how the English poet Wilfred Owen gave words to the horrors of World War I in 1917. Written under the impression of the trench warfare in Flanders, he called the poem "Anthem for Doomed Youth": To him and his fellow-soldiers the world had become a place of hopelessness and despair.

Armed conflicts seem to be inextricably linked to human nature. They reduce men to mere animals and bring about utter despair; men "grope in the dark without light" (Job 12:25). Yet humans are by nature extremely vulnerable, with neither a crocodile's plate armour nor an elephant's tusks, weight and size: War should be essentially foreign to their nature. In spite of their claim to rationality, though, which supposedly distinguishes them from animals, humans continue trying to solve their problems by taking up arms against each other.

Representations of conflicts have found their way into various art forms. The Bible, the written cornerstone of the Christian faith - with forgiveness and peacefulness as central tenets - , contains many tales of military engagements, of murder and conquest. Conflicts do not always imply the use of armed force, though. There are also less deadly, though not necessarily less fierce 'wars': wars of ideology, for example, or the 'price wars' of retailers. The papers in this volume explore a variety of different conflicts and their representations - among them the wars in Vietnam, Iraq and Afghanistan in American films - but also depictions of other kinds of hostilities closer to home, such as the 'Shakespeare wars'. 